\title{
Value-Based decisions : situational influences and neural mechanisms
}

Citation for published version (APA):

Wölbert, E. M. (2013). Value-Based decisions : situational influences and neural mechanisms. [Doctoral Thesis, Maastricht University]. Maastricht University. https://doi.org/10.26481/dis.20130529ew

Document status and date:

Published: 01/01/2013

DOI:

10.26481/dis.20130529ew

Document Version:

Publisher's PDF, also known as Version of record

\section{Please check the document version of this publication:}

- A submitted manuscript is the version of the article upon submission and before peer-review. There can be important differences between the submitted version and the official published version of record.

People interested in the research are advised to contact the author for the final version of the publication, or visit the DOI to the publisher's website.

- The final author version and the galley proof are versions of the publication after peer review.

- The final published version features the final layout of the paper including the volume, issue and page numbers.

Link to publication

\footnotetext{
General rights rights.

- You may freely distribute the URL identifying the publication in the public portal. please follow below link for the End User Agreement:

www.umlib.nl/taverne-license

Take down policy

If you believe that this document breaches copyright please contact us at:

repository@maastrichtuniversity.nl

providing details and we will investigate your claim.
}

Copyright and moral rights for the publications made accessible in the public portal are retained by the authors and/or other copyright owners and it is a condition of accessing publications that users recognise and abide by the legal requirements associated with these

- Users may download and print one copy of any publication from the public portal for the purpose of private study or research.

- You may not further distribute the material or use it for any profit-making activity or commercial gain

If the publication is distributed under the terms of Article $25 \mathrm{fa}$ of the Dutch Copyright Act, indicated by the "Taverne" license above, 


\section{Value-Based Decisions:}

Situational Influences and

Neural Mechanisms 
Value-Based Decisions: Situational Influences and Neural Mechanisms (C) Copyright Eva Wölbert, Maastricht 2013

All rights reserved. No part of this publication may be reproduced, stored in a retrieval system, or transmitted, in any form, or by any means, electronic, mechanical, photocopying, recording or otherwise, without the prior permission in writing from the author.

This book was typeset by the author using $\mathrm{HT}_{\mathrm{E}} \mathrm{X}$.

ISBN 978-90-9027561-1

Printed in the Netherlands by Datawyse 


\title{
Value-Based Decisions: \\ Situational Influences and Neural Mechanisms
}

\author{
DISSERTATION \\ to obtain the degree of Doctor at \\ Maastricht University, \\ on the authority of the Rector Magnificus, Prof. dr. L.L.G. Soete, \\ in accordance with the decision of the Board of Deans, \\ to be defended in public \\ on Wednesday 29 May 2013, at 10:00 hours
}

by

Eva Martina Wölbert 


\section{Supervisors:}

Prof. dr. A. Riedl

Prof. dr. R. Goebel

\section{Co-Supervisor:}

Dr. S. Okamoto-Barth

\section{Assessment Committee:}

Prof. dr. B. Jansma (chair)

Dr. K. Hyndman

Prof. dr. T. Kalenscher, Heinrich Heine University Düsseldorf, Germany

Dr. C. Nederkoorn

Prof. dr. A. Sanfey, Radboud Universiteit Nijmegen 


\section{Contents}

1 General Introduction $\quad 1$

2 Temptation in Economic Decision Making: Effects of Immediate Reward and Reward-Cues $\quad 13$

2.1 Introduction . . . . . . . . . . . . . . . . . . 14

2.2 Immediate exposure to reward and reward predicting stimuli affects economic decisions . . . . . . . . . . . . . 15

2.3 Could immediacy to reward underlie biased economic decisions? 19

2.4 Conclusion . . . . . . . . . . . . . . . . . 28

3 Flexible Valuations for Consumer Goods as Measured by the Becker-DeGroot-Marschak Mechanism $\quad 37$

3.1 Introduction . . . . . . . . . . . . . . . . 38

3.2 Methods . . . . . . . . . . . . . . . . . . . 41

3.3 Results . . . . . . . . . . . . . . . . . . . 44

3.4 Discussion . . . . . . . . . . . . . . . . . . . . 49

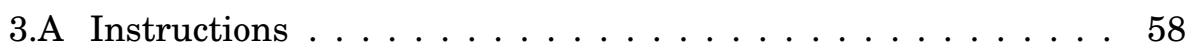

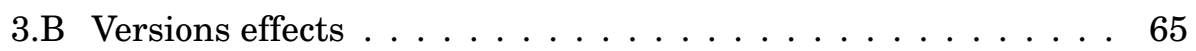

4 Measuring Time and Risk Preferences: Reliability, Stability, Domain Specificity $\quad 67$

4.1 Introduction . . . . . . . . . . . . . . . . 68

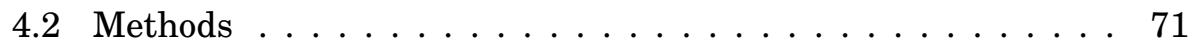


4.3 Results . . . . . . . . . . . . . . . 78

4.4 Summary and conclusion . . . . . . . . . . . . . . 92

4.A Screenshot of lottery choice task . . . . . . . . . . . . . 97

4.B Self-report scales . . . . . . . . . . . . . . . 98

4.C Tests statistics . . . . . . . . . . . . . . . 99

5 White Matter Integrity and Impulsiveness 101

5.1 Introduction . . . . . . . . . . . . . . . . . . . . . . 102

5.2 Methods . . . . . . . . . . . . . . . 106

5.3 Results . . . . . . . . . . . . . . . . . . 110

5.4 Discussion . . . . . . . . . . . . . . . . . . . 113

6 Value Signals in the Prefrontal Cortex Predict Individual Preferences Within and Across Reward Categories 123

6.1 Introduction . . . . . . . . . . . . . . . . . . . 124

6.2 Methods . . . . . . . . . . . . . . . . 126

6.3 Results . . . . . . . . . . . . . . . . . . 128

6.4 Discussion . . . . . . . . . . . . . . . . . 134

$\begin{array}{lll}7 & \text { Summary and Conclusions } & 137\end{array}$

$\begin{array}{ll}\text { Acknowledgements } & 143\end{array}$

$\begin{array}{lc}\text { Short Curriculum Vitae } & 144\end{array}$ 


\section{List of Figures}

3.1 Histogram over the bids . . . . . . . . . . . . . . 45

3.2 Scatterplot of bid against revealed price. . . . . . . . . 46

4.1 Test-retest data for discount rates. . . . . . . . . . . . . 81

4.2 Test-retest data for risk preferences. . . . . . . . . . . . 87

4.3 Screenshot of a lottery choice situation. . . . . . . . . 97

5.1 Results of TBSS analysis. . . . . . . . . . . . . . 111

5.2 Scatterplot of average FA and BIS-11 scores . . . . . . . . 112

6.1 Scatterplots of actual and predicted subjective values for one exemplary subject. . . . . . . . . . . . . . . . . 130

6.2 Proportion of correctly predicted binary choices . . . . . . . 132

6.3 Brain areas encoding subjective value for both reward categories. . . . . . . . . . . . . . . . . . 133 


\section{List of Tables}

3.1 Descriptive statistics for bids . . . . . . . . . . . . . . . 44

3.2 Individual standard deviations $\ldots \ldots \ldots \ldots$

3.3 The effect of the revealed price on the bid . . . . . . . . . . 48

3.4 Interaction of revealed price and wanting to buy . . . . . 50

3.5 Versions effects . . . . . . . . . . . . . 65

4.1 Intertemporal choice questions $\ldots \ldots \ldots \ldots \ldots$

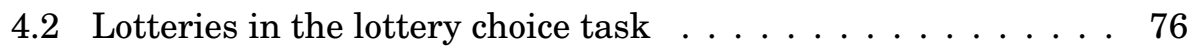

4.3 Descriptive statistics of time preferences $\ldots \ldots \ldots \ldots$

4.4 Reliability measures for discount rates . . . . . . . . . . . . 82

4.5 Correlations of discount rates with self-report items . . . . . . 84

4.6 Descriptive statistics of risk preferences . . . . . . . . 86

4.7 Reliability measures for risk preferences . . . . . . . . 88

4.8 Correlations of risk preferences with self-report items $\ldots . .90$

4.9 Items of the Barratt Impulsiveness Scale . . . . . . . . . . 98

4.10 Items for attitudes towards risk . . . . . . . . . . . . . . 99

4.11 Comparison of the retested and not-retested subsamples . . . 99

4.12 Correlations of risk preferences with self-report items in 2011 sample . . . . . . . . . . . . . . . . . . . 100

4.13 Correlations of discount rates with self-report items in 2011 sample . . . . . . . . . . . . . . . . 100

4.14 Correlation of time preferences with risk preferences $\ldots . .100$

5.1 Descriptive statistics $\ldots \ldots \ldots \ldots \ldots \ldots$ 


\section{Chapter 1}

\section{General Introduction}

Life requires individuals to make decisions all the time. These range from relatively simple and frequent decisions, such as choosing a breakfast cereal, to complex and infrequent decisions, such as choosing a profession or a spouse. Ultimately, such decisions depend on the value each option holds for an individual. The study of the neural mechanisms underlying valuebased decisions has seen a rapid development in the past decade, fuelled by the emergence of neuroeconomics. This relatively new discipline draws from insights, theories and techniques of the three major fields that investigate value-based decisions. Psychology provides a wealth of experimental choice data under various conditions, as well as theories on the processes underlying learning and decision making. Economics provides rigorous theoretical models that specify the computations that are theoretically necessary to make optimal decisions across a large range of situations. And neuroscience provides the knowledge and the techniques to study how value-based decisions are implemented in the brain. Drawing from these three disciplines to guide hypothesis building and experiment design should ultimately lead to a theory of value-based decision making that is constrained by the actual neural and computational processes underlying decisions and therefore biologically plausible (Rangel, Camerer, \& Montague, 2008).

The neuroscientific techniques that are used in this thesis comprise functional magnetic resonance imaging (fMRI) and diffusion weighted imaging (DWI). fMRI measures brain activity with good spatial and temporal reso- 
lution. Based on the magnetic properties of blood, it allows to investigate which parts of the brain increase or decrease in activity when a person engages in a certain task. In contrast, DWI does not measure brain function, but brain structure. Based on water diffusion, it allows to assess the structure and the quality of white matter in the brain. White matter contains the connections between different brain regions and its intactness is vital for and shaped by the communication between brain regions.

\section{Economic theory as a starting point}

Traditional economic models of decision making identify the computations that are theoretically necessary to make optimal decisions. Therefore, they provide a good starting point for the neuroeconomic analysis of decision making. Of particular importance is the economic concept of utility, where utility is understood as quantifying the desirability of an option. Economic models are explicitly agnostic about the process that generates a decision. They aim at accurately predicting a decision, but not at explaining how a decision is actually achieved, and are therefore often called "as if" models. They suggest that a chooser behaves as if performing a certain set of computations and following a certain set of rules to achieve a decision, but it is not implied that the chooser actually engages in these processes.

The weak axiom of revealed preference (Samuelson, 1938), a key result in economic theory, is an example for this approach. It states that, as long as individuals choose in a consistent manner, they choose as if their choice was guided by a utility function. That is, they choose as if they compute and store an ordering of all options with respect to their desirability, and pick the highest ranked option on this list. Of course desirability of an option is different for each individual. The only restriction that this axiom imposes on the utility computation is monotonicity: more is always better. Further, the traditional economic approach assumes that only aspects relevant to the outcome enter the utility computation, not irrelevant aspects such as the wording used in the description of the choice problem. Within this approach, it is considered irrelevant how the decision maker arrives at the solution as long as the observed choice behaviour is in line with the predictions of the model (Gul \& Pesendorfer, 2005; Kable \& Glimcher, 2009). 
Two prominent models in economic decision theory concern decisions under uncertainty and intertemporal choices. Outcomes of choices are often uncertain. For example, when selecting fruit in the supermarket it is uncertain whether the fruit will be of good, or of bad quality. Likewise, when investing money it is often not clear whether there will be a large or a small return to the investment, or even a loss. Of course the probability with which each of the possible outcomes materializes is important to define the desirability of an option. According to expected utility theory, the utility of such options with uncertain outcomes is defined by a weighted sum of the utilities of the outcomes (von Neumann \& Morgenstern, 1944). The utility of each outcome is thereby weighted according to the probability with which it occurs. That is, the lower the probability that a preferred outcome (e.g. high return on investment) actually occurs, the smaller the expected utility of the option.

Intertemporal decisions require a tradeoff of events that occur at different moments in time. For example, saving money requires to refrain from consuming now, in order to be able to consume sometime in the future. Both economics and psychology assume that - all else equal - a decision maker would like to receive a desirable outcome sooner rather than later (Frederick, Loewenstein, \& O'Donoghue, 2002; Kalenscher \& Pennartz, 2008). Intertemporal decisions are often modelled by computing a "present value" for each option that incorporates the desirability of each outcome as such, and the delay with which it occurs. Under most discounting models, the present value of desirable events decreases with an increasing delay. The farther in the future an event, such as receiving $€ 100$, occurs, the lower its present value to the decision maker. Discounted utility theory suggests exponential discounting, i.e. future rewards should be discounted at a constant rate (Samuelson, 1937). This implies that delaying an outcome by an additional day imposes always the same relative decrease in present value, no matter whether the outcome was postponed from today to tomorrow, or from 364 days to 365 days.

\section{Inconsistent choice can inform neuroeconomics}

Although economic theories do not prescribe what a person should choose, they make powerful predictions about the consistency of individual deci- 
sions. If an individual faces the same decision situation repeatedly, and no relevant parameters have changed, then theory predicts that the same option should be chosen each time. One of the reasons that neuroeconomics continues to receive a lot of attention is the fact that there exist many examples where human choice is inconsistent with economic models, so-called biases or decision anomalies. Decision biases highlight the need for a more realistic theory of decision making.

More importantly, these biases are extremely useful to study the processes underlying decision making. Just as visual illusions gave important insights into the neural architecture of the visual system (Goldstein, 2001), systematic deviations from normative economic models of decision making contain information on the actual processes underlying valuation and choice. In Chapter 2 of this thesis I summarize prominent examples where choice behaviour is influenced by irrelevant aspects of the choice situation, and thus at odds with economic theory (with Rainer Goebel). Drawing from economic models, and insights from neuroscience and psychology on situational control of behaviour, I suggest that immediacy to reward or exposure to reward predicting stimuli may contribute to a wide variety of biases in decisions under uncertainty, intertemporal choice, and simple consumer decisions.

In Chapter 3 of this thesis I investigate whether people behave consistently in a frequently used value elicitation-mechanism, the Becker-DeGroot-Marschak (Becker, DeGroot, \& Marschak, 1964) mechanism (with Agnieszka Tymula and Paul Glimcher). One of the methodological influences of economics on neuroeconomics is the use of real incentives. While psychologists often ask subjects to make hypothetical choices (e.g. Kahneman \& Tversky, 1979), the necessity to have experimental subjects engage in real decisions with real incentives is one of the cornerstones of experimental economics (Camerer \& Hogarth, 1999; Hertwig \& Ortmann, 2003).

The Becker-DeGroot-Marschak mechanism is one way of doing so when the researcher is interested in the monetary value individuals assign to a good or an option. In this mechanism, participants are asked to state the maximum amount they would be willing to pay for a given good. The actual price for the good is then determined randomly from a distribution of possible prices. If the stated willingness to pay (WTP) is higher than the actual 
price, the participant will buy the good from the experimenter, paying the actual price. If the WTP is lower than the price, the participant will not buy the good (Becker et al., 1964). Expected utility theory predicts that an individual's stated WTP for a given item should be equal to the subjective value of the item, and should not vary with the distribution used to determine the actual price. In contrast, we find that an individual's bid for a given consumer good varies substantially with the price distribution used, and this distributional dependence persists over multiple repetitions of the mechanism. It is most pronounced when the mass of the price distribution is close to the subject's valuation for the item. Taken together, these results show that distributional dependence in the BDM mechanism is a real and pervasive, but complex phenomenon and requires further clarification.

\section{Interindividual differences can inform neuroeconomics}

People differ in their preferences and in the way they make decisions. Next to decision biases, interindividual differences are a second important source of information on the decision process. Within the framework of economics, the most important dimensions in which people are assumed to differ are risk preference, time preference, and - more recently - cognitive ability and social preferences (Borghans, Duckworth, Heckman, \& ter Wel, 2008). Time preference relates to people's attitudes towards delay. For some people, it may have a strong influence on the desirability of an option if an outcome occurs only after a certain delay. In a typical intertemporal choice situation, where a chooser is asked to decide between a smaller, but sooner and a larger, but later option, such an impatient chooser will likely choose the smaller, sooner option. Other people choose much more patiently, presumably because, even if they have to wait a long time to receive the outcome, this barely affects the present value of an option. Likewise, risk preference relates to people's attitudes towards risk. Some people are extremely risk averse, e.g. when offered the choice between a sure amount of money and a gamble that has an expected value of $€ 10$, they will prefer the sure amount over the gamble even if the sure amount is much smaller than $€ 10$. Other 
people are less risk averse, or even risk seeking. A risk seeking person would prefer the gamble over a sure amount, even if the sure amount was higher than $€ 10$. Explaining interindividual heterogeneity in preferences can help to uncover the mechanisms underlying such choices.

Time and risk preferences are fundamental elements of economic models, and it is typically assumed that they are stable properties of the individual chooser, and that they affect decisions across a wide range of situations (Barseghyan \& Prince, 2011; Frederick et al., 2002). Because of their importance to both economic theory and neuroeconomic investigation, individual time and risk preferences are measured in many studies of human decision making. A methodological influence from psychology on neuroeconomics could be the rigour with which psychological constructs and their measurement instruments are evaluated with respect to reliability and validity. In Chapter 4 of this thesis I investigate whether commonly used measures of time and risk preferences are reliable, and whether time and risk preferences are stable over time and across contexts (with Arno Riedl). We find that a set of lottery choices and a set of intertemporal choices measures time and risk preferences with high reliability and that individual behaviour in these tasks is remarkably stable over time. Correlations of thus derived indicators of time and risk preferences with conceptually related self-report scales are low and confined to self-report items on financial decision making. This suggests that time and risk preferences are stable over time, but not across situations.

A psychological construct that is relevant to interindividual differences in decision making is impulsiveness, i.e. the tendency to act without much hesitation or deliberation, low self-control, as well as acting with little concern for future consequences. Impulsiveness is often associated with a lack of cognitive control, executed by parts of the frontal cortex. There are stable interindividual differences in the tendency to act impulsively, which account for a variety of outcomes including the risk for substance abuse (Dalley, Everitt, \& Robbins, 2011). Recently, neuroscientists have started to appreciate such stable interindividual differences as a source of information on the relationship between brain and behaviour (Kanai \& Rees, 2011). In Chapter 5 of this thesis I investigate how differences in self-reported impulsiveness are related to differences in brain structure (with Pim Pullens, Sanae 
Okamoto-Barth, Martin Strobel, Arno Riedl, and Rainer Goebel). We use diffusion weighted magnetic resonance imaging to assess whether the individual degree of impulsiveness is related to a derived measure of white matter intactness. We find that higher impulsiveness is associated with higher white matter integrity in parts of the frontal cortex. This finding is at odds with the assumption that impulsive behaviour is generally a result of low cognitive control by the frontal cortex. Instead, it suggests that impulsive tendencies arise mostly from excessive motivation or drive.

\section{The neuroeconomic model of choice}

Interestingly, the emerging neural models of decision making are remarkably similar to traditional economic models. Because of this similarity, it is important to emphasize the difference between the two types of models. In contrast to the agnostic approach of traditional economic theory, the underlying process is of central interest when building a neurophysiological model of decision making. These models are therefore referred to as "as is" or "because" models (Fehr \& Rangel, 2011; Kable \& Glimcher, 2009). Despite it being a relatively young science, neuroeconomics has made considerable progress towards such a model already. Inspired by traditional economic models, the emerging concept of the decision process has two core elements: valuation and action selection (Fehr \& Rangel, 2011; Kable \& Glimcher, 2009; Rangel et al., 2008). Valuation refers to a computation that integrates all attributes of an option that are relevant to the decision into a quantity called decision value or subjective value. According to the model, this subjective value should be similar to the utility concept introduced above, but there are also important differences (see Glimcher, 2011). Converging evidence suggests that some form of subjective value is represented in the ventromedial part of the prefrontal cortex, as well as the striatum (Levy \& Glimcher, 2012). Moreover, lesion studies have shown that the computations performed by the prefrontal cortex are necessary for consistent choice (Camille, Griffiths, Vo, Fellows, \& Kable, 2011; Henri-Bhargava \& Simioni, 2012), suggesting that subjective value is indeed causally relevant for choice. However, it is still unclear in how far neurally encoded subjective value shares properties of the utility concept (Webb, Glimcher, 
Levy, Lazzaro, \& Rutledge, 2012).

For the second component of the model, action selection, the subjective values of all considered options need to be compared, and the action (i.e. a motor response) that leads to the highest valued option needs to selected and initiated. The neural mechanism underlying action selection has been investigated intensely in monkeys, and recently also in humans using fMRI. The available evidence suggests that a highly connected network of motorrelated brain regions, comprising dorsal parts of the frontal cortex and the intraparietal sulcus, performs this task (e.g. Glimcher, 2011; Hare, Schultz, Camerer, O'Doherty, \& Rangel, 2011; Kable \& Glimcher, 2009).

Humans often face choices between fundamentally different options, and a straightforward comparison, e.g. by quantity, is normally not possible. For example, a chooser might need to decide whether to spend spare money on a new mobile phone, or a weekend vacation. These options are fundamentally different. The former might serve communication, convenience, and status, whereas the latter might serve relaxation, culture and quality time. Yet, it is clear that humans are capable of choosing between such options. To date, it is unclear how this is achieved. It has frequently been demonstrated that the brain computes some form of subjective value, as observed brain activity varies meaningfully with the subjective value of an option presented. However, most studies have used only one very confined category of reward, such as snack food items, or delayed or probabilistic monetary rewards (e.g. Kable \& Glimcher, 2007; Knutson, Taylor, Kaufman, Peterson, \& Glover, 2005; Plassmann, O'Doherty, \& Rangel, 2007). Those studies that have used more than one category of reward, have focused on spatial overlap of value-representing regions, and have employed categories that are still relatively similar and frequently compared in daily life, such as snack foods, trinkets and money (Chib, Rangel, Shimojo, \& O'Doherty, 2009; FitzGerald, Seymour, \& Dolan, 2009; Levy \& Glimcher, 2011).

Thus, there is evidence that the spatial location of subjective value representation overlaps for different types of consumption goods and for monetary rewards. However, showing that subjective value is represented in the same brain area is not sufficient evidence to say that there exists an abstract, utility-like representation of subjective value in the brain. If a subjective value computation should provide the necessary information to 
enable choice between different kinds of options, then subjective value must also be encoded in a similar fashion, in a "common currency" of desirability for all sorts of options. That is, the neurally encoded subjective value must at some point be independent of the category of reward, and comparable across different reward categories, akin to the economic utility concept introduced above.

In Chapter 6 of this thesis I investigate whether subjective value representation for two fundamentally distinct reward categories is indeed comparable, namely snack food items (e.g. chocolate muffin) and activities (e.g. playing tennis) (together with Joerg Gross, Jan Zimmerman, Sanae OkamotoBarth, Arno Riedl and Rainer Goebel). Using multivariate analysis of fMRI data, we find that a subregion in the ventromedial prefrontal cortex encodes subjective value for both categories of items in a similar way. This provides strong evidence for the existence of abstract, utility-like subjective value signals in the ventromedial prefrontal cortex, as is hypothesized by the currently emerging neuroeconomic model of choice. 


\section{References}

Barseghyan, L., \& Prince, J. (2011). Are risk preferences stable across contexts? Evidence from insurance data. American Economic Review, 101(2), 591-631.

Becker, G. M., DeGroot, M. H., \& Marschak, J. (1964). Measuring utility by a single-response sequential method. Behavioral Science, 9(3), 226-232.

Borghans, L., Duckworth, A. L. A., Heckman, J. J., \& ter Wel, B. (2008). The economics and psychology of personality traits. Journal of Human Resources, 43(4), 972-1059.

Camerer, C., \& Hogarth, R. (1999). The effects of financial incentives in experiments: a review and capital-labor-production framework. Journal of Risk and Uncertainty, 19(1-3), 7-42.

Camille, N., Griffiths, C. A., Vo, K., Fellows, L. K., \& Kable, J. W. (2011). Ventromedial frontal lobe damage disrupts value maximization in humans. Journal of Neuroscience, 31(20), 7527-7532.

Chib, V. S., Rangel, A., Shimojo, S., \& O’Doherty, J. P. (2009). Evidence for a common representation of decision values for dissimilar goods in human ventromedial prefrontal cortex. Journal of Neuroscience, 29(39), 12315-12320.

Dalley, J. W., Everitt, B. J., \& Robbins, T. W. (2011). Impulsivity, compulsivity, and top-down cognitive control. Neuron, 69(4), 680-694.

Fehr, E., \& Rangel, A. (2011). Neuroeconomic foundations of economic choice recent advances. The Journal of Economic Perspectives, 25(4), 3-30.

FitzGerald, T. H. B., Seymour, B., \& Dolan, R. J. (2009). The role of human orbitofrontal cortex in value comparison for incommensurable objects. Journal of Neuroscience, 29(26), 8388-8395.

Frederick, S., Loewenstein, G., \& O'Donoghue, T. (2002). Time discounting and time preference: a critical review. Journal of Economic Literature, 40(2), 351-401.

Glimcher, P. W. (2011). Foundations of Neuroeconomic Analysis. New York: Oxford University Press.

Goldstein, E. B. (2001). Sensation and Perception (6th ed.). Belmont: Wadsworth Pub Co.

Gul, F., \& Pesendorfer, W. (2005). The case for mindless economics (Princeton University Working Paper). Retrieved 6.03.2013, from http://www.hss.caltech .edu/ camerer/NYU/mindless2.pdf

Hare, T. A., Schultz, W., Camerer, C. F., O’Doherty, J. P., \& Rangel, A. (2011). Transformation of stimulus value signals into motor commands during simple choice. Proceedings of the National Academy of Sciences, 108, 1812018125.

Henri-Bhargava, A., \& Simioni, A. (2012). Ventromedial frontal lobe damage disrupts the accuracy, but not the speed, of value-based preference judgments. 
Neuropsychologia, 50(7), 1533-1542.

Hertwig, R., \& Ortmann, A. (2003). Economists' and psychologists' experimental practices. In I. Brocas \& J. D. Carrillo (Eds.), The psychology of economic decisions. Volume 1: Rationality and well-being (pp. 253-272). Oxford: Oxford University Press.

Kable, J. W., \& Glimcher, P. W. (2007). The neural correlates of subjective value during intertemporal choice. Nature Neuroscience, 10(12), 1625-1633.

Kable, J. W., \& Glimcher, P. W. (2009). The neurobiology of decision: consensus and controversy. Neuron, 63(6), 733-745.

Kahneman, D., \& Tversky, A. (1979). Prospect theory: an analysis of decision under risk. Econometrica, 47(2), 263-291.

Kalenscher, T., \& Pennartz, C. M. A. (2008). Is a bird in the hand worth two in the future? The neuroeconomics of intertemporal decision-making. Progress in Neurobiology, 84, 284-315.

Kanai, R., \& Rees, G. (2011). The structural basis of inter-individual differences in human behaviour and cognition. Nature Reviews Neuroscience, 12, 231242.

Knutson, B., Taylor, J., Kaufman, M., Peterson, R., \& Glover, G. (2005). Distributed neural representation of expected value. Journal of Neuroscience, 25(19), 4806-4812.

Levy, D. J., \& Glimcher, P. W. (2011). Comparing apples and oranges: using reward-specific and reward-general subjective value representation in the brain. Journal of Neuroscience, 31(41), 14693-14707.

Levy, D. J., \& Glimcher, P. W. (2012). The root of all value: a neural common currency for choice. Current Opinion in Neurobiology, 22(6), 1-12.

Plassmann, H., O’Doherty, J., \& Rangel, A. (2007). Orbitofrontal cortex encodes willingness to pay in everyday economic transactions. Journal of Neuroscience, 27(37), 9984-9988.

Rangel, A., Camerer, C., \& Montague, P. R. (2008). A framework for studying the neurobiology of value-based decision making. Nature Reviews Neuroscience, $9(7), 545-556$.

Samuelson, P. A. (1937). A note on measurement of utility. Review of Economic Studies, 4(2), 155-161.

Samuelson, P. A. (1938). A note on the pure theory of consumer's behaviour. Economica, 5(17), 61-71.

von Neumann, J., \& Morgenstern, O. (1944). Theory of Games and Economic Behavior. Princeton N.J.: Princeton University Press.

Webb, R., Glimcher, P. W., Levy, I., Lazzaro, S. C., \& Rutledge, R. B. (2012). Neural random utility (Working Paper). Retrieved 6.03.2012, from http://ssrn.com/ abstract $=2143215$ 



\title{
Chapter 2
}

\section{Temptation in Economic Decision Making: Effects of Immediate Reward and Reward-Cues}

\begin{abstract}
Immediate exposure to reward or reward predicting stimuli (cues) influences behaviour. For example chips placed right in front of us are likely to get eaten even if we wish to lose weight or don't actually like chips so much. In this paper we review evidence which shows that immediate exposure to reward and the presence of reward-cues can change economic behaviour across various decision domains. Reward cues lead to less patient intertemporal choice, seem to increase risk aversion and bias consumer choice. This may explain various, at first glance very different behavioural phenomena, such as dynamic inconsistency, the certainty effect and the endowment effect. We suggest that immediacy in time, certainty, and physical possession all create immediacy to a rewarding outcome which might bias choice in a similar way as other reward predicting stimuli.
\end{abstract}

Based on: Woelbert, E. \& Goebel, R. (2013) Temptation in economic decision making: effects of immediate reward and reward-cues. Neuroscience and Neuroeconomics, 2, 11-19. 


\subsection{Introduction}

Environmental stimuli can exert powerful control over behaviour. Relapses of drug addicts often occur when the person finds themselves in an environment in which they used to consume drugs, or when confronted with drug-related materials (Robbins \& Everitt, 1999). More commonly experienced, food-related stimuli such as the smell of freshly baked cookies or the sight of a hamburger not only make our mouths water, but also stimulate our appetite and increase subsequent food intake (Ferriday \& Brunstrom, 2008). Drug abuse and overeating have received considerable attention in psychology, neuroscience and in economics since they constitute major public health problems, but also because they seem at odds with self-interest and are often explicitly regretted. It is puzzling why people engage in these behaviours nevertheless, especially under the assumption that stable, welldefined preferences guide behaviour.

While each of these different disciplines has described and analysed this phenomenon within their own framework, there is a common underlying spirit in their explanations. From a psychological perspective, the effect of contextual cues on behaviour may be seen as a manifestation of pavlovian and instrumental learning. The smell of cookies has frequently preceded the consumption of cookies and thus leads to an expectation of cookies and activates behaviours leading to consumption (Balleine \& Ostlund, 2007). Neuroscientific data suggests that dopamine plays an important role in the underlying neural processes (Yun, Wakabayashi, Fields, \& Nicola, 2004). Firing of dopaminergic cells increases in response to reward-predictive stimuli such as the sight of a hamburger (Bayer \& Glimcher, 2005; Schultz, Dayan, \& Montague, 1997). At the same time, dopamine is involved in motivation and action selection (Corbit, Janak, \& Balleine, 2007; Kahnt et al., 2009; O'Doherty et al., 2004; Sharot, Shiner, Brown, Fan, \& Dolan, 2009). Assuming that these two functions interact somehow, the occurrence of a rewardpredictive stimulus might enhance the motivation to pursue a particular reward (Berridge \& Robinson, 2003). Similar ideas have been formalized by economists, assuming that consumption in the presence of specific cues may be (or seem) more valuable to the organism than in the absence of the stimulus (Bernheim \& Rangel, 2004; Laibson, 2001; Loewenstein, 1996). 
A situation which contains reward cues and leads to behaviour that is at odds with long term goals resulting from rational deliberation, such as a healthy lifestyle, is frequently described as "tempting" (Fishbach, Friedman, \& Kruglanski, 2003). There is accumulating evidence that the stimulus environment not only influences decisions about primary needs like food, or physiological stimulation from drugs, but a wider range of economically relevant decisions including intertemporal choice over money, decisions under uncertainty and consumer choice. In this review article we summarize evidence on the effects of immediate exposure to reward and reward predicting stimuli on economic decision making. We then revisit literature on well-documented biases in decision making like certainty effects and the endowment effect and explore whether they might be driven by a similar mechanism.

\subsection{Immediate exposure to reward and reward predicting stimuli affects economic decisions}

\section{Impatient intertemporal decisions}

Intertemporal choices require tradeoffs between outcomes that vary in value, but also occur at different moments in time. Typical intertemporal choices we encounter in everyday life are savings decisions and health-oriented behaviour such as exercising, smoking and food choices. Healthy behaviour is often associated with some immediate inconvenience, such as foregoing desert, whereas the benefits will only become apparent weeks or years after these decisions. Similarly, saving money requires refraining from spending money in the present in order to be able to spend it at some point in the future. In experiments, such decisions are often mimicked by giving subjects the choice between receiving a smaller, but sooner reward, and a larger, but delayed one - typically money. While many interesting behavioural phenomena have been observed in intertemporal decision making, we focus on evidence which shows that exposure to reward related stimuli decreases patience in intertemporal choice. For a more general overview on the intertemporal choice literature there exist several comprehensive reviews (Berns, Laibson, \& Loewenstein, 2007; Frederick, Loewenstein, \& 
O'Donoghue, 2002; Kalenscher \& Tobler, 2008).

Perhaps the most comprehensive evidence on determinants of intertemporal choice stems from an instructive series of experiments on delay of gratification in children (Mischel, Shoda, \& Rodriguez, 1989). Children at preschool age performed intertemporal choices about food and toy rewards under different conditions. Typically, children were left alone in a room with a small quantity of the reward. Children were then told that if they waited for some time without consuming the reward or calling for the experimenter they would receive a larger amount of the same reward. If exposure to reward predicting stimuli influences intertemporal choice, the physically immediate reward should decrease the children's ability to wait. Indeed, waiting times decreased when the reward was put immediately in front of the children. Interestingly, waiting times decreased monotonically with the amount of reward that the children were immediately exposed to (Mischel $\&$ Ebbesen, 1970). Thus, being physically close to a reward did not only decrease the ability to delay gratification, but the strength of this effect also depended on the quantity of reward the subjects were exposed to. A similar effect was observed when children were not physically exposed to the reward, but instructed to think about the appetitive properties of the reward. Likewise, the effect of a physically present reward could be diminished by instructing the children to distract themselves from the appetitive nature of the stimulus, for example by focusing on non-rewarding properties of the stimulus. These findings suggest that reward exposure leads to less patient intertemporal choices, and that this effect is mediated by attention to the appetitive properties of the available reward (Mischel et al., 1989).

Based on these findings, Van den Bergh, Dewitte, and Warlop (2008) hypothesized that a general appetitive motivational state leads to impatience in intertemporal choice. They exposed men to erotic cues, followed by a series of intertemporal choices involving money, candy bars, and soft drinks. Relative to a control group that saw neutral stimuli, these subjects decided less patiently. Thus, exposure to erotic cues increased preference for the smaller, sooner reward across various types of reward. This effect was only present for those men who scored higher on a self-report measure of individual sensitivity to rewards, suggesting that the effect of erotic stimuli on discounting was indeed mediated by an appetitive motivational state. Like- 
wise, Wilson and Daly (2004) found that exposure to pictures of attractive faces of the opposite sex, but also attractive cars, increased discounting of future rewards relative to exposure to unattractive faces and cars.

In sum, exposure to reward and reward related stimuli results in less patient intertemporal choices. This effect seems to be mediated by an appetitive motivational state.

\section{Risk averse choices}

Decisions across various life domains involve uncertainty. For example when investing money, choosing for a specific education, or accepting a job offer the decision maker is uncertain which of several possible outcomes - some more favourable than others - will occur. Expected utility theory provides a powerful normative framework for decision making under uncertainty, but many situations have been described where people's actual behaviour deviates from the predictions of the theory (Tversky \& Kahneman, 1981).

The role of the stimulus environment has received less attention in research on decisions under uncertainty than in intertemporal choice. However, one recent experiment suggests that both reward- and punishmentrelated stimuli can influence choices between certain and uncertain gains. In a pavlovian conditioning phase, Guitart-Masip, Talmi, and Dolan (2010) trained subjects to learn that certain artificial visual stimuli were always followed by a gain and certain others always followed by a loss. Afterwards, subjects made a series of binary choices between sure outcomes and gambles. The stimuli from the conditioning phase (conditioned stimuli, henceforth $C S$ ) were visually presented together with these choices, but were completely irrelevant to the decision and not informative of the outcome. Nevertheless, they influenced choice behaviour. When a stimulus which had previously been predictive of gains $(C S+)$, but was then completely irrelevant, was visually presented during choice, people showed an enhanced preference for certainty. In the presence of a stimulus previously predictive of losses $\left(C S^{-}\right)$people made more risky choices. Since in this study the conditioned stimulus was always visually underlying the sure option it seems that choices were biased towards the appealing conditioned stimulus 
and away from the unappealing one. ${ }^{1}$ Choices in accordance with this effect went along with higher activity in the amygdala, and the ventral striatum (Guitart-Masip et al., 2010). This is consistent with the current understanding of the amygdala as a brain region that is central to the influence of emotional stimuli on behaviour (Phelps, 2006). These data suggest that irrelevant stimuli which are associated with reward and punishment can influence decisions under uncertainty.

\section{Consumer decisions}

Knowing the value a person places on an item is of great interest in decision making research, marketing and public policy. It is often measured as the maximum amount a person is willing to pay to obtain an item. A recent experiment investigated systematically whether willingness to pay (WTP) could be influenced by the way items were presented to the subjects. Bushong, King, Camerer, and Rangel (2010) elicited WTP for both snack food items and trinkets, while varying the display format of the items. Subjects who had the items physically in front of them reported higher WTP than subjects who saw text or image displays. Interestingly, there was no effect on rating how much one likes the item and WTP was increased across the whole liking range. That is, even for disliked items, the physical presence of the good increased WTP. In order to test competing explanations for this observation, the authors performed a series of control experiments: Combining the image and text displays with pre-tasting a small amount of the food item did not elevate WTP, suggesting that the effect is also not attributable to differences in experienced utility or information about the good. Finally, the authors observed that placing a fully transparent plexiglas barrier between the subject and the food item resulted in WTP comparable to the text and picture conditions. Thus, the effect of the physically present good on WTP was diminished by a plexiglas barrier, although the actual distance and information available to the subject was held constant. This shows that the physical presence of the good has a strong effect on WTP, but only if the good is within easy reach of the subject. The authors suggest that when

\footnotetext{
${ }^{1}$ It is also possible that the mere presence of a reward predicting stimulus lead to higher preference for certainty, independent of the location of the stimulus.
} 
physically immediate, a good functions like a $C S$, which in turn promotes behaviours that lead to obtaining the good and thus increases WTP.

That conditioned stimuli can indeed affect simple consumer decisions has been demonstrated by Bray, Rangel, Shimojo, Balleine, and O'Doherty (2008). Subjects first underwent a pavlovian conditioning phase where they learned the association between specific visual stimuli (which then served as $C S$ ) and the delivery of a small quantity of a specific drink, like juice or chocolate milk. In a second, entirely independent phase subjects were allowed to choose their drink out of two alternatives on every trial. In a third phase, subjects made these choices again, but were also shown one of the conditioned stimuli on each trial. The presence of a conditioned stimulus biased subjects' choices towards the drink that was associated with this stimulus. For example, subjects chose chocolate milk more often in the presence of a $C S$ that has been associated with chocolate milk in the past. Relative to such cue-congruent choices, choices that were incongruent with the present $C S$ were associated with lower activity in the ventrolateral putamen. Based on these findings the authors suggest that a $C S$ might automatically activate an action plan to obtain the associated outcome. Choosing an alternative outcome would then require suppression of these cue-triggered processes.

In sum, there is evidence from experiments across various decision domains that immediate exposure to reward or reward predicting stimuli influences economic decisions: People decide less patiently, more risk averse and show higher WTP and biased choice when faced with reward predicting stimuli. In the following we will explore whether some well-known biases in economic decisions could be explained by the fact that the decision situations in which they occur naturally entail greater immediacy to rewarding outcomes.

\subsection{Could immediacy to reward underlie biased economic decisions?}

According to standard economic theory decisions should only depend on the likely outcomes they produce - and not on the elicitation procedure. Dec- 
ades of research have shown however, that decisions can be influenced by theoretically irrelevant aspects of the choice problem or the decision situation.

When deciding about future consequences, such as dieting or saving money, people tend to choose more patiently when all options concern outcomes in the future, than when some outcomes are realized immediately and thus involve immediate gratification (Frederick et al., 2002; Kirby \& Herrnstein, 1995). Likewise, when deciding under uncertainty, people show a strong, disproportionate preference for certain outcomes when these are available (Allais, 1953; Huck \& Müller, 2012; Starmer, 2000). A third robust behavioural phenomenon in is the so-called endowment effect, or gap between willingness to pay and willingness to accept (WTA). Asking people how much compensation they demand to part with an object robustly yields higher value estimates than asking them how much they would be willing to pay to acquire the same object (Kahneman, Knetsch, \& Thaler, 1990; Knetsch, 1989).

The special appeal of immediately available reward relative to future reward is a popular explanation for biased decision making in intertemporal choice. Various, mostly unrelated explanations have been put forward to account for certainty effects and the endowment effect. In the light of the results summarized above we argue that these very different behavioural phenomena could, at least in part, all be driven by some form of immediacy to a rewarding outcome in the decision situation.

\section{Dynamic inconsistency}

Discounted utility theory, which is today the predominant normative framework for intertemporal choice, suggests that future rewards should be discounted at a constant rate (Frederick et al., 2002; Kalenscher \& Tobler, 2008; Samuelson, 1937). This implies that a person who prefers $€ 100$ now over $€ 150$ in 1 month will also prefer $€ 100$ in 1 year over $€ 150$ in 1 year and 1 month. Intertemporal choice experiments with both animals and humans have aimed at understanding how organisms actually decide between immediate and delayed rewards (Commons, Mazur, Nevin, \& Rachlin, 1987; Madden \& Bickel, 2009). Many of these found that both animals and hu- 
mans show a disproportionate preference for immediate rewards, which can result in choices that are dynamically inconsistent (Ainslie, 1974; Ainslie \& Herrnstein, 1981; Green \& Estle, 2003; Green, Fristoe, \& Myerson, 1994; Kirby \& Herrnstein, 1995; Loewenstein \& Thaler, 1997). For example, consider a subject who prefers a smaller amount of money that is delivered immediately after the experiment over a larger amount that is delivered with a delay. The same subject may prefer the larger, later reward when neither of the rewards is available immediately, although the amounts of reward, as well as the delay from the sooner to the later reward are kept constant (Kirby \& Herrnstein, 1995). Likewise, suppose that in January a person makes the plan to save the end-of-the-year bonus she will receive in December and invest it for one year to gain interest. When December comes and the bonus is immediately available she might change this plan, and decide to spend the money right away on Christmas presents. However, under discounted utility theory the decision situation in January is equivalent to the decision in December, and the change of plan is inconsistent (Frederick et al., 2002; Samuelson, 1937).

The fact that people make use of commitment devices, which make a change of plan impossible or very costly, provides compelling evidence that preferences are dynamically inconsistent at times, and that decision makers are aware of this. In the above example, the decision maker would prefer to commit to her saving plan in January in a way that makes it impossible or unappealing to change it - provided that they foresee the change of mind. Various forms of commitment devices have been described in the literature (Ainslie, 1975; Frederick et al., 2002), and today their existence and popularity is evident in the internet. Several websites (e.g. stickk.com) allow users to commit to a goal and to determine a binding punishment in case of failing to reach the goal. Interestingly, the most popular goals that call for commitment devices seem to be saving money, exercising, sticking to a certain diet, and not smoking.

Many authors have explained such dynamic inconsistency in intertemporal decision making by assuming that immediacy in time - that is 'now' - is special, and that an immediately available reward is tempting and hard to resist (Berns et al., 2007; Frederick et al., 2002; Laibson, 1997). While this idea is intuitively appealing and fairly accepted, the question why im- 
mediately available reward might have this effect has only recently received more attention.

\section{Immediately available reward and brain activity}

Luo, Ainslie, Giragosian, and Monterosso (2009) investigated brain activity during the anticipation of delayed rewards. Each reward, consisting of a money amount available after a specified delay, was presented individually in a magnetic resonance imaging (MRI) scanner. Importantly, each subject performed a series of binary choices before the scanning session. Subjects' choices in this task were used to calibrate the amounts used during scanning such that immediate and delayed options were equally preferred by the individual. Despite this preference-matching of the immediate and delayed options, the basal ganglia, the midbrain and the anterior insula showed higher activity when immediate as opposed to delayed rewards were presented, and subjects responded faster during these trials. Previous studies using the same experimental task found that the activity level in these brain regions correlated with anticipated reward value (Knutson, Fong, \& Adams, 2001; Knutson, Taylor, Kaufman, Peterson, \& Glover, 2005). The authors therefore suggest that immediate rewards elicit stronger reward anticipation than the preference-matched delayed rewards. Higher activity in reward related brain regions for immediate versus delayed rewards was also reported by McClure et al., both for monetary and for primary rewards like juice and water (McClure, Ericson, Laibson, Loewenstein, \& Cohen, 2007; McClure, Laibson, Loewenstein, \& Cohen, 2004).

Although such differential brain activity is not unequivocally interpretable as stronger reward anticipation, other studies support the idea that immediate options induce disproportionately strong reward anticipation that may lead to strong preference for immediate reward, which can in turn be counteracted using cognitive control. Hariri et al. (2006) measured individual discount rates using a behavioural delay discounting task. The same subjects also played a guessing task in the fMRI scanner, which allowed measurement of blood oxygenation level-dependent (BOLD) signals in response to gains and losses.

How strongly the ventral striatum reacted to gains relative to losses was 
associated with individual discount rates in the intertemporal choice task. That is, subjects that had a higher reactivity in this reward-sensitive brain region decided less patiently, which suggests a relation of neural reward sensitivity to discounting behaviour.

Transcranial magnetic stimulation (TMS) allows to temporarily disrupt function in parts of the brain. Applying TMS over the left dorsolateral prefrontal cortex (DLPFC), a region implicated in cognitive control, Figner et al. (2010) found a decrease in the proportion of patient choices specifically when an immediate reward was available. This indicates that the DLPFC contributes towards more patient decision making, but only when immediate rewards are available. The authors conclude that DLPFC activity in intertemporal choice represents self-control processes, counteracting the temptation of immediately available reward.

Taken together, these studies suggest that immediate rewards elicit disproportionately strong reward anticipation. The behavioural results summarized in Section 2.2 demonstrate that exposure to appetitive cues results in less patient intertemporal choices (Mischel et al., 1989; Van den Bergh et al., 2008). Thus, dynamically inconsistent intertemporal choices could be driven by an appetitive state that is induced by the prospect of immediate reward, but absent or weaker for the prospect of delayed reward.

\section{Certainty effects}

Many, though not all, deviations from expected utility theory arise when one available option involves outcomes that occur with certainty (Allais, 1953; Andreoni \& Sprenger, 2010a; Kahneman \& Tversky, 1979; Starmer, 2000). That certain outcomes are different from probabilistic outcomes has first been pointed out by Allais (1953). He proposed two sets of choice problems to demonstrate that people show a disproportionate preference for certainty and violate predictions of expected utility theory.

1. The common consequence effect

(A) Certainty of 100 million

(B) $10 \%$ chance of 500 million; $89 \%$ chance of 100 million, $1 \%$ chance of nothing 
(A') $11 \%$ chance of 100 million; $89 \%$ chance of nothing

(B') $10 \%$ chance of 500 million; $90 \%$ chance of nothing

2. The common ratio effect

(C) Certainty of 1 million

(D) $98 \%$ chance of 500 million; $2 \%$ chance of nothing

(C') $1 \%$ chance of 100 million; $99 \%$ chance of nothing

(D') $0.98 \%$ chance of 500 million; $99.02 \%$ chance of nothing

Using problems with a similar structure, but moderate gains, Kahneman and Tversky (1979) empirically confirmed that more people act more risk averse when there is a certain option available, than when there is not. That is, (A) was preferred over (B) much more often than (A') was preferred over (B'). Likewise (C) was preferred more often than (C'), showing that a substantial number of people reverses their preference when there is no certain option available. Both are robust findings, and the common consequence effect has recently been replicated in a large representative sample with both real and hypothetical payoffs (Huck \& Müller, 2012; Weber \& Chapman, 2005). Strong preference for certainty is apparent even when a given outcome is not actually certain at the time of decision making, but merely framed as certain by dividing a lottery into two or more stages. That is, an outcome that is certain, conditional on a first random event, is preferred over an outcome that has a conditional probability smaller than one, giving rise to the so-called isolation effect (Kahneman \& Tversky, 1979). Even more striking, when asked to assign a monetary value to a certain outcome, and to a lottery ticket that will result in the same or a better outcome, people assign a higher monetary value to the certain outcome than to the lottery ticket. For example, people value a voucher for a dinner in a certain restaurant higher than they value a lottery over a voucher for the same or a better restaurant (Gneezy, List, \& Wu, 2006). 


\section{Certainty as as form of immediacy}

While there is ample evidence that humans exhibit a strongly disproportionate preference for certain outcomes, there has been little consideration about why certainty is special. Here, we propose that certain outcomes are special because they are more immediate to the subject and easier to anticipate than uncertain outcomes. Any uncertain outcome involves a mechanism that resolves uncertainty and might lead to an unfavourable result. On the other hand, the only thing that separates the subject from an outcome offered with certainty is the subject's decision.

To see how reducing the probability of an outcome can indeed reduce immediacy of an outcome, consider the following experiment (Keren \& Roelofsma, 1995): Subjects were given a simple intertemporal choice problem, having to decide between receiving

(A) fl. ${ }^{2} 100$ now or

(B) fl. 110 in 4 weeks.

A different group of subjects was faced with a similar problem, but all outcomes were delayed by an additional 26 weeks (a so-called front-end delay). That is, for them the choice was between

(A') fl. 100 in 26 weeks or

(B') fl. 110 in 30 weeks.

When there was no explicit uncertainty, i.e. all outcomes were assigned probability 1 , there was a substantial difference between the two conditions. More subjects preferred (A) over (B) than there were subjects preferring (A') over (B'). That is, the earlier of the two options was preferred more often when it was available immediately than when it was available in the future, although the delay between the early and the late option was 4 weeks in both cases. This provides strong evidence for the above mentioned dynamic inconsistency and temptation by the immediate option. Interestingly, the effect of the front-end delay was dramatically reduced when outcomes were not certain, but were all assigned a probability of 0.9 . When all outcomes

\footnotetext{
${ }^{2}$ The experiment was conducted using dutch guilders
} 
occurred only with probability of 0.5 , (A) was chosen equally often as (A'). That is, when outcomes were sufficiently uncertain, subjects did not show any dynamic inconsistency (Keren \& Roelofsma, 1995; Weber \& Chapman, 2005).

These and similar results have led researchers to note that uncertainty and delay have similar effects on behaviour, and different interpretations for these similarities have been put forward. Some have argued that dynamic inconsistency arises due to the increased uncertainty associated with future outcomes, and more generally, that delay discounting is a derivative of uncertainty inherent in the future (Epper, Bruhin, \& Fehr-Duda, 2009; Keren $\&$ Roelofsma, 1995). Others have argued that delay is psychologically more fundamental, as uncertainty frequently leads to omission of reward and thus results in experience of delay (Rachlin, Raineri, \& Cross, 1991). Since behavioural evidence on the interaction of risk and delay is inconclusive (Andreoni \& Sprenger, 2010b; Weber \& Chapman, 2005), brain imaging studies have tried to resolve the question whether delay discounting and probability discounting are equivalent. Although decision making under risk and intertemporal choice invoked partially the same brain regions, clear distinctions in brain activity were also observed. Activity in the ventral striatum and the orbitofrontal cortex correlated with subjective value for both probabilistic and delayed rewards (Peters \& Büchel, 2009). Among others, the posterior parietal cortex, lateral prefrontal cortex, and anterior insula were found to be more involved in decision making under risk, whereas the lateral parietal cortex and posterior cingulate were preferentially active in intertemporal choice (Peters \& Büchel, 2009; Weber \& Huettel, 2008). Thus, it seems unlikely that delay discounting is fundamental to probability discounting, or vice versa.

Instead, choice behaviour shows that both temporal immediacy and certainty contribute to inducing decision biases like the certainty effect and dynamic inconsistency. In many cases, both temporal immediacy and certainty are necessary to induce these biases (Keren \& Roelofsma, 1995; Weber \& Chapman, 2005). Therefore, we suggest that uncertainty might reduce the immediacy to the offered reward in a similar manner as temporal delay does, without needing to assume that risk and delay are per se psychologically equivalent. Certain outcomes would then be disproportionately preferred 
because they are more immediate to the subject.

\section{Endowment effect}

A third prominent behavioural anomaly in economic decision making is the gap between valuations when elicited as WTP and WTA. For example, when subjects are endowed with a mug and asked for their WTA for selling the mug they will typically state substantially higher valuations than subjects that are asked for their WTP for buying the same mug (Knetsch, 1989). Many behavioural studies of this "endowment effect" suggest that several factors, both cognitive and emotional, contribute to biasing the valuations of buyers and sellers in opposite directions (Brenner, Rottenstreich, Sood, \& Bilgin, 2007; Carmon \& Ariely, 2000; Johnson, Häubl, \& Keinan, 2007; Lerner, Small, \& Loewenstein, 2004; Lin, Chuang, Kao, \& Kung, 2006). The endowment effect has also been observed in non-human primates (Lakshminaryanan, Chen, \& Santos, 2008), which indicates that at least some of the contributing factors might be evolutionarily older than the emergence of private property rights. One circumstance that is frequently overlooked in endowment effect experiments is that elicitation of WTA naturally goes along with placing the good at stake physically close to the subject, whereas WTP elicitation does not.

Two studies have explicitly attended to the role of physical proximity in the endowment effect by manipulating physical proximity independently of legal ownership of the object (Knetsch \& Wong, 2009; Reb \& Connolly, 2007). That is, one group of subjects was told that they now owned a good, but it was not given to them physically. Another group of subjects was physically given the good, but informed that it did not belong to them. Strikingly, both studies found that the physical possession of an object induced an increase in valuation and a reluctance to trade the object for an alternative. Being told that one owns the object, on the other hand, had no such effect (Knetsch \& Wong, 2009; Reb \& Connolly, 2007). Thus, the physical possession of a good increased subjects' valuation for a good, whereas legal ownership did not. This is in line with the findings of Bushong et al. (2010) (see Section 2.2). 


\section{Effects of endowment and physical proximity on brain activity}

Investigating the neural basis of the endowment effect, De Martino, Kumaran, Holt, and Dolan (2009) found that the BOLD response in both the orbitofrontal cortex and the dorsal striatum correlated with the subjective value of an item, irrespective of whether the subject was engaged in buying or selling the item. The endowment effect was evident in the activity pattern of the ventral striatum. That is, when subjects stated high selling prices or low buying prices, activity in the ventral striatum increased. These findings are in line with the current understanding that the orbitofrontal and ventromedial prefrontal cortices encode an abstract, possibly referenceindependent value signal (Levy \& Glimcher, 2012) and the ventral striatum encodes a reward prediction error (Bayer \& Glimcher, 2005; Hare, O’Doherty, Camerer, Schultz, \& Rangel, 2008).

Evidence on the effects of physical proximity on brain activity in humans is very limited due to the substantial practical difficulties associated with bringing physical objects in the fMRI environment and in sight of the subject. Recent studies that have overcome this problem show that brain regions relevant for visuomotor control respond more strongly to objects within reach, as opposed to objects that are out of reach of the subject (Gallivan, Cavina-Pratesi, \& Culham, 2009; Gallivan, McLean, \& Culham, 2011). That is, the brain seems to represent possible reaching targets constantly, even if reaching is not required by the task. The effect of physical proximity on valuation might thus arise from an interaction of constantly updated motor affordances with value computation processes.

\subsection{Conclusion}

There is ample evidence from both animals and humans that irrelevant stimuli can bias choice behaviour if they have been associated with reward or punishment in the past (Corbit et al., 2007; Holmes, Marchand, \& Coutureau, 2010; Huys et al., 2011). Recent experiments show that this is also the case for abstract economic decisions. When immediately exposed to reward or reward predicting stimuli, subjects make less patient intertemporal choices, are less risk averse in choice under uncertainty and are influ- 
enced in their consumer decisions (Bray et al., 2008; Bushong et al., 2010; Guitart-Masip et al., 2010; Van den Bergh et al., 2008; Wilson \& Daly, 2004). These findings constitute stimulus-induced, momentary changes in choice behaviour that are at odds with rational deliberation and thus resemble effects of temptation.

Some of the most robust biases in economic decision making arise when there are options which are available immediately, occur with certainty, or are physically close to the subjects. Although clearly psychologically distinct, temporal immediacy, certainty and physical proximity entail a form of immediacy to reward and might therefore act like reward predicting stimuli and tempt the decision maker to choose an option he would not otherwise choose. Understanding how immediacy to reward and exposure to reward predicting cues influence valuation and choice could thus help to explain seemingly dissimilar decision biases and organize experimental results across various decision situations. Further, exploring the neural mechanisms underlying the effects of exposure to reward and reward predicting stimuli would contribute towards a more complete understanding of the neural mechanisms underlying decision making and thus help to improve prediction accuracy of economic models. 


\section{References}

Ainslie, G. W. (1974). Impulse control in pigeons. Journal of the Experimental Analysis of Behavior, 21(3), 485-489.

Ainslie, G. W. (1975). Specious reward: a behavioral theory of impulsiveness and impulse control. Psychological Bulletin, 82(4), 463-496.

Ainslie, G. W., \& Herrnstein, R. (1981). Preference reversal and delayed reinforcement. Learning \& Behavior, 9(4), 476-482.

Allais, M. (1953). Le comportement de l'homme rationnel devant le risque: critique des postulats et axiomes de l'ecole americaine. Econometrica, 21(4), 503-546.

Andreoni, J., \& Sprenger, C. (2010a). Certain and uncertain utility: the Allais paradox and five decision theory phenomena (Working Paper). Retrieved 6.03.2013, from http://citeseerx.ist.psu.edu/viewdoc/download?doi=10 .1.1.153.7812\&amp;rep=rep1\&amp;type=pdf

Andreoni, J., \& Sprenger, C. (2010b). Risk preferences are not time preferences: discounted expected utility with a disproportionate preference for certainty (NBER Working Paper). Retrieved 6.03.2013, from http://www.nber.org/ papers/w16348

Balleine, B. W., \& Ostlund, S. B. (2007). Still at the choice-point: action selection and initiation in instrumental conditioning. Annals of the New York Academy of Sciences, 1104, 147-171.

Bayer, H. M., \& Glimcher, P. W. (2005). Midbrain dopamine neurons encode a quantitative reward prediction error signal. Neuron, 47(1), 129-141.

Bernheim, B. D., \& Rangel, A. (2004). Addiction and cue-triggered decision processes. American Economic Review, 94(5), 1558-1590.

Berns, G. S., Laibson, D., \& Loewenstein, G. (2007). Intertemporal choice - toward an integrative framework. Trends in Cognitive Sciences, 11(11), 482-488.

Berridge, K. C., \& Robinson, T. E. (2003). Parsing reward. TRENDS in Neurosciences, 26(9), 507-513.

Bray, S., Rangel, A., Shimojo, S., Balleine, B., \& O'Doherty, J. P. (2008). The neural mechanisms underlying the influence of pavlovian cues on human decision making. Journal of Neuroscience, 28(22), 5861-5866.

Brenner, L., Rottenstreich, Y., Sood, S., \& Bilgin, B. (2007). On the psychology of loss aversion: possession, valence, and reversals of the endowment effect. Journal of Consumer Research, 34(3), 369-376.

Bushong, B., King, L. M., Camerer, C. F., \& Rangel, A. (2010). Pavlovian processes in consumer choice: The physical presence of a good increases willingness-topay. American Economic Review, 100(4), 1556-1571.

Carmon, Z., \& Ariely, D. (2000). Focusing on the foregone: How value can appear so different to buyers and sellers. Journal of Consumer Research, 27(3), 360- 
370.

Commons, M., Mazur, J., Nevin, J., \& Rachlin, H. (Eds.). (1987). The effect of delay and intervening events on reinforcement value. volume: 5 . Hillsdale, NJ: Lawrence Erlbaum Associates.

Corbit, L. H., Janak, P. H., \& Balleine, B. W. (2007). General and outcome-specific forms of pavlovian-instrumental transfer: the effect of shifts in motivational state and inactivation of the ventral tegmental area. The European Journal of Neuroscience, 26(11), 3141-3149.

De Martino, B., Kumaran, D., Holt, B., \& Dolan, R. J. (2009). The neurobiology of reference-dependent value computation. Journal of Neuroscience, 29(12), 3833-3842.

Epper, T., Bruhin, A., \& Fehr-Duda, H. (2009). Uncertainty breeds decreasing impatience: the role of risk preferences in time discounting. IEW Discussion Paper. Retrieved 6.03.2013, from http://www.iew.uzh.ch/wp/iewwp412.pdf

Ferriday, D., \& Brunstrom, J. M. (2008). How does food-cue exposure lead to larger meal sizes? British Journal of Nutrition, 100, 1325-1332.

Figner, B., Knoch, D., Johnson, E. J., Krosch, A. R., Lisanby, S. H., Fehr, E., \& Weber, E. U. (2010). Lateral prefrontal cortex and self-control in intertemporal choice. Nature Neuroscience, 13(5), 538-539.

Fishbach, A., Friedman, R. S., \& Kruglanski, A. W. (2003). Leading us not unto temptation: Momentary allurements elicit overriding goal activation. Journal of Personality and Social Psychology, 84(2), 296-309.

Frederick, S., Loewenstein, G., \& O’Donoghue, T. (2002). Time discounting and time preference: a critical review. Journal of Economic Literature, 40(2), 351-401.

Gallivan, J. P., Cavina-Pratesi, C., \& Culham, J. C. (2009). Is that within reach? fMRI reveals that the human superior parieto-occipital encodes objects reachable by the hand. Journal of Neuroscience, 29(14), 4381-4391.

Gallivan, J. P., McLean, A., \& Culham, J. C. (2011). Neuroimaging reveals enhanced activation in a reach-selective brain area for objects located within participants' typical hand workspaces. Neuropsychologia, 49(13), 37103721.

Gneezy, U., List, J. A., \& Wu, G. (2006). The uncertainty effect: When a risky prospect is valued less than its worst possible outcome. The Quarterly Journal of Economics, 121(4), 1283-1309.

Green, L., \& Estle, S. (2003). Preference reversals with food and water reinforcers in rats. Journal of the Experimental Analysis of Behavior, 79(2), 233-242.

Green, L., Fristoe, N., \& Myerson, J. (1994). Temporal discounting and preference reversals in choice between delayed outcomes. Psychonomic Bulletin \& Review, 1(3), 383-389. 
Guitart-Masip, M., Talmi, D., \& Dolan, R. (2010). Conditioned associations and economic decision biases. NeuroImage, 53(1), 206-214.

Hare, T. A., O'Doherty, J., Camerer, C. F., Schultz, W., \& Rangel, A. (2008). Dissociating the role of the orbitofrontal cortex and the striatum in the computation of goal values and prediction errors. Journal of Neuroscience, 28(22), 56235630 .

Hariri, A. R., Brown, S. M., Williamson, D. E., Flory, J. D., de Wit, H., \& Manuck, S. B. (2006). Preference for immediate over delayed rewards is associated with magnitude of ventral striatal activity. Journal of Neuroscience, 26(51), 13213-13217.

Holmes, N. M., Marchand, A. R., \& Coutureau, E. (2010). Pavlovian to instrumental transfer: a neurobehavioural perspective. Neuroscience \& Biobehavioral Reviews, 34(8), 1277-1295.

Huck, S., \& Müller, W. (2012). Allais for all: revisiting the paradox in a large representative sample. Journal of Risk and Uncertainty, 44(3), 261-293.

Huys, Q. J. M., Cools, R., Gölzer, M., Friedel, E., Heinz, A., Dolan, R. J., \& Dayan, P. (2011). Disentangling the roles of approach, activation and valence in instrumental and pavlovian responding. PLoS Comput Biol, 7(4), e1002028.

Johnson, E. J., Häubl, G., \& Keinan, A. (2007). Aspects of endowment: a query theory of value construction. Journal of Experimental Psychology: Learning, Memory, and Cognition, 33(3), 461-474.

Kahneman, D., Knetsch, J. L., \& Thaler, R. H. (1990). Experimental tests of the endowment effect and the Coase theorem. Journal of Political Economy, 98(6), 1325-1348.

Kahneman, D., \& Tversky, A. (1979). Prospect theory: an analysis of decision under risk. Econometrica, 47(2), 263-291.

Kahnt, T., Park, S. Q., Cohen, M. X., Beck, A., Heinz, A., \& Wrase, J. (2009). Dorsal striatal-midbrain connectivity in humans predicts how reinforcements are used to guide decisions. Journal of Cognitive Neuroscience, 21(7), 13321345 .

Kalenscher, T., \& Tobler, P. N. (2008). Interdisciplinary perspectives on decision making. Cognitive, Affective \& Behavioral Neuroscience, 8(4), 345-347.

Keren, G., \& Roelofsma, P. (1995). Immediacy and certainty in intertemporal choice. Organzational Behavior and Human Decision Processes, 63(3), 287-297.

Kirby, K. N., \& Herrnstein, R. J. (1995). Preference reversals due to myopic discounting of delayed reward. Psychological Science, 6(2), 83-89.

Knetsch, J. L. (1989). The endowment effect and evidence of nonreversible indifference curves. American Economic Review, 79(5), 1277-1284.

Knetsch, J. L., \& Wong, W.-K. (2009). The endowment effect and the reference state: 
evidence and manipulations. Journal of Economic Behavior \& Organization, 71(2), 407-413.

Knutson, B., Fong, G., \& Adams, C. (2001). Dissociation of reward anticipation and outcome with event-related fMRI. NeuroReport, 12(17), 3683-3687.

Knutson, B., Taylor, J., Kaufman, M., Peterson, R., \& Glover, G. (2005). Distributed neural representation of expected value. Journal of Neuroscience, 25(19), 4806-4812.

Laibson, D. (1997). Golden eggs and hyperbolic discounting. The Quarterly Journal of Economics, 112(2), 443-477.

Laibson, D. (2001). A cue-theory of consumption. The Quarterly Journal of Economics, 116(1), 81-119.

Lakshminaryanan, V., Chen, M. K., \& Santos, L. R. (2008). Endowment effect in capuchin monkeys. Philosophical Transactions of the Royal Society B: Biological Sciences, 363(1511), 3837-3844.

Lerner, J. S., Small, D. A., \& Loewenstein, G. (2004). Heart strings and purse strings: carryover effects of emotions on economic decisions. Psychological Science, 15(5), 337-341.

Levy, D. J., \& Glimcher, P. W. (2012). The root of all value: a neural common currency for choice. Current Opinion in Neurobiology, 22(6), 1027-1038.

Lin, C.-H., Chuang, S.-C., Kao, D. T., \& Kung, C.-Y. (2006). The role of emotions in the endowment effect. , 27(4), 589-597.

Loewenstein, G. (1996). Out of control: visceral influences on behavior. Organizational Behavior and Human Decision Processes, 65(3), 272-292.

Loewenstein, G., \& Thaler, R. H. (1997). Intertemporal choice. Journal of Economic Perspectives, 3(4), 181-193.

Luo, S., Ainslie, G., Giragosian, L., \& Monterosso, J. R. (2009). Behavioral and neural evidence of incentive bias for immediate rewards relative to preferencematched delayed rewards. Journal of Neuroscience, 29(47), 14820-14827.

Madden, G., \& Bickel, W. K. (Eds.). (2009). Impulsivity: The behavioral and neurological science of discounting (1st ed.). Washington, D.C.: American Psychological Association.

McClure, S. M., Ericson, K. M., Laibson, D. I., Loewenstein, G., \& Cohen, J. D. (2007). Time discounting for primary rewards. Journal of Neuroscience, 27(21), 5796-5804.

McClure, S. M., Laibson, D. I., Loewenstein, G., \& Cohen, J. D. (2004). Separate neural systems value immediate and delayed monetary rewards. Science, 306(5695), 503-507.

Mischel, W., \& Ebbesen, E. B. (1970). Attention in delay of gratification. Journal of Personality and Social Psychology, 16(2), 329-337. 
Mischel, W., Shoda, Y., \& Rodriguez, M. L. (1989). Delay of gratification in children. Science, 244(4907), 933-938.

O’Doherty, J., Dayan, P., Schultz, J., Deichmann, R., Friston, K., \& Dolan, R. J. (2004). Dissociable roles of ventral and dorsal striatum in instrumental conditioning. Science, 304(5669), 452-454.

Peters, J., \& Büchel, C. (2009). Overlapping and distinct neural systems code for subjective value during intertemporal and risky decision making. Journal of Neuroscience, 29(50), 15727-15734.

Phelps, E. (2006). Emotion and cognition: insights from studies of the human amygdala. Annual Review of Psychology, 57, 27-53.

Rachlin, H., Raineri, A., \& Cross, D. (1991). Subjective probability and delay. Journal of the Experimental Analysis of Behavior, 55(2), 233-244.

Reb, J., \& Connolly, T. (2007). Possession, feelings of ownership and the endowment effect. Judgment and Decision Making, 2(2), 107-114.

Robbins, T. W., \& Everitt, B. J. (1999). Drug addiction: bad habits add up. Nature, 398(6728), 567-570.

Samuelson, P. A. (1937). A note on measurement of utility. Review of Economic Studies, 4(2), 155-161.

Schultz, W., Dayan, P., \& Montague, P. R. (1997). A neural substrate of prediction and reward. Science, 275(5306), 1593-1599.

Sharot, T., Shiner, T., Brown, A. C., Fan, J., \& Dolan, R. J. (2009). Dopamine enhances expectation of pleasure in humans. Current Biology, 19(24), 20772080.

Starmer, C. (2000). Developments in non-expected utility theory: the hunt for a descriptive theory of choice under risk. Journal of Economic Literature, 38, $332-382$.

Tversky, A., \& Kahneman, D. (1981). The framing of decisions and the psychology of choice. Science, 211(4481), 453-458.

Van den Bergh, B., Dewitte, S., \& Warlop, L. (2008). Bikinis instigate generalized impatience in intertemporal choice. Journal of Consumer Research, 35(1), 85-97.

Weber, B. J., \& Chapman, G. B. (2005). The combined effects of risk and time on choice: Does uncertainty eliminate the immediacy effect? Does delay eliminate the certainty effect? Organzational Behavior and Human Decision Processes, 96(2), 104-118.

Weber, B. J., \& Huettel, S. A. (2008). The neural substrates of probabilistic and intertemporal decision making. Brain Research, 1234, 104-115.

Wilson, M., \& Daly, M. (2004). Do pretty women inspire men to discount the future? Proceedings of the Royal Society of London. Series B: Biological Sciences, 271 
Suppl 4, S177-S179.

Yun, I. A., Wakabayashi, K. T., Fields, H. L., \& Nicola, S. M. (2004). The ventral tegmental area is required for the behavioral and nucleus accumbens neuronal firing responses to incentive cues. Journal of Neuroscience, 24(12), 2923-2933. 



\title{
Chapter 3
}

\section{Flexible Valuations for}

\section{Consumer Goods as}

\section{Measured by the}

\section{Becker-DeGroot-Marschak}

\section{Mechanism}

\begin{abstract}
This paper experimentally investigates whether valuations elicited by the commonly used Becker-DeGroot-Marschak procedure depend on the distribution of prices used in the elicitation mechanism. To answer this question we created a novel within-subject design that allowed us to observe an individual's bid for a given product repeatedly, while varying the price distribution. Our data clearly show that subjects do not bid constantly the same amount for each good on each offer, as would be predicted by expected utility theory. Instead, they bid higher when a high price occurs with high probability, than when a low price is highly likely. This effect persists over several rounds where subjects repeatedly bid on the same goods. The observed flexible valuations are at odds with expected utility maximization and the pattern of distributional dependence is not in line with predictions of anchoring, or theories of reference dependent preferences.
\end{abstract}

Based on: Woelbert, E., Tymula, A., \& Glimcher, P. Flexible valuations for consumer goods as measured by the Becker-DeGroot-Marschak mechanism (in preparation). 


\subsection{Introduction}

Knowing a person's true valuation for a good is important for research on human decision making, marketing, and for policy decisions on the provision of public goods. Simply asking someone to state their valuation, without giving any incentives to tell the truth, has been found to lead to inflated value estimates (List \& Gallet, 2001; Wertenbroch \& Skiera, 2002). To increase the accuracy of the measurement, so-called incentive-compatible value elicitation methods are often used. Here, participants face a real trading situation, the valuations they state have consequences for their trades, and misstating their valuation is thus potentially costly for participants. The Becker-DeGroot-Marschak mechanism (BDM) is one such method. Thanks to its relative simplicity and high degree of control for the experimenter it is widely used in experimental economics, marketing, and in neuroscientific research on decision making. In this mechanism, subjects are asked to state the maximum amount they would be willing to pay for a given good. The actual price for the good is then determined randomly from a distribution of possible prices. If the stated willingness to pay is higher than the actual price, the subject will buy the good from the experimenter, paying the actual price. If the willingness to pay is lower than the price, the subject will not buy the good (Becker, DeGroot, \& Marschak, 1964).

This procedure is assumed to provide the right incentives for subjects to truthfully reveal their valuation for a good. The intuition behind this is simply that bidding below one's true valuation might result in foregoing the chance to buy the good at stake for an acceptable price. Likewise, when bidding above one's true valuation one might have to buy the good at a price higher than the individual valuation of the good, thus incurring a loss. Both of these undesirable scenarios can be avoided by bidding equal to true valuation. Assuming that the decision maker maximizes expected utility, it is indeed optimal to place a bid that is equal to true valuation (Becker et al., 1964; Horowitz, 2006). Experimental evidence on whether subjects do bid truthfully in the BDM mechanism is mixed, however.

One approach for assessing its validity has been to compare average bids placed in the BDM with those placed in equally incentive compatible pro- 
cedures like the Vickrey auction. ${ }^{1}$ Although theoretically both procedures should yield identical value estimates, BDM and Vickrey auction consistently yield different average bids for the same product. This demonstrates that at least one of these methods leads to inaccurate bids and that theoretical incentive-compatibility does not necessarily result in truthful revelation (Kaas \& Ruprecht, 2006; Noussair, Robin, \& Ruffieux, 2004; Rutström, 1998; Shogren et al., 2001). Lusk, Alexander, and Rousu (2007) point out that these two mechanisms differ mainly with respect to the distribution of possible prices that the bidder faces. This suggests that bidders might be influenced by the price distribution.

The distribution of possible prices is a central feature of the BDM mechanism that the researcher controls. Under expected utility theory the specific price distribution - just as the number of players and their expected bids in the Vickrey auction — does not affect the optimal bidding strategy. ${ }^{2}$ That is, if the BDM mechanism is indeed incentive-compatible in practice, then bids should not change as a function of the price distribution. In contrast to the prediction of the standard model, bids for the same product seem to vary with the distribution of possible prices used (Bohm, Lindén, \& Sonnegård, 1997; Mazar, Köszegi, \& Rabin, 2010; Urbancic, 2011).

Bohm et al. (1997) elicited valuations for a petrol voucher using the BDM mechanism. Varying the upper bound of the price distribution between subjects, they observed higher bids when the upper bound was higher. Also using a between-subject comparison, Mazar et al. (2010) found that BDM bids for a travel mug were higher when the price distribution assigned a high probability to the highest possible price, than when the lowest price was highly probable. Interestingly, this difference was much smaller in a withinsubject comparison, i.e. when the same subjects were asked to place two bids on the travel mug, one for each distribution. Since subjects reported similar valuations when forced to bid under both distributions, the authors conclude that people do not truly hold different WTP for different price distributions, but that when considering only one price distribution people make mistakes

\footnotetext{
${ }^{1}$ In this auction only the person who, among all bidders, placed the highest bid on a given good will buy the good, paying a price equal to the second highest bid.

${ }^{2}$ More specifically, the optimal bidding strategy is not affected as long as the bidder's true value is within the range of possible prices.
} 
in reporting their true WTP. In contrast, Urbancic (2011) observed distributional dependence of BDM bids also when the same subjects repeatedly bid on a voucher for cookies under varying price distributions. Most subjects had a higher WTP under left-skewed price distributions than under right-skewed price distributions, whereas few showed the opposite pattern.

In this paper we seek to clarify whether distributional dependence in the BDM mechanism is a genuine and significant bias. Therefore, we investigate whether the effect persists after several rounds under varying price distributions, and - if so - to quantify the effect. We had subjects place on average more than 50 bids on the same good, while varying the probabilities assigned to the possible prices from round to round. In each round one randomly selected price between 0 and 50 was assigned a much higher probability (51\%) than all other prices (1\%). To understand which subject- or good-specific factors influence distributional dependence in the BDM mechanism, subjects placed bids on three different goods and answered a set of debriefing questions at the end of the experiment. Using goods with suggested retail prices above $\$ 50$ we provide significant incentives for subjects to pay attention throughout the experiment and to report their valuations truthfully. Since distributional dependence may arise as a consequence of misunderstanding the nature of the mechanism (Cason \& Plott, 2012; Urbancic, 2011) our subjects were instructed in detail using examples, and were only allowed to participate once they had answered a set of comprehension questions correctly.

We find that subjects bid higher when the price that is most likely selected is higher. This bias is strongest when the most likely price is relatively close to the subject's average bid for the respective good. Interestingly, we find that subjects show distributional dependence mostly for one or two, but not for all goods. Further, they are affected by the price distribution more when they are bidding on goods that they wish to buy more strongly. 


\subsection{Methods}

\section{Participants}

In total, 27 paid volunteers (12 females) participated in this experiment. Data acquisition took place at the Center for Experimental Social Science (CESS) at New York University. Participants were recruited via Email from the CESS subject pool, which consists of students of all fields of New York University. All participants gave informed consent in accordance with the procedures of the University Committee on Activities Involving Human Subjects of New York University. Each session lasted approximately 90 minutes and subjects were compensated with $\$ 50$ and the opportunity to purchase one of three consumer goods. The recruitment message clearly stated that part of the compensation for the experiment could be a backpack, an iPod or a pair of headphones.

\section{Instructions}

At the beginning of the experiment, participants were informed that they will be asked to state their maximum willingness to pay for three different goods, a backpack, an iPod shuffle, and a pair of noise-cancelling headphones repeatedly. Participants learned that, out of all rounds they completed, one randomly selected round will be implemented for real. Participants were not told the exact market price of the good, but were informed that the suggested retail price of all three products was higher than any possible price in the experiment, that is, above $\$ 50$. To ensure that subjects had enough information about the goods to understand what they were bidding on, they were given substantial time to inspect the products.

The BDM procedure was explained to the participants in detail using written instructions (see Appendix 3.A). The instructions stressed that the actual price of a good was determined randomly, and could not be influenced by the subject's bid. It has been suggested that inconsistent bids in the BDM mechanism might result from subject misconceptions, such as mistaking the BDM mechanism for a first price auction (Cason \& Plott, 2012). Examples were used to emphasize that if the subject's bid was higher than the randomly determined price, the subject would not have to pay the bid, but only 
the randomly determined price. To ensure that all participants understood the rules of the experiment, and the BDM mechanism in particular, they were asked to answer a set of comprehension questions. Only participants who answered the comprehension questions correctly were allowed to enter the next stage of the experiment. Participants were informed that answering comprehension questions incorrectly would result in a compensation of $\$ 5$ and exclusion from the experiment. This strict rule ensures that inconsistent bids do not arise from misunderstandings of the procedure. In the debriefing questionnaire all participants indicated that the instructions were either clear or very clear.

\section{The task}

Upon completion of the comprehension questions, subjects were endowed with $\$ 50$. The task was presented on a computer screen using ePrime 2.0 software (Psychology Software Tools, Pittsburgh, PA), and survey questions were presented using a Google documents form. In order to familiarize participants with the experiment, they were given five example rounds, which were not relevant for their payoff. Each participant worked through the experiment at their own pace and in private, completing on average 140 rounds $(S D=33.98)$.

In each round, participants stated their maximum WTP for one of the goods, following always the same structure: At the beginning, participants were informed which good they were bidding on in the current round. Importantly, they were also shown one price in each round which had a probability of 0.51 to be selected as the actual price. Since this most likely price is revealed to them at the time of bidding, we term it the "revealed price". All other prices between $\$ 1$ and $\$ 50$ (in steps of $\$ 1$ ) had an equal probability of .01 to be selected as the actual price in the current round. After observing the information on the good and the revealed price, participants could enter a bid for the current round, which was constrained to be between $\$ 0$ and $\$ 50$. On each round, the actual price was determined randomly and revealed only after the bid was made. That is, subjects learned the randomly determined actual price in each round, as well as whether they would buy the good or not if this round counted for payment. 
Following the standard BDM procedure, any bid higher than or equal to the randomly selected price would result in purchasing the good at the randomly selected price. Any bid lower than the price would result in not purchasing the good. To provide incentives for truthful revelation throughout the experiment, one of all rounds was selected at the end of the experiment to be implemented for real. Thus, each round had a chance to be relevant for payment.

Participants who made no purchase kept the endowment of $\$ 50$ and received none of the goods, participants who made a purchase paid the actual, randomly selected price out of their $\$ 50$ endowment and kept the rest of the money. The experiment was conducted in different versions that varied minimally. ${ }^{3}$ Note that, irrespective of the version, standard theory predicts that a subject constantly bids the same amount for a given good.

\footnotetext{
${ }^{3}$ There were no differences in the magnitude of the treatment effect between any of the versions (see Table 3.5 in Appendix 3.B). Eight participants completed a fixed number of 156 rounds and the goods were presented in random order. At the end of the experiment one of the rounds was chosen at random and the participant's decision was implemented. For 9 of the participants, goods were presented in random order as well, but a hazard function was applied that could end the experiment at any round, after which the last played round would be implemented for payment. These participants were informed that over $90 \%$ of the study participants would stop at some randomly determined round and that on average each round had more than a $1.8 \%$ chance of being played for real. If the experiment was not ended after 156 rounds (10\% of the participants in expectation), it ended at this point and no round was implemented, so they kept their endowment. For another 5 participants the same hazard function was applied, the good was kept constant for a block of 28 rounds, each good was presented at most for two blocks of 28 rounds. We used a dynamically adjusting hazard function of the following form:
}

$$
p(\text { end })=0.01+\left(\frac{\text { round\# }}{125}\right)^{10}
$$

The remaining 5 participants were endowed with $\$ 100$ at the beginning of the experiment and were given a chance to purchase all of the goods. The good was kept constant for one block with a maximum of 56 rounds and the following hazard function was applied for each block:

$$
p(\text { end })=0.01+\left(\frac{\text { round\# }}{40}\right)^{10}
$$




\subsection{Results}

Subjects bid on average $\$ 19.57$, indicating that they were interested in buying the goods on offer. Mean bids for each good, and standard deviations are shown in Table 3.1. Plotting the distribution of bids (see Figure 3.1) illustrates that subjects tended to bid multiples of 5 much more often than all other prices, which resulted in a multimodal distribution of bids. Overall, $62 \%$ of the bids were equal to these focal points.

Table 3.1: Descriptive statistics for bids

\begin{tabular}{lcc}
\hline Good & $\begin{array}{c}\text { Mean } \\
\text { bid }\end{array}$ & $\begin{array}{c}\text { SD } \\
\text { bid }\end{array}$ \\
\hline Backpack & $\$ 17.16$ & 15.62 \\
Headphones & $\$ 20.60$ & 14.90 \\
iPod & $\$ 21.10$ & 16.52 \\
\hline Total & $\$ 19.57$ & 15.78 \\
\hline
\end{tabular}

Our first important finding is that - contrary to the prediction under expected utility theory (Becker et al., 1964) — subjects did not state a constant maximum WTP for each good. Only one out of 27 participants provided a constant WTP for a good throughout the experiment. ${ }^{4}$ The bid of an average subject for a given good varied substantially, with an average standard deviation of 3.35. Subjects differed with respect to the variability in the bids for one good, one subject bidding constantly the same amount for a good and some subjects changing their WTP substantially from round to round. Table 3.2 shows descriptive statistics for individual standard deviations separately for the first and second half of the experiment. There is a decrease in variability over the course of the experiment, but bids still vary considerably in the second half of the experiment.

\footnotetext{
${ }^{4}$ This subject bid $\$ 50$ for each of the goods on each round. In the debriefing questionnaire this subject stated the intention to resell any good bought at the experiment.
} 


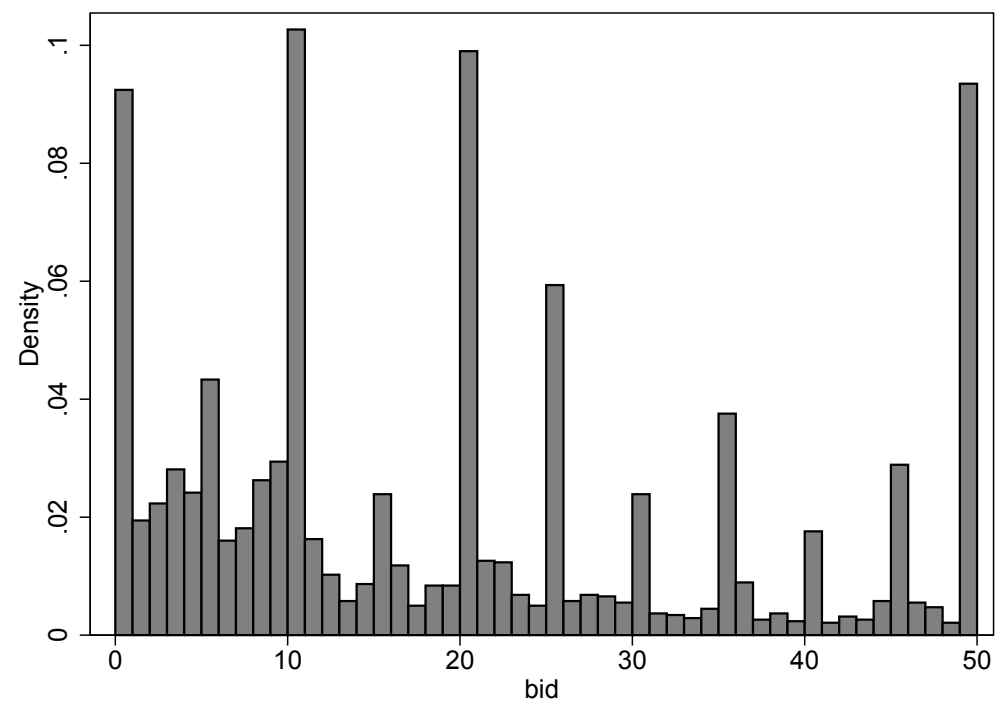

Figure 3.1: Histogram over the bids

\section{The effect of the revealed price}

To determine whether there is an effect of the revealed price on bids we compare average bids in rounds where the revealed price was high (equal to or higher than $\$ 25$ ) than when it was low. We find that bids are significantly higher when the revealed price is high, than when it is low ( $\$ 20.3$ versus $\$ 18.8, p<0.01$, two-sided t-test).

In order to understand the effect of the revealed price on bids, we plot the bid on each round as a function of the revealed price in that round. We account for between-subject variability by plotting both bid and and revealed price relative to the subject's mean bid for the respective good. That is, from each bid and revealed price we subtract the mean bid a subject placed on this good over the course of the experiment. A scatterplot of these normalized bids against normalized revealed price shows that the data points are separable into two very distinct patterns (see Figure 3.2). For some, there is a strong influence of the revealed price on the bid (with a slope near 1), whereas for others there is no influence of the revealed price at all. 
Table 3.2: Summary statistics for standard deviations of the bids an individual subject placed for one specific good

\begin{tabular}{lrrrr}
\hline & mean & median & min & $\max$ \\
\hline First half & 3.46 & 2.30 & 0 & 16.38 \\
Second half & 2.42 & 1.71 & 0 & 13.96 \\
All & 3.35 & 2.30 & 0 & 15.88 \\
\hline
\end{tabular}

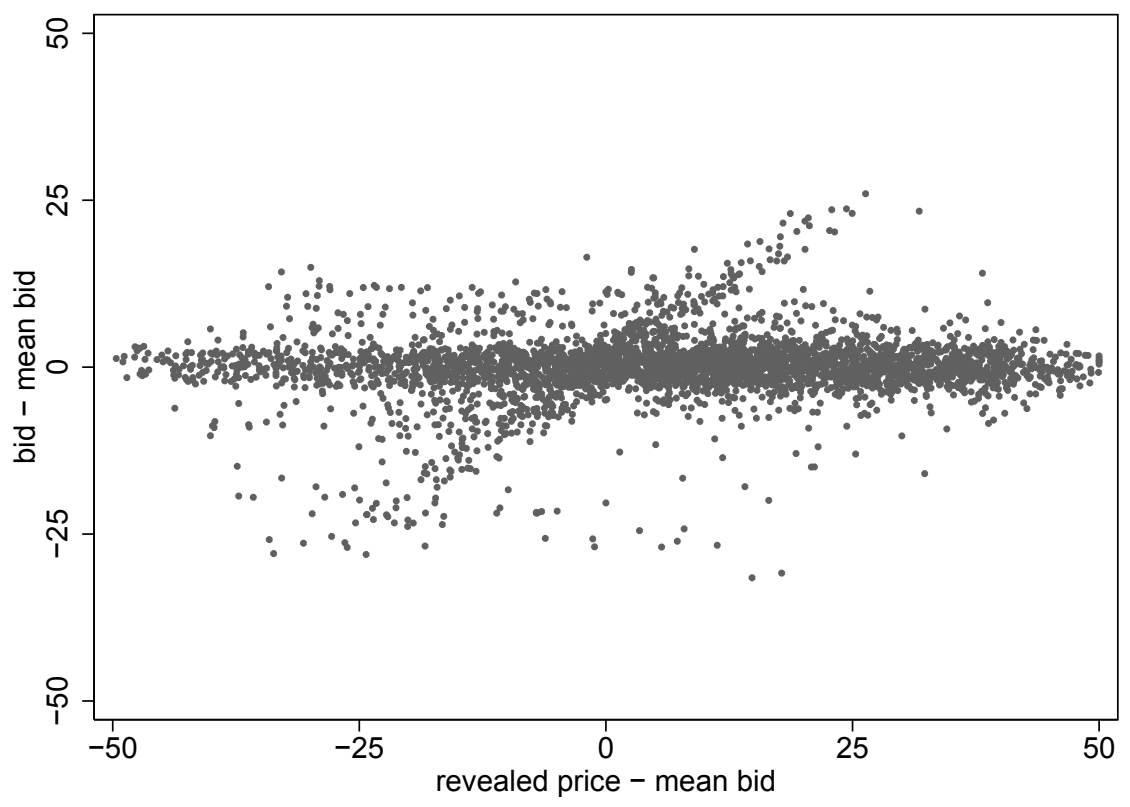

Figure 3.2: Scatterplot of bid against revealed price, both centred on the mean bid of the subject for the respective good 
To quantify the effect of the revealed price on the bid we regressed the bid in each round on the revealed price. To account for individual and goodspecific differences in willingness to pay we use a fixed effects model, where each subject/good combination was considered a group of observations. Figure 3.2 suggests that the revealed price affects bids not across the whole range of possible values, but mostly when it is relatively close to the mean bid a subject places on a good. Therefore, we perform this regression on the full data set, as well as on reduced data sets which include only rounds where the revealed price was relatively close to a subject's mean bid for a good (see Table 3.3). ${ }^{5}$ The coefficient for the revealed price is larger when considering only rounds where the revealed price was relatively close to the subject's average bid. When the revealed price is in the range of +/- $1 S D$ of the mean bid it increases the bid by on average $\$ 0.41$ for each $\$ 1$ increase in the revealed price.

The previous bid and the previous revealed price were included as predictors to control for potential influences they might have on the current bid. Neither showed a significant effect on the bid, nor was there a systematic change in the bids over the course of the experiment. It could be that subjects initially reacted stronger to the revealed price because they were uncertain about their valuation for a good or about the procedure, but became more certain by bidding repeatedly. If this were the case, we would expect to see a decrease in the effect of the revealed price over time. In order to test for this, we included the interaction term revealed price*round in the regression. There was no significant effect of this interaction term, indicating that there was no change in the effect of the revealed price over the course of the experiment.

\section{Variability in the effect of the revealed price}

Some of the subjects did not vary their bids at all throughout the experiment and others varied it a lot (see Table 3.2). Further, Figure 3.2 shows that sometimes there is a strong effect of the revealed price, but sometimes

\footnotetext{
${ }^{5}$ We used the population $S D$ to determine whether the revealed price was 'close'. Since the revealed price was drawn from a uniform distribution, this eliminates a comparable number of rounds for each subject, irrespective of the subject's individual variability in bids.
} 
Table 3.3: The effect of the revealed price on the bid

\begin{tabular}{llllr}
\hline dep. var.: bid & & within & \multicolumn{1}{c}{ within } & within \\
& all data & $+/-2 \mathrm{SD}$ & $+/-1.5 \mathrm{SD}$ & +/-1SD \\
\cline { 2 - 5 } & Coef./se & Coef./se & Coef./se & Coef./se \\
\hline revealed price & $0.09^{*}$ & $0.23^{* * *}$ & $0.31^{* * *}$ & $0.41^{* * *}$ \\
& $(0.05)$ & $(0.07)$ & $(0.07)$ & $(0.08)$ \\
previous bid & 0.14 & 0.11 & 0.09 & 0.11 \\
previous revealed price & $(0.10)$ & $(0.08)$ & $(0.08)$ & $(0.09)$ \\
& -0.00 & -0.01 & -0.01 & -0.00 \\
round & $(0.01)$ & $(0.01)$ & $(0.01)$ & $(0.01)$ \\
& 0.02 & -0.01 & -0.01 & -0.01 \\
revealed price*round & $(0.01)$ & $(0.01)$ & $(0.01)$ & $(0.01)$ \\
& -0.00 & 0.00 & 0.00 & 0.00 \\
constant & $(0.00)$ & $(0.00)$ & $(0.00)$ & $(0.00)$ \\
& $13.85^{* * *}$ & $13.59^{* * *}$ & $12.04^{* * *}$ & $9.25^{* * *}$ \\
\hline$R^{2}$ & $(2.81)$ & $(1.83)$ & $(1.88)$ & $(3.07)$ \\
\hline No. of obs. & 0.086 & 0.172 & 0.175 & 0.216 \\
\hline
\end{tabular}

Note. Subject/good fixed effects included. Standard errors clustered by subject.

${ }^{*} p<0.10,{ }^{* *} p<0.05,{ }^{* * *} p<0.01$ 
no effect at all. In order to understand the significance of the results it is important to know how many subjects in the studied population show the effect. To answer this question we regressed the bid on the revealed price separately for each good and each subject (up to three regressions per subject, depending on when the payment relevant round occurred and experiment finished). In these individual regressions, $52 \%$ (44\%) of the subjects showed a significant effect of the revealed price for at least one good at the $10 \%(5 \%)$ level. Interestingly, a subject that shows an effect of the revealed price does not necessarily show it for all the goods. Instead, many subjects show a significant effect for one or two of the goods, but not for another good.

The fact that there is variability in the effect of the revealed price both within and across subjects suggests that individual and good-specific factors play a role in determining how strongly a person responded to the revealed price. Therefore, we investigated whether people's response was stronger for goods that they wished to buy more strongly. In the debriefing questionnaire subjects answered the question "At the beginning of the experiment, how strongly did you want to buy the iPod / Backpack / Headphones?" on a 5point Likert scale, which ranged from 'not at all' to 'really wanted to buy'. We re-ran the above regressions including an interaction term of the revealed price and the self-reported wish to buy the good. As can be seen in Table 3.4, the interaction term is significant in the full data set. When restricting the range of the revealed price to the vicinity of the mean bid, the interaction is insignificant and the revealed price itself is a strong predictor of the bid. This suggests that subjects who express a strong wish to buy a good will react to the revealed price even if it is relatively far away from their average bid. If people do not express a strong wish to buy the good, they will still react to the revealed price, but only if it is close to their mean bid.

\subsection{Discussion}

We find that subjects' bids in the BDM mechanism depend on the price distribution used, and that distributional dependence persists over more than 140 rounds where subjects repeatedly bid on the same three goods. Specifically, we find that subjects bid higher when faced with a price distribution that assigns a high probability to a high price. Moreover, we observe that 
Table 3.4: The effect of the revealed price depends on how strongly the subjects wants to buy good

\begin{tabular}{llllr}
\hline dep. var.: bid & all data & $\begin{array}{l}\text { within } \\
+/-2 S D\end{array}$ & $\begin{array}{r}\text { within } \\
+/-1.5 \mathrm{SD}\end{array}$ & $\begin{array}{r}\text { within } \\
+/-1 \mathrm{SD}\end{array}$ \\
\cline { 2 - 5 } & Coef./se & Coef./se & Coef./se & Coef./se \\
\hline revealed price & 0.01 & $0.37^{* * *}$ & $0.48^{* *}$ & 0.68 \\
& $(0.03)$ & $(0.09)$ & $(0.17)$ & $(0.41)$ \\
previous bid & 0.14 & 0.11 & 0.10 & 0.12 \\
previous revealed price & $(0.10)$ & $(0.09)$ & $(0.09)$ & $(0.10)$ \\
& -0.00 & -0.01 & -0.01 & -0.00 \\
round & $(0.01)$ & $(0.01)$ & $(0.01)$ & $(0.01)$ \\
& 0.01 & 0.01 & 0.01 & 0.02 \\
wanting* & $(0.01)$ & $(0.01)$ & $(0.01)$ & $(0.01)$ \\
revealed price & $0.02^{* *}$ & -0.02 & -0.04 & -0.06 \\
constant & $(0.01)$ & $(0.03)$ & $(0.05)$ & $(0.12)$ \\
& $15.02^{* * *}$ & $12.43^{* * *}$ & $11.44^{* * *}$ & $8.41^{*}$ \\
\hline$R^{2}$ & $(2.68)$ & $(2.67)$ & $(2.53)$ & $(4.12)$ \\
\hline No. of obs. & 0.095 & 0.154 & 0.148 & 0.168 \\
\hline & 3491 & 787 & 592 & 400 \\
\hline
\end{tabular}

Note. Subject/good fixed effects included. Standard errors clustered by subject.

${ }^{*} p<0.10,{ }^{* *} p<0.05,{ }^{* * *} p<0.01$ 
subjects are more prone to adjust their bid towards the highly likely price when this price is close to the bid they placed on a good on average.

Assuming that subjects are insecure about their valuation for the product on offer, the literature suggests several ways how the price distribution could influence the subjects' bids. In the following, we discuss how our within subject design rules out several of those factors, and evaluate our findings in light of the predictions made by applicable models.

First of all, a price distribution may be interpreted as a credible signal of market value and quality. Following this reasoning, a higher price distribution may lead to higher bids because subjects believe that they are bidding on a more valuable product. While this is a valid concern for between-subject comparisons, it does not apply to our study. Subjects were repeatedly bidding on the same good under varying price distributions and they knew that these distributions were randomly generated. It is unreasonable to assume that subjects would update their belief about the market value and quality for the same good every time when faced with a different, randomly generated price distribution.

Similarly, it has been suggested that prices which are close to a person's initial guess for her valuation can provide an incentive to think about one's exact value for a good and come to a more precise estimate (Wathieu $\&$ Bertini, 2007). Accordingly, if a price that is slightly higher or lower than the individual's initial guess for her valuation occurs with high probability this might lead the subject to think more carefully about what the item is worth and to refine her valuation. Once a more precise estimate is found, however, the subject would be expected to stick to bidding this value. If such a value-refinement process was driving distributional dependence in our experiment, we should observe a decay in the effect of the revealed price over time. Instead, we observe that the effect of the revealed price does not change over time, indicating that distributional dependence is not due to subjects refining their valuation based on the revealed price and an initial, imprecise guess.

Further, bringing random numbers, such as digits of the individual socials security number, to the subjects' attention has been found to exert a strong influence on WTP for consumer goods (Ariely, Loewenstein, \& Prelec, 2003). A recent attempt to replicate this finding has found qualita- 
tively similar, but quantitatively much weaker effects (Fudenberg, Levine, $\&$ Maniadis, 2012). Since we implemented different price distributions by assigning a high probability to one specific price, subjects uncertain in their valuation may be anchoring on this price from round to round. According to the anchoring and adjustment heuristic, when uncertain about a true value, people sometimes anchor on available numbers, and then adjust in the direction of the true value (Tversky \& Kahneman, 1974). If people make use of this heuristic, this does not have to lead to biased answers, however. Answers only depend only on the initial anchor if adjustment is insufficient. This is most likely the case when the anchor is far away from the true value. Thus, if anchoring and adjustment should account for the effect of the revealed price in our data, a stronger effect would be expected for revealed prices that are far away from the subject's average bid because then the effects of insufficient adjustment would be most apparent. We observe the opposite pattern, indicating that anchoring and adjustment cannot account for distributional dependence in our data.

Lusk et al. (2007) and Kaas and Ruprecht (2006) assume that subjects might deviate from the optimal bid due to e.g. uncertain valuations, curiosity, or experimenter demand effects, and analyse the expected costs of such deviation in the BDM mechanism. Whether failing to bid optimally is actually costly for the bidder depends on the realization of the randomly drawn price. For example, bidding too low will only be costly in case the randomly drawn price turns out to be lower than the actual value for the good, but higher than the bid. In this case the subject foregoes the chance of buying at a favourable price. Likewise, bidding too high will be costly if the price turns out to be higher than the valuation, but lower than the bid. In this case the subject has to pay more than her valuation for the good. Consequently, expected costs of deviating from optimal bidding increase as the likelihood of these events increases. Bidders who deviate from bidding equal to their valuation are assumed to do so less in the direction of higher expected costs. Applying this approach to our design, we would expect the following: If the revealed price falls near, but above their value estimate, bidding higher is likely to be consequential, and thus results in high expected cost of deviating from the optimal bid. Such bidders should thus be less likely to bid higher when the revealed price is close, but above their value estimate. We observe 
the opposite.

Assuming that subjects have a fixed valuation for the good and respond optimally to the BDM, their bid could still be affected by the price distribution. This may be the case if bidders care about the buying probability, or the probability of certain prices (Horowitz, 2006). In our case, as the revealed price exceeds the subject's bid, buying probability decreases sharply. In the model of reference dependent preferences by Köszegi and Rabin (2006) such a probability distribution defines a reference point, against which outcomes are evaluated. Outcomes that are more favourable than expected create additional positive utility (gain utility), whereas failing to meet expectations creates negative utility (loss utility). Following the notion of loss aversion, failing to meet expectations weighs heavier than exceeding expectations. In this model, subjects care about the buying probability and about probabilities attached to the possible prices, thus distributional dependence would be expected (Heidhues \& Köszegi, 2010; Köszegi \& Rabin, 2006). However, also this model predicts the opposite of the bias we observe, i.e. subjects are expected to bid lower when prices above their valuation for the good are most likely, and to bid higher when prices below their valuation are most likely. One prominent driving factor in this result is that subjects dislike intermediate buying probabilities, as these bring maximal uncertainty about whether they will buy the good and pay the expected price, which results in maximal expected loss utility (Heidhues \& Köszegi, 2010). If the revealed price is lower than the subjects' valuation, they expect to buy with high probability (above 0.5). Bidding higher is then attractive because it reduces uncertainty about the outcome. If the revealed price is above their valuation, on the other hand, they expect to buy with low probability (below 0.5). Bidding lower is attractive in this case, because it further decreases the buying probability, which decreases uncertainty about the outcome, and hence expected loss utility. Thus, our data is not in line with a model of reference dependent preferences (Heidhues \& Köszegi, 2010; Köszegi \& Rabin, 2006).

\section{Comparison to similar studies}

Two recent studies have aimed at investigating the nature of distributional dependence on WTP (Mazar et al., 2010; Urbancic, 2011). Mazar et al. 
(2010) conducted a series of experiments on distributional dependence using reservation prices in a simple purchasing task, and BDM bids on mugs and boxes of chocolate. Urbancic elicited WTP for cookies repeatedly in the same subjects, while varying the price distribution. In line with our finding, both observe strong distributional dependence. The results of Urbancic (2011) confirm our finding that the price distribution is more likely to influence bids when likely prices are close to the subject's valuation for the good.

Interestingly, Mazar et al. (2010) found that distributional dependence was decreased when subjects reported their maximum WTPs simultaneously for two different distributions. A strong decrease in distributional dependence was also observed when subjects were repeatedly prompted to reflect on the stated WTP and to adjust it if they felt it was not accurate. Although statistically insignificant in the analyses presented, in both of these experiments the average WTP was still considerably higher when high prices were more likely. Our results, as well as those of Urbancic (2011), show that even if distributional dependence is decreased in a within-subject design, it is not eliminated. Notably, similar to our current study, all price distributions in Mazar et al. (2010) contained one highly likely price and were otherwise uniform. However, this likely price was either the highest or the lowest of all possible prices. The range of possible prices in Mazar et al. (2010) is chosen such that most subjects' valuations are expected to lie somewhere in the middle, i.e. relatively far from the most likely price. As our results show, distributional dependence is strongest when the likely price is close to the subject's valuation (see also Urbancic, 2011). Therefore, the setup of Mazar et al. (2010) is likely underestimating the true extent of distributional dependence.

Urbancic (2011) found that distributional dependence decreased as a consequence of detailed instructions, suggesting that distributional dependence may arise from misunderstanding the procedure. Therefore we gave detailed instructions on the BDM mechanism, highlighting the sequence of events and the resulting independence of bid and realized price. Moreover, we gave several examples and had subjects complete three comprehension questions before admitting them to the experiment. In contrast to Urbancic (2011), we also resolved the BDM mechanism in each round. That is, subjects learned in each round what the actual price was, and whether they 
would buy or not if this round counted for payoff. Thus resolving the BDM in each round should correct any remaining misconceptions about the mechanism. Although we observed a decrease in variance in the individual bids over the course of the experiment, distributional dependence persisted over on average 140 rounds per subject. In addition, subjects showed distributional dependence mostly for one or two goods, but not for all. It is implausible to assume that subjects would misunderstand the procedure for one good, but not for the other. Taken together, misunderstanding the BDM mechanism is unlikely to be the reason for the distributional dependence observed in our experiment.

\section{Conclusion}

This study demonstrates that in repeated rounds of the BDM mechanism subjects do not bid constantly the same amount for the same good, but are surprisingly flexible. Elicited valuations vary with the distribution underlying the random price in form of a mass-seeking bias. That is, subjects tend to bid higher when the price distribution assigns a high probability to a high price, and bid lower when a low price is highly probable. Overall, distributional dependence is frequent when the the likely price is close to the average bid a subject places on a given good. Subjects who wish to buy a good more strongly are more likely to show distributional dependence for a wide range of price distributions.

Such bidding behaviour cannot be reconciled with the standard assumption that consumers have a fixed valuation for a good and maximize expected utility. Furthermore, our results are not in line with predictions of anchoring or reference-dependence. Distributional dependence in our experiment is unlikely to result from misunderstanding the BDM, because subjects repeatedly bid on the same products and received detailed instructions and feedback on the BDM mechanism. Taken together, these results show that distributional dependence in the BDM mechanism is a persistent, but complex phenomenon. Further understanding the driving factors would contribute towards a better understanding of value construction. Moreover, it would enable us to modify the BDM in such a way that elicited valuations are more valid. 


\section{References}

Ariely, D., Loewenstein, G., \& Prelec, D. (2003). Coherent arbitrariness: stable demand curves without stable preferences. The Quarterly Journal of Economics, 118(1), 73-106.

Becker, G. M., DeGroot, M. H., \& Marschak, J. (1964). Measuring utility by a single-response sequential method. Behavioral Science, 9(3), 226-232.

Bohm, P., Lindén, J., \& Sonnegård, J. (1997). Eliciting reservation prices: Becker-deGroot-Marschak mechanisms vs. markets. The Economic Journal, 107(443), 1079-1089.

Cason, T. N., \& Plott, C. R. (2012). Misconceptions and game form recognition of the BDM method: Challenges to theories of revealed preference and framing (Working Paper). Retrieved 7.03.2013, from http://ssrn.com/abstract= 2151661

Fudenberg, D., Levine, D. K., \& Maniadis, Z. (2012). On the robustness of anchoring effects in WTP and WTA experiments. American Economic Journal: Microeconomics, 4(2), 131-45.

Heidhues, P., \& Köszegi, B. (2010). Regular prices and sales (ESMT Working Paper). Retrieved 7.03.2013, from http://ssrn.com/abstract $=1713080$

Horowitz, J. K. (2006). The Becker-DeGroot-Marschak mechanism is not necessarily incentive compatible, even for non-random goods. Economics Letters, 93(1), 6-11.

Kaas, K. P., \& Ruprecht, H. (2006). Are the Vickrey auction and the BDM mechanism really incentive compatible? Empirical results and optimal bidding strategies in cases of uncertain willingness-to-pay. Schmalenbach Business Review, 58(1), 37-55.

Köszegi, B., \& Rabin, M. (2006). A model of reference-dependent preferences. Quarterly Journal of Economics, 121(4), 1133-1165.

List, J. A., \& Gallet, C. A. (2001). What experimental protocol influence disparities between actual and hypothetical stated values? Environmental and Resource Economics, 20(3), 241-254.

Lusk, J. L., Alexander, C., \& Rousu, M. C. (2007). Designing experimental auctions for marketing research: the effect of values, distributions, and mechanisms on incentives for truthful bidding. Review of Marketing Science, 5(3).

Mazar, N., Köszegi, B., \& Rabin, M. (2010). Price-sensitive preferences (Working Paper). Retrieved 7.03.2013, from http://ssrn.com/abstract=1665017

Noussair, C., Robin, S., \& Ruffieux, B. (2004). Revealing consumers' willingness-topay: a comparison of the BDM mechanism and the Vickrey auction. Journal of Economic Psychology, 25(6), 725-741.

Rutström, E. E. (1998). Home-grown values and incentive compatible auction de- 
sign. International Journal of Game Theory, 27(3), 427-441.

Shogren, J. F., Cho, S., Koo, C., List, J., Park, C., Polo, P., \& Wilhelmi, R. (2001). Auction mechanisms and the measurement of WTP and WTA. Resource and Energy Economics, 23(2), 97-109.

Tversky, A., \& Kahneman, D. (1974). Judgment under uncertainty: heuristics and biases. Science, 185(4157), 1124-1131.

Urbancic, M. (2011). Testing distributional dependence in the Becker-DeGrootMarschak mechanism (Working Paper). Retrieved 7.03.2013, from http:// urbancic.net/mike/Urbancic\%20-\%20Job\%20Market\%20Paper.pdf

Wathieu, L., \& Bertini, M. (2007). Price as a stimulus to think: the case for willful overpricing. Marketing Science, 26(1), 118-129.

Wertenbroch, K., \& Skiera, B. (2002). Measuring consumers' willingness to pay at the point of purchase. Journal of Marketing Research, 39(2), 228-241. 


\section{A Instructions}

Welcome! You are participating in an experiment on economic decision making and will be asked to make a number of choices. The study will last about 90 minutes, which consist of filling out questionnaires and participating in the experiment. Your choices are very important in this task and will determine your final payment. Read the instructions carefully. Your final earnings will be determined by the decisions you make in the experiment.

This is the procedure of the whole experiment:

1. You will read the instructions for the experiment

2. Comprehension questions. If you answer comprehension questions correctly, you will be allowed to participate in the study and you will receive $\$ 50$ from the experiment that is yours to keep. If you do not answer the questions correctly, you will receive $\$ 5$ show up fee and will not be allowed to participate in the study. You will be allowed to use these written instructions while answering comprehension questions.

3. You can practice the task

4. The task (60 min)

5. The computer will show your earnings to you.

6. A short questionnaire (10 $\mathrm{min})$

Please proceed to reading the instructions on the next pages. Whenever you have a question, please ask the experimenter for clarification. 


\section{Task:}

\section{Instructions}

In this experiment, you will have an opportunity to buy one of three products from our store using the $\$ 50$ that you received from the experimenter. The products that are available in this experiment are real: an iPod shuffle, a backpack and a pair of noisecancelling headphones. You can have a look at these goods before the experiment. Your task in this experiment is to decide and tell us the maximum amount that you would be willing to pay for one of these goods right now, at this moment. We will call this amount your current bid. You may be asked this question multiple times for each good, depending on chance as explained below.

\section{Round structure:}

The experiment thus may consist of many rounds, all of which would have a similar structure. In each round:

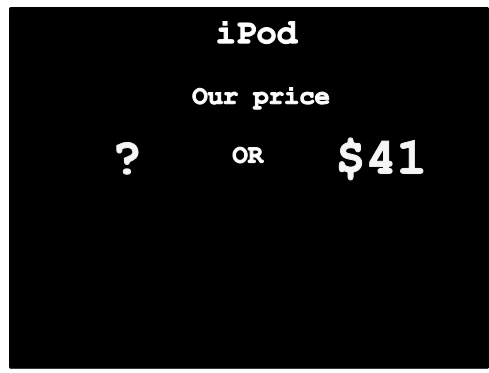

1. First, you would see which good is on offer in this round, and you would be shown two prices in our store.

One of the prices will be revealed and the other will be hidden. The prices in our store range from $\$ 1$ to $\$ 50$. Both prices are randomly selected each time and are always below the suggested retail price of the good.

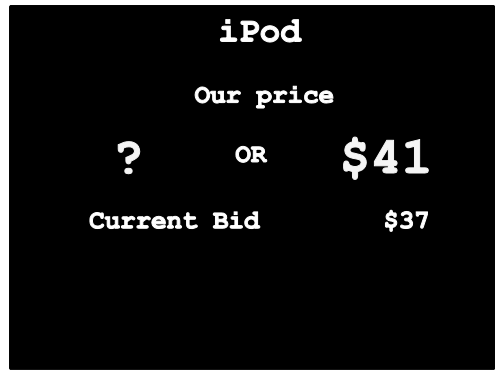

2. After you are shown the store's prices, there will be a short delay. Then you will submit your bid (the maximum amount that you are willing to pay) for the good during this round. You will need to enter a number between 0 and 50 .

IMPORTANT: Your bid does not influence hidden the price! 
3. After you enter your bid, the computer will randomly choose and let you know which price, the revealed price or the hidden price, will be our store's price in this round. We call it current store price.

IMPORTANT: Your bid does not influence whether the revealed or hidden price is chosen by the computer. There is equal chance that it will be the revealed price or the hidden price.

Then, the computer compares your bid to the current store price and you can see whether your bid is higher or lower than the store price:
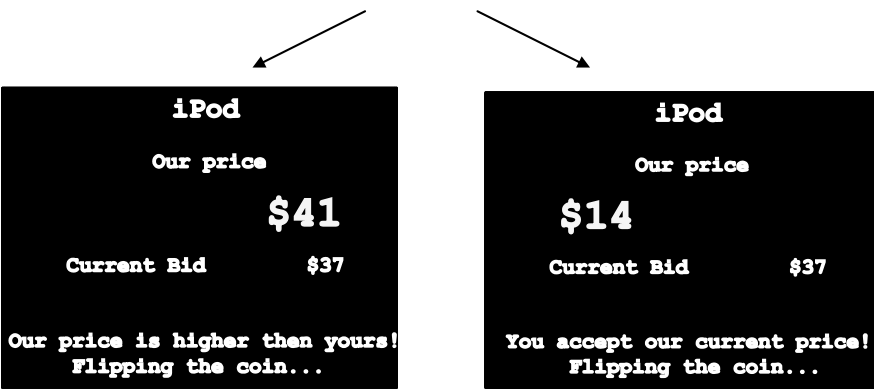

4. The computer now randomly determines whether this round is implemented for payoff or the experiment continues. If it continues, then you will see the following screen and move on to the next round without any disruption:

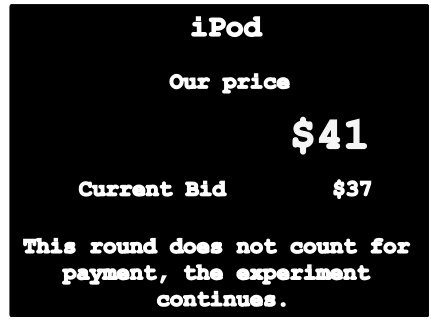

If this trial is implemented for payoff, whether you buy the good or not and at what price is now determined. 


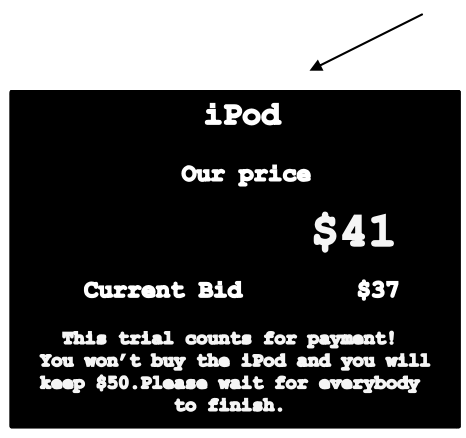

If your bid in the payment round is lower than the chosen current store price, then our price is too high for you. You do not buy and keep $\$ 50$.
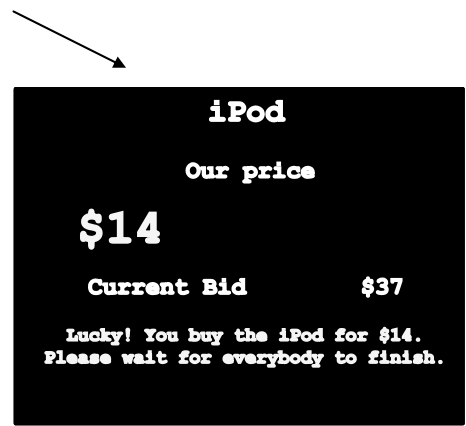

If your bid in the payment round is higher or equal to the chosen current store price, then you accept our price. You buy the good that was offered on this trial at the price equal to the current store price and keep the change.

If you continue to play for more than 21 rounds, you will be allowed to take a break every 21 rounds. After the break, you can press a button to continue whenever you're ready.

\section{When does a trial get played for real and experiment ends?}

Any round can be played for real. Therefore, it is really important that you pay attention on each round and treat it as the one that will determine your earnings. On average over $90 \%$ of the study participants will stop at some randomly determined round. On average each trial has over a $1.8 \%$ chance of being played for real. For the remaining $10 \%$ of the participants the experiment will end after the $8^{\text {th }}$ block. They will keep $\$ 50$ and will not buy anything.

\section{Your earnings:}

At the beginning of the experiment, you received $\$ 50$ dollars. You can use this money to bid on the goods. If you don't end up buying, you keep your initial $\$ 50$. If you buy a good, then you receive the good and get to keep the difference between $\$ 50$ and the price you paid, just like in an everyday transaction. 
A few examples:

Example 1: The revealed price for the backpack is $\mathbf{\$ 1 5}$. Manuel decides that his current bid is $\$ 10$. The computer randomly selects the hidden price, equal to $\$ 40$, to be the current store price. The computer randomly generates a number to determine whether the current trial is the one played for real. The current trial is not the one played for real.

The experiment continues and Manuel's earnings are not determined yet.

Example 2: The revealed price for the iPod shuffle is \$20. Manuel decides that his current bid is $\$ 25$. The computer randomly selects the revealed price (\$20) to be the current store price. The computer randomly generates a number to determine whether the current trial is the one played for real. The current trial is the one played for real. Manuel buys the iPod Shuffle for $\mathbf{\$ 2 0}$ because the current price (\$20) is smaller than his maximum willingness to pay (\$25) and keeps the remaining \$30.

Example 3: The revealed price for the headphones is \$35. Manuel decides that his current bid is $\mathbf{\$ 3 8}$. The computer randomly selects the hidden price, equal to $\mathbf{\$ 8}$, to be the current store price. The computer randomly generates a number to determine whether the current trial is the one played for real. The current trial is the one played for real.

Manuel buys the headphones for $\mathbf{\$ 8}$ because his bid is greater than the current price.

Example 4: The revealed price for the iPod shuffle is $\$ 40$. Manuel decides that his current bid is $\$ 45$. The computer randomly selects the revealed price (\$40) to be the current store price. The computer randomly generates a number to determine whether the current trial is the one played for real. The current trial is not the one played for real. Throughout the whole experiment, the computer did not pick a trial to count for payment. Manuel does not buy anything and keeps the money.

Example 5: The revealed price for the headphones is \$10. Manuel decides that his current bid is $\$ 15$. The computer randomly selects the hidden price, equal to $\$ 25$, to be the current store price. The computer randomly generates a number to determine whether the current trial is the one played for real. The current trial is the one played for real.

Manuel does not buy the headphones because his bid is smaller than the current price.

PLEASE PROCEED TO ANSWERING THE COMPREHENSION QUESTIONS

LET THE EXPERIMENTER KNOW WHEN YOU'VE COMPLETED ANSWERING THE QUESTIONS 
Comprehension questions (first part): (Choose all that apply)

1. Suppose that, after seeing the revealed price for an iPod, you decide that your current bid is $\mathbf{\$ 4 8}$ and the current store price turns out to be $\mathbf{\$ 3}$. The computer randomly decides that this is the last round. What happens? Choose all that apply.
a) The experiment continues
b) The experiment ends
c) I buy the iPod for $\$ 48$
d) I buy the iPod for $\$ 3$
e) I don't buy the iPod
f) My earnings in cash are $\$ 50$
g) My earnings in cash are $\$ 47$
h) My earnings are not determined yet

2. Suppose that, after seeing the revealed price for a backpack, you decided that your current bid is $\mathbf{\$ 8}$ and the current store price turns out to be $\mathbf{\$ 3 5}$. The computer randomly decides that this is the last round. What happens? Choose all that apply.
a) I do not buy the backpack
b) I buy the backpack for $\$ 8$
c) I buy the backpack for $\$ 35$
d) The experiment continues
e) The experiment ends
f) My earnings are not determined yet
g) My earnings in cash are $\$ 15$
h) My earnings in cash are $\$ 50$

3. Suppose that after seeing the revealed price for the iPod, you decided that your current bid is \$27 and the current store price turns out to be \$24. The computer randomly decides that this is not the last round. What happens? Choose all that apply.
a) I buy the iPod for $\$ 24$
b) I buy the iPod for $\$ 27$
c) The experiment continues
d) The experiment ends
e) My earnings in cash are $\$ 26$
f) My earnings in cash are $\$ 50$
g) My earnings are not determined yet 
Comprehension questions (second part): (Choose all that apply)

4. Suppose that, after seeing the revealed price for the iPod, you decide that your current bid is $\mathbf{\$ 4 8}$ and the current store price turns out to be $\$ \mathbf{4 9}$. The computer randomly decides that this is the last round. What happens? Choose all that apply.
a) The experiment continues
b) The experiment ends
c) I buy the iPod for $\$ 49$
d) I buy the iPod for $\$ 48$
e) I don't buy the iPod
f) My earnings in cash are $\$ 50$
g) My earnings in cash are $\$ 1$
h) My earnings are not determined yet

5. Suppose that, after seeing the revealed price for the headphones, you decided that your current bid is $\mathbf{\$ 2 8}$ and the current store price turns out to be $\mathbf{\$ 3}$. The computer randomly decides that this is the last round. What happens? Choose all that apply.
a) I do not buy the headphones
b) I buy the headphones for $\$ 28$
c) I buy the headphones for $\$ 3$
d) The experiment continues
e) The experiment ends
f) My earnings are not determined yet
g) My earnings in cash are $\$ 47$
h) My earnings in cash are $\$ 50$

6. Suppose that after seeing the revealed price for the iPod, you decided that your current bid is $\$ 17$ and the current store price turns out to be $\$ 14$. The computer randomly decides that this is not the last round. What happens? Choose all that apply.
a) I buy the iPod for $\$ 14$
b) I buy the iPod for $\$ 17$
c) The experiment continues
d) The experiment ends
e) My earnings in cash are $\$ 36$
f) My earnings in cash are $\$ 50$
g) My earnings are not determined yet 


\section{B Versions effects}

Table 3.5: Versions effects

\begin{tabular}{lr}
\hline & Coef./se \\
\hline revealed price & $0.04^{* * *}$ \\
& $(0.01)$ \\
treatment2*revealedprice & 0.14 \\
& $(0.15)$ \\
treatment3*revealedprice & -0.00 \\
& $(0.04)$ \\
treatment4*revealedprice & 0.01 \\
& $(0.05)$ \\
treatment5*revealedprice & -0.01 \\
& $(0.03)$ \\
constant & $-1.08 * * *$ \\
& $(0.39)$ \\
\hline Adj. $R^{2}$ & 0.911 \\
No. of obs & 3808 \\
\hline
\end{tabular}

The experiment was run in minimally different versions (see section 3.2). The effect of the revealed price did not differ across the treatments.

Standard errors are clustered by subject. ${ }^{*} p<0.10,{ }^{* *} p<0.05,{ }^{* * *} p<0.01$ 



\title{
Chapter 4
}

\section{Measuring Time and Risk Preferences: Reliability, Stability, Domain Specificity}

\begin{abstract}
Individual time and risk preferences are fundamental determinants of behaviour in economic models. These models typically assume that preferences are stable both over the lifespan and across various decision contexts. We test these assumptions by applying different measures of time and risk preferences repeatedly to the same subjects. We find that the parameters of time and risk preferences are highly correlated within one test date, as well as across test dates. This indicates that the employed measures are sufficiently reliable and that individual behaviour in these tasks is stable over several weeks. Correlations of time and risk preference parameters with self-reported impulsiveness and risk attitudes are at best moderate, and highest for self-report items on financial decision making. This suggests that experimentally elicited time and risk preferences might not reflect general attitudes towards time and risk, but rather attitudes specific to the domain of financial decisions.
\end{abstract}

Based on: Woelbert, E. \& Riedl, A. Measuring time and risk preferences: reliability, stability, domain specificity (in preparation). 


\subsection{Introduction}

Decisions often involve consequences that are delayed or uncertain. Consequently, individual time and risk preferences are fundamental elements of economic models. Their importance to the understanding of human decision making is also evident in the psychological and neuroscientific literature (e.g. Fox \& Tannenbaum, 2011; Kable \& Glimcher, 2007; Kirby, Petry, \& Bickel, 1999; Trepel, Fox, \& Poldrack, 2005). In economic research and applications preferences are typically understood as stable characteristics of the individual that determine behaviour across various decision contexts. Despite their importance to the validity of economic research and the effectiveness of policy implementations, these assumptions have not been sufficiently addressed in the literature (Borghans, Duckworth, Heckman, \& ter Wel, 2008). In this paper we provide a comprehensive assessment of the psychometric quality for commonly used time and risk preference elicitation tasks. We draw attention to different techniques that can be used to assess and enhance the quality of measurement instruments, but are relatively unknown in the economic literature.

In economic experiments and surveys, time and risk preferences are usually quantified based on behaviour in a decision making task. Here, subjects are asked to make several decisions involving uncertain and/or delayed (monetary) rewards. It is typically simply assumed that these tasks are reliable measures, i.e. that their results are reproducible and measurement error is small. However, the reliability of these tasks is unknown. If reliability is low, then elicited preferences in one task cannot be expected to be temporally stable or correlate well with behaviour in other settings, simply due to high measurement error. Reliability can and should be directly tested, for example using indicators of reliability described in the psychological literature (e.g. Gregory, 2007). This would allow to improve existing preference elicitation techniques and make an informed decision between the various existing methods.

Further, using elicited time and risk preferences to explain field behaviour and derive potential policy implications, one assumes that a person's decisions in such tasks reflect underlying dispositions that are stable both over time and across different situations. That is, a person's prefer- 
ences at one point in time are thought to be predictive of her preferences at another point in time, and preferences in one life domain are thought to be predictive of preferences in a different domain. However, behaviour in choice tasks, even if suitably incentivised, need not necessarily reflect longlasting, all-encompassing attitudes of the individual towards every type of risk or delay. Instead, it might be highly dependent on the subject's state or the decision context (Fox \& Tannenbaum, 2011). Whether and how time and risk preferences affect choice behaviour is an important, ultimately empirical question that economists have only recently begun to address.

Investigating the temporal stability of time preferences, Kirby (2009) and Meier and Sprenger (2010b) both found that discount rates elicited in a monetary intertemporal choice task were relatively stable over a period of one year. Although many different elicitation methods for time preferences have been explored (see Frederick, Loewenstein, \& O'Donoghue, 2002, for review), there is little evidence on the stability of individual time preferences across different choice contexts. The few studies that have investigated how elicited discount rates relate to field behaviour find mixed results: Present bias in an intertemporal choice task was found to be associated with credit card debt and preference for a commitment savings product (Ashraf, Karlan, \& Yin, 2006; Meier \& Sprenger, 2010a), but Chabris, Laibson, Morris, Schuldt, and Taubinsky (2008) as well as Borghans and Golsteyn (2006) found that experimentally elicited discount rates correlate only very weakly with health-oriented behaviour such as exercising and smoking. Interestingly, Reuben, Sapienza, and Zingales (2010a) observed that discount rates over monetary rewards predicted procrastination on an unpleasant task. Evidence on the stability of risk attitudes is equally scarce. Andersen, Harrison, Lau, and Rutström (2008b) found that individual risk aversion measured with a typical multiple price list (Holt \& Laury, 2002) was only moderately stable over time and also Zeisberger, Vrecko, and Langer (2012) observe considerable instability of risk aversion and probability weighting over a period of 1 month. First field studies addressing the stability of risk aversion across different contexts suggest that many individuals do not exhibit comparable degrees of risk aversion in different life domains, such as health, disability or car insurance (Barseghyan \& Prince, 2011; Einav, Finkelstein, \& Pascu, 2012). 
In sum, in order to be able to draw valid conclusions from elicited time and risk preferences, the measurement techniques that are used need more careful evaluation. First of all, it is important to know whether the method employed is reliable, i.e. to what extent the individual results are reproducible under similar conditions. In addition, the nature of preferences themselves needs more empirical clarification. A first important question is whether individual time and risk preferences should be understood as long-lasting and all-encompassing, or rather as variable over time and/or decision contexts.

In this paper we address each of these questions for an intertemporal choice task and a lottery choice task, respectively. Variants of these tasks are frequently used in economic experiments and surveys (e.g. Andersen et al., 2008b; Bruhin, Fehr-Duda, \& Epper, 2010; Chabris et al., 2008; Dohmen, Falk, Huffman, \& Sunde, 2010; Ifcher \& Zarghamee, 2011). In each task, subjects decide repeatedly between different amounts of money that are associated with varying delays in intertemporal choice, or with varying winning probabilities in lottery choice. Subjects' choices are then used to derive parameters describing the individual's discount rate, risk aversion and degree of nonlinear probability weighting. We assess reliability of preference elicitation techniques by correlating the individual results from two choice subsets. Establishing good reliability provides the foundation for estimating the stability of preferences over time and addressing questions of validity. Then, in order to estimate test-retest stability, we repeated the experiment on the same subjects after several weeks and correlate parameters derived at the two different test dates. And lastly, to contribute towards establishing validity of these measurement techniques, we report correlations of risk and time preference parameters with conceptually related self-report scales that include questions on future orientation, savings, and risk attitudes.

We find that the parameters of time and risk preferences are highly correlated across subsets, as well as across test dates. This indicates that the employed measures are sufficiently reliable and that individual behaviour in these tasks is stable over several weeks. The fact that we, in contrast to Andersen et al. (2008b), find high stability of risk preference parameters demonstrates the benefit of aggregating data from several choices to minimize measurement error. Correlations of time and risk preference parame- 
ters with self-report scales are at best moderate, and highest for self-report items on financial decision making. This suggests that these measures of time and risk preference might not reflect general attitudes towards time and risk, but rather attitudes specific to the domain of financial decisions.

\subsection{Methods}

Subjects completed a series of choices between smaller, sooner and larger, later amounts of money, as well as choices between guaranteed and probabilistic payments, all of which were fully incentivised. After the decision tasks, subjects completed a set of questionnaires on impulsiveness and risk attitudes. In order to assess the stability of the measured time and risk preferences, subjects were asked to return to the lab for the same experiment 5-10 weeks after the first data acquisition. All tasks and questionnaires are described below, followed by details on the experimental procedure in Section 4.2.

\section{Measuring time preference}

A set of intertemporal decisions over monetary rewards was used to assess time preference. Subjects faced 27 choices between a smaller, sooner amount and a larger, later amount. For example, subjects were asked to decide "Would you prefer to receive $€ 25$ today or $€ 30$ in 80 days?". The set of intertemporal choices that we used contained three subsets of 9 choices each. Smaller, sooner amounts ranged from $€ 11$ to $€ 54$, and the larger, later amounts ranged from $€ 25$ to $€ 60$. Delays ranged from 7 days to 200 days. Note that these choices were presented individually and in no logical order, following a sequence suggested by Kirby et al. (1999). Set 1 contained items from the intertemporal choice questions introduced by Kirby et al. (1999). These questions ask the subject to choose between an amount available immediately after the session and a larger amount available after a delay of $d$ days.

In order to assess whether time inconsistent behaviour arises, and under which circumstances, we created two more sets of 9 items each. Specifically, we modified the items of set 1 by adding a fixed delay of one day (set 2) or 
14 days (set 3 ) to both the sooner and the later amount. As a result, the smaller, sooner amounts in set 2 were available after one day, the larger, later amounts after $d+1$ days. In set 3 all smaller, sooner amounts were available after 14 days, all larger, later amounts after $d+14$ days. The values and delays used for all 27 intertemporal choice questions, as well as the order of presentation are given in Table 4.1.

Each of the three subsets allowed an estimate for the individual discount rate. For ease of interpretation, we determined an exponential discount parameter $\rho$ for each subject and each choice set according to the following specification:

$$
V=A e^{-\rho D},
$$

where $V$ denotes the current subjective value of the delayed amount, $A$ denotes the monetary amount, $D$ the delay in days. ${ }^{1}$

In Table 4.1 intertemporal choice questions are presented not in the sequence presented to the subjects, but ordered into the three sets. Within each set the questions are sorted according to the discount rate that would make an individual indifferent between the two options. There, it is easy to see that the choices within each set range from requiring extreme patience when preferring the later option (e.g. wait 186 days to receive $€ 1$ more), to extreme impatience when preferring the sooner option (e.g. not wait 7 days to receive $€ 19$ more). Most people's time preferences lie somewhere in between these two extremes. That is, they prefer the smaller, sooner option up to a given point - their switch point - and prefer the larger, later option in all remaining questions. The discount rate of the subject can then be assumed to lie in the interval between the two indifference parameters of the questions where the switch occurs. The geometric mean of this interval was then assigned as an estimate of discount rate for this subject (Kirby et al., 1999). In case a subject displayed more than one switch point within a set, the discount rate was assigned such that it minimizes the number of choices

\footnotetext{
${ }^{1}$ In principle, several specifications for individual discount rates are feasible. Note that our results do not depend on the specification of the discount rate, since $\rho$ values are not estimated by fitting an exponential function to the data, but are simply assigned depending on the switching behaviour of the subject. Since subjects did not show evidence of present bias, we consider an exponential specification appropriate here.
} 
Table 4.1: Intertemporal choice questions

\begin{tabular}{|c|c|c|c|c|c|c|}
\hline Set & $\begin{array}{c}\text { Order } \\
\text { of } \\
\text { presentation }\end{array}$ & $\begin{array}{c}\text { Smaller, } \\
\text { sooner } \\
\text { amount }\end{array}$ & $\begin{array}{l}\text { Larger, } \\
\text { later } \\
\text { amount }\end{array}$ & $\begin{array}{c}\text { Days } \\
\text { to smaller } \\
\text { amount }\end{array}$ & $\begin{array}{l}\text { Days } \\
\text { to later } \\
\text { amount }\end{array}$ & $\begin{array}{c}\text { Indifference } \\
\rho\end{array}$ \\
\hline \multirow{9}{*}{1} & 13 & $€ 34$ & $€ 35$ & 0 & 186 & 0.00016 \\
\hline & 20 & $€ 28$ & $€ 30$ & 0 & 179 & 0.00039 \\
\hline & 26 & $€ 22$ & $€ 25$ & 0 & 136 & 0.00094 \\
\hline & 22 & $€ 25$ & $€ 30$ & 0 & 80 & 0.00228 \\
\hline & 3 & $€ 19$ & $€ 25$ & 0 & 53 & 0.00518 \\
\hline & 18 & $€ 24$ & $€ 35$ & 0 & 29 & 0.01301 \\
\hline & 5 & $€ 14$ & $€ 25$ & 0 & 19 & 0.03052 \\
\hline & 7 & $€ 15$ & $€ 35$ & 0 & 13 & 0.06518 \\
\hline & 11 & $€ 11$ & $€ 30$ & 0 & 7 & 0.14333 \\
\hline \multirow{9}{*}{2} & 1 & $€ 34$ & $€ 35$ & 1 & 187 & 0.00016 \\
\hline & 6 & $€ 28$ & $€ 30$ & 1 & 180 & 0.00039 \\
\hline & 24 & $€ 22$ & $€ 25$ & 1 & 137 & 0.00094 \\
\hline & 16 & $€ 25$ & $€ 30$ & 1 & 81 & 0.00228 \\
\hline & 10 & $€ 19$ & $€ 25$ & 1 & 54 & 0.00518 \\
\hline & 21 & $€ 24$ & $€ 35$ & 1 & 30 & 0.01301 \\
\hline & 14 & $€ 14$ & $€ 25$ & 1 & 20 & 0.03052 \\
\hline & 8 & $€ 15$ & $€ 35$ & 1 & 14 & 0.06518 \\
\hline & 27 & $€ 11$ & €30 & 1 & 8 & 0.14333 \\
\hline \multirow{9}{*}{3} & 9 & $€ 34$ & $€ 35$ & 14 & 200 & 0.00016 \\
\hline & 17 & $€ 28$ & $€ 30$ & 14 & 193 & 0.00039 \\
\hline & 12 & $€ 22$ & $€ 25$ & 14 & 150 & 0.00094 \\
\hline & 15 & $€ 25$ & $€ 30$ & 14 & 94 & 0.00228 \\
\hline & 2 & $€ 19$ & $€ 25$ & 14 & 67 & 0.00518 \\
\hline & 25 & $€ 24$ & $€ 35$ & 14 & 43 & 0.01301 \\
\hline & 23 & $€ 14$ & $€ 25$ & 14 & 33 & 0.03052 \\
\hline & 19 & $€ 15$ & $€ 35$ & 14 & 27 & 0.06518 \\
\hline & 4 & $€ 11$ & $€ 30$ & 14 & 21 & 0.14333 \\
\hline
\end{tabular}

Note. For presentation in this table, questions are grouped into the three sets. Within each set, they are ordered according to the exponential discount rate that would make a decision maker indifferent between the two options. Column 2 indicates the position in the order of presentation to the subjects. 
that would be a mistake according to this value. ${ }^{2}$ This procedure was followed independently for each of the three intertemporal choice sets, yielding three estimates for the discount rate per subject, which we denote as $\rho_{1}, \rho_{2}$ and $\rho_{3}$.

\section{Measuring risk preference}

In order to measure the curvature of subjects' utility function, as well as their degree of nonlinear probability weighting, we elicited certainty equivalents for lotteries. We used 20 lotteries and followed the procedure described in Epper, Bruhin, and Fehr-Duda (2009) and Bruhin et al. (2010). Each lottery was presented to the subjects on a decision screen that showed the specific lottery as well as a list of 20 sure amounts. Probabilities were visualized as a pie chart in order to facilitate understanding for the subjects. The sure amounts ranged from the higher to the lower outcome of the specific lottery and were equally spaced. For each of these sure amounts, subjects had to indicate whether they preferred to receive the lottery or this sure amount (see Appendix 4.A for a screenshot of a decision screen for one lottery). In each decision screen subjects were allowed to switch only once between preferring the sure amount and preferring the lottery, i.e. monotonicity was enforced in this task. For each lottery the certainty equivalent was then determined as the arithmetic mean of the smallest sure amount the subjects preferred over the lottery, and the next smaller amount on the list. All lotteries consisted of two non-negative outcomes in the range of $€ 0$ to $€ 90$, probabilities attached to these outcomes ranged from 0.05 to 0.95 . The full set of lotteries as well as the order of presentation are shown in Table $4.2 .^{3}$

Certainty equivalents were used to jointly estimate a utility function and a probability weighting function for each subject. We chose the following

\footnotetext{
${ }^{2}$ Within one intertemporal choice set most subjects answer consistently, i.e. they display a single switch point (85.79\% of all subjects were consistent in all three sets and $93.91 \%$ of all sets were answered consistently). Only two subjects displayed multiple switch points in all three choice sets and were therefore excluded from the analysis of the intertemporal choice task.

${ }^{3}$ Since we were mainly interested in individual variability in this task, we presented the lotteries in the same order to all participants. Potential effects of the order of presentation should affect all subjects equally.
} 
specification for the curvature of the utility function:

$$
v(x)=x^{\alpha}, x \geq 0, \alpha>0
$$

where $x$ denotes the monetary value of the outcome. Given this specification, $0<\alpha<1$ indicates risk aversion, $\alpha=1$ indicates risk neutrality and $\alpha>1$ indicates risk seeking. In line with Epper et al. (2009), we chose the following parameterization for nonlinear probability weighting, which was originally suggested by Prelec (1998):

$$
\omega(p)=\exp \left(-(-\ln p)^{\gamma}\right), 0<\gamma<1
$$

where $p$ denotes the objective probability, and smaller values of $\gamma$ refer to larger deviations from linearity, in the form of an inverted S-shape. That is, small probabilities are overweighted and larger probabilites are underweighted. These functional forms for the utility function and the probability weighting function have been shown to be parsimonious and at the same time fit decision data well (Bruhin et al., 2010; Gonzalez \& Wu, 1999; Stott, 2006). For each subject, $\alpha$ and $\gamma$ were estimated simultaneously by minimizing the squared distance between the estimated subjective utility of the lottery and the measured certainty equivalent (Wakker, 2008). To correct for heteroscedasticity, the outcomes of each lottery were normalized to uniform length.

\section{Self-report scales}

In order to investigate how behaviour in a monetary choice task in the laboratory relates to conceptually close psychological measures, subjects completed questionnaires on impulsiveness and general attitudes towards risks.

Impulsiveness is a psychological construct that is closely related to intertemporal choice. The inability to delay gratification is considered the core problem of impulsive behaviours, for example when the immediate pleasure of eating sweet food is preferred over the delayed health benefits associated with refraining from it (Ainslie, 1975; Logue, 1988). Likewise, in economics it is assumed that an intertemporal choice between an immediately available and a delayed reward requires self-control and that impatience is exacerbated by impulsivity (Frederick et al., 2002; Laibson, 1997; McClure, 
Table 4.2: Lotteries in the lottery choice task

\begin{tabular}{ccccccccc}
\hline Order & $p_{x 1}$ & $x 1$ & $x 2$ & & Order & $p_{x 1}$ & $x 1$ & $x 2$ \\
\cline { 6 - 8 } 9 & 0.1 & $€ 12$ & $€ 6$ & & 7 & 0.25 & $€ 30$ & $€ 12$ \\
13 & 0.5 & $€ 12$ & $€ 6$ & & 19 & 0.5 & $€ 30$ & $€ 12$ \\
6 & 0.9 & $€ 12$ & $€ 6$ & & 17 & 0.75 & $€ 30$ & $€ 12$ \\
11 & 0.05 & $€ 24$ & $€ 6$ & & 2 & 0.95 & $€ 30$ & $€ 12$ \\
18 & 0.25 & $€ 24$ & $€ 6$ & & 20 & 0.05 & $€ 90$ & $€ 30$ \\
3 & 0.5 & $€ 24$ & $€ 6$ & & 1 & 0.5 & $€ 6$ & $€ 0$ \\
12 & 0.75 & $€ 24$ & $€ 6$ & & 8 & 0.5 & $€ 12$ & $€ 0$ \\
14 & 0.95 & $€ 24$ & $€ 6$ & & 5 & 0.05 & $€ 24$ & $€ 0$ \\
4 & 0.05 & $€ 30$ & $€ 12$ & & 10 & 0.95 & $€ 30$ & $€ 0$ \\
16 & 0.1 & $€ 90$ & $€ 0$ & & 15 & 0.25 & $€ 24$ & $€ 0$ \\
\hline
\end{tabular}

Note. Outcomes $x 1$ and $x 2$ are stated in Euro, $p_{x 1}$ denotes the probability for outcome $x 1$. Order denotes the position in the order of presentation to the subject.

Laibson, Loewenstein, \& Cohen, 2004). The evidence on the association of impulsiveness with intertemporal choice tests is mixed, however (de Wit, Flory, Acheson, McCloskey, \& Manuck, 2007; Kirby et al., 1999; Reimers, Maylor, Stewart, \& Chater, 2009; Reynolds, Ortengren, Richards, \& de Wit, 2006). For the purpose of this study, the Barratt Impulsiveness Scale (BIS11) by Patton, Stanford, and Barratt (1995) was employed. The BIS-11 is a well-validated and standardized self-report questionnaire for measuring impulsiveness (see Table 4.9 in Appendix 4.B). There is ample evidence that high scores on the BIS-11 are associated with behaviours that reflect a lack of self-control and future-orientation, such as smoking, alcohol and illegal substance abuse, attention deficits, as well as a higher sensitivity to reward and punishment (for review see Stanford et al., 2009). Next to a sum score that reflects general impulsiveness, the BIS-11 allows computing a subscore for nonplanning impulsiveness. This subscore has been shown to capture interindividual differences in self-control and future-orientation that are often assumed to contribute to individual differences in intertemporal choice behaviour.

To assess self-reported willingness to take risks in different contexts, subjects answered the general risk questions from the German Socioeco- 
nomic Panel (SOEP). Here, subjects indicate on an 11-point scale how willing they are to take risks in general, and in six specific domains such as financial investments or driving a car (see Table 4.10 in Appendix 4.B).

\section{General procedure}

The data acquisition took place at the Behavioural and Experimental Economics lab (BEElab) of the School of Business and Economics at Maastricht University in June to October 2010. Subjects were recruited via Email from the BEElab subject pool which consists of students of all fields of Maastricht University, the majority being students of Business and Economics. In total, 144 students participated in the experiment, $50.7 \%$ of these were female, $75 \%$ were enrolled in the School of Business and Economics. The time interval between the first time a subject was tested, and the retest ranged from 5 to 10 weeks. In total 53 participants returned for the retest. ${ }^{4}$

All decisions and questionnaires were presented on a computer screen using the software package zTree (Fischbacher, 2007). At the beginning of the experiment, subjects were informed that there would be several decision making tasks and that they will receive detailed instructions before each task. Subjects received a show-up fee of $€ 3$ in cash. One of all decisions made during the experiment was selected at random and the subject's choice in this decision situation was then implemented and paid out. This procedure allowed us to provide salient incentives for several tasks while minimizing the problem that decisions might be influenced through house money effects or risk hedging. ${ }^{5}$ Subjects received detailed information on the payment procedure at the beginning of the experiment and were again reminded of the determination of earnings before each of the different decision making tasks.

In case a lottery was selected for payout, risk was resolved by a random

\footnotetext{
${ }^{4}$ In the results section, the retested group is compared to those subjects that did not return for the retest in order to assess whether the retest data is affected by self-selection of subjects. There are no significant differences in the tested variables between retested and the nonretested subjects.

5Importantly, Hey and Lee (2005) have shown that subjects' behaviour is in line with the assumption that each decision is considered as an independent decision under this incentive scheme.
} 
draw of the computer. All payoffs except delayed payoffs were paid out in private immediately after the experiment in cash. Delayed payments were delivered by bank transfer in order to minimize transaction costs for the delayed payments. ${ }^{6}$ Subjects were allowed to make their decisions at their own speed. On average, the experiment lasted 1.5 hours. Total earnings ranged from $€ 3$ to $€ 129.50$, with an average of $€ 27.55$.

\subsection{Results}

We obtained data on time and risk preferences, as well as self report scales on two separate test dates for the same group of subjects. In the following, we first describe the data on time preferences, and second the data on risk preferences. The central questions addressed in this section are: First, how reliably does each task measure individual preferences? Second, how stable are individual preferences over two separate test dates? And third, how well do elicited preferences correlate with conceptually related self-report scales? In the beginning of each section, descriptive statistics are presented in order to compare our sample to the existing literature and check for general effects of repeated testing and selective drop-out. All correlations reported are Spearman rank correlations, all $p$-values refer to two-sided tests.

\section{Time preferences}

At both of the two test dates subjects answered three sets of intertemporal choice questions, each of which allowed us to estimate a daily discount rate for the subject $\left(\rho_{1}, \rho_{2}, \rho_{3}\right)$. Table 4.3 shows descriptive statistics of the daily discount rates for both test dates. In annual terms, the median discount rate of our sample corresponds to a rate of $288 \%$. This is comparable to the discount rates reported by others who are using the same procedure (Chabris et al., 2008; Kirby, 2009), or procedures that involve comparable reward sizes and delays (Thaler, 1981), see Frederick et al. (2002) for review.

\footnotetext{
${ }^{6}$ Money in a Dutch bank account is accessible at virtually no transaction costs, since payment by debit card is widely accepted and a large number of conveniently situated ATMs is available $24 \mathrm{~h}$ and free of charge. We therefore are confident that the difference in transaction costs between immediate and delayed payments is negligible.
} 
Table 4.3: Descriptive statistics of time preferences

\begin{tabular}{lccccr}
\hline & $\mathrm{N}$ & & Median & $\mathrm{Mean}^{1}$ & $95 \%$ CI of Mean \\
\hline Date 1 & & $\rho_{1}$ & 0.00821 & 0.00685 & {$[0.00538,0.00872]$} \\
whole & 142 & $\rho_{2}$ & 0.00821 & 0.00622 & {$[0.00499,0.00776]$} \\
sample & & $\rho_{3}$ & 0.00737 & 0.00694 & {$[0.00558,0.00862]$} \\
\hline Date 1 & & $\rho_{1}$ & 0.00821 & 0.00646 & {$[0.00430,0.00970]$} \\
retest & \multirow{2}{*}{53} & $\rho_{2}$ & 0.00821 & 0.00540 & {$[0.00377,0.00773]$} \\
subsample & & $\rho_{3}$ & 0.00737 & 0.00602 & {$[0.00415,0.00875]$} \\
\hline & & $\rho_{1}$ & 0.00821 & 0.00589 & {$[0.00382,0.00907]$} \\
Date 2 & 53 & $\rho_{2}$ & 0.00821 & 0.00620 & {$[0.00422,0.00911]$} \\
& & $\rho_{3}$ & 0.00821 & 0.00618 & {$[0.00401,0.00953]$} \\
\hline
\end{tabular}

\footnotetext{
${ }^{1}$ Note. Discount rates are positively skewed. Therefore, mean discount rates are estimated as the means of the log-transformed values (Kirby, 2009). The reported means hence correspond to the geometric means of the discount rates. For the same reason, confidence intervals are reported instead of standard errors. Here, lower and upper bounds were determined on the log-transformed values and then transformed back into the original space.
}

In total, 53 subjects returned for the retest. To test whether our results from the retested sample might be biased by selective dropout, we compared the average discount rates of those that returned for the retest and those that did not. Discount rates at the first test date were not significantly different between these groups, indicating that with respect to the variable of interest there is no effect of self-selection on the data obtained at test date 2 ( $p \geq .354$ ). Kolmogorov-Smirnov and Mann-Whitney test statistics of all pairwise comparisons are given in Table 4.11 in Appendix 4.C.

In order to estimate the reliability of the measured discount rates, we correlated the individual estimates obtained from the three different sets within one test date. All correlations are high (Spearman's Rho $\geq .80$, see Table 4.4), which means that subjects who discount steeply when there is an immediate reward available do so very consistently also when there is no immediate reward available. This indicates that measurement error in this intertemporal choice task is small, but also casts doubt on the assumption 
that discounting with and without immediately available reward employs separable, independent processes (Laibson, 1997; McClure et al., 2004).

In the aggregate, discount rates are stable across the two test dates. That is, for the subsample of all subjects that were tested twice, the discount rates do not differ between the two test dates (Wilcoxon Signed-Rank Tests, all $p \geq .152$ ). In order to assess stability on the individual level, we correlated the measured discount rates across the two test dates. Figure 4.1 plots the individual discount rates measured at date 2 against those measured on date 1 . We find that discount rates measured at date 1 are highly correlated with those measured at date 2 (Spearman's Rho $\geq .61$, see Table 4.4 for complete statistics), indicating that subjects who discount steeply at one test date do so also at the second test date. ${ }^{7}$

In sum, we find that discount rates derived from three different intertemporal choice sets are highly correlated and we observe good test-retest correlations over an interval of 5-10 weeks for discount rates elicited in a monetary intertemporal choice task. This corroborates recent findings of Kirby (2009) and Meier and Sprenger (2010a) and shows that the monetary intertemporal choice task used in this study has satisfactory reliability and that time preferences over monetary rewards are remarkably stable over time.

\footnotetext{
${ }^{7}$ Considering that we used the same set of choice items for both test dates, the test-retest correlations reported here could be inflated by subjects remembering their previous choices and wishing to be consistent. To test for this, we computed correlations between the different sets across test dates in addition. These are highly significant and range from Spearman's $\mathrm{Rho}=.58$ to Spearman's Rho $=.71$, indicating that this effect is unlikely to play a role.
} 


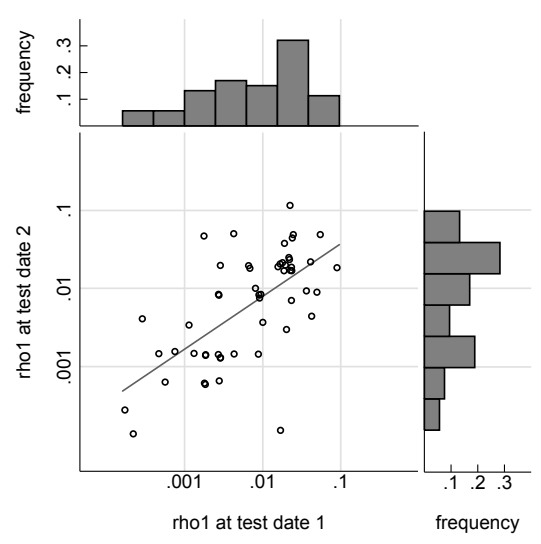

(a) Set 1

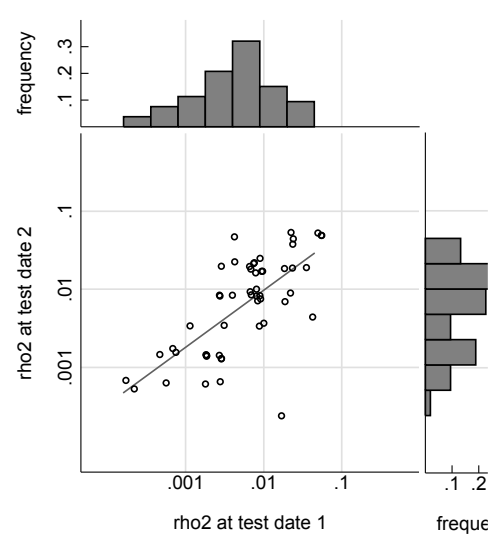

(b) Set 2

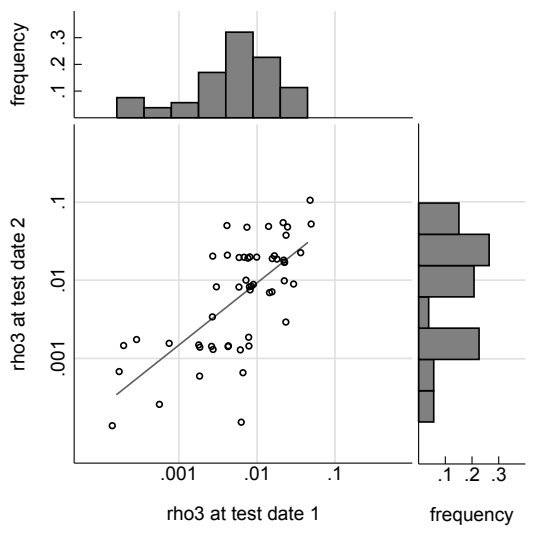

(c) Set 3

Figure 4.1: Test-retest data for discount rates. For each intertemporal choice set, the discount rate at the second test date is plotted as a function of the discount rate at the first test date, together with univariate histograms of each estimated discount rate. 


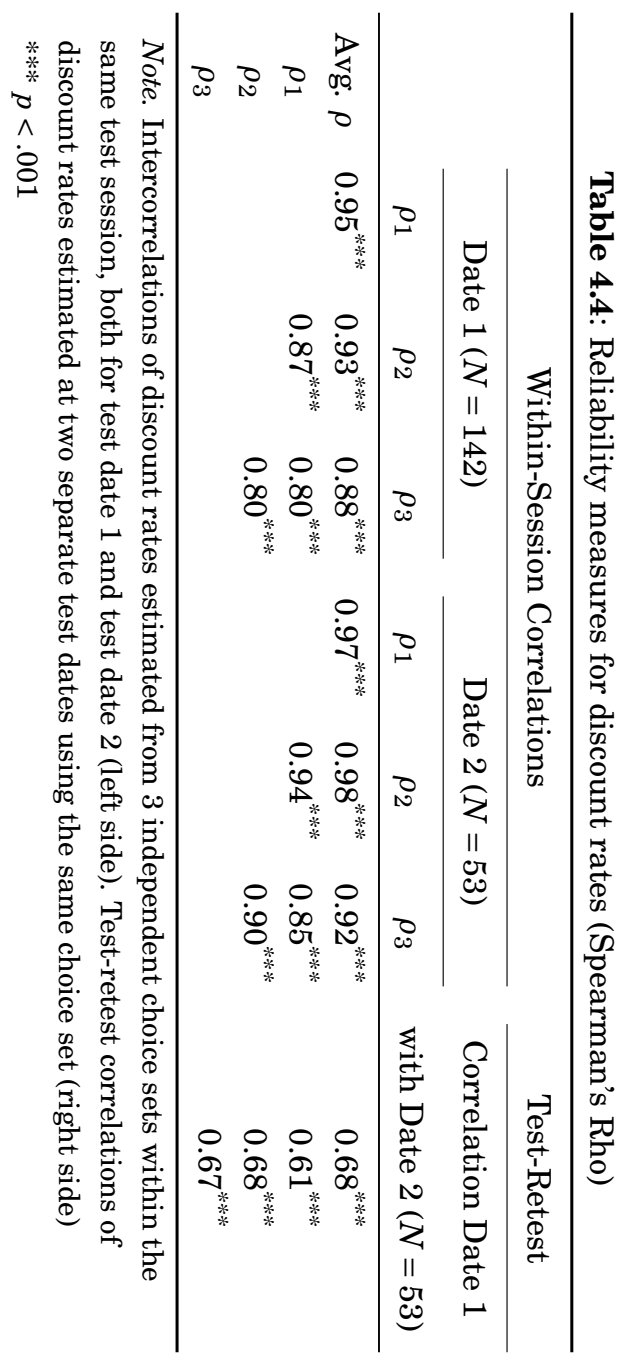


While there is accumulating evidence that intertemporal choice tasks measure with high precision, it is still an open question what it actually is that they measure. In other words, what do we learn about someone who acts impatiently in an intertemporal choice task, in comparison to someone who acts patiently? In both the economic and the psychological literature it is often assumed that an intertemporal choice involving an immediately available reward invokes a self-control problem (Berns, Laibson, \& Loewenstein, 2007; Frederick et al., 2002; Fudenberg \& Levine, 2006; Laibson, 1997; McClure et al., 2004), which results in less patient choice behaviour. In fact, monetary intertemporal choice tasks, like the one used in the present study, are often employed to measure impulsiveness (e.g. Crockett, Clark, Lieberman, Tabibnia, \& Robbins, 2010; Figner et al., 2010; Kirby \& Finch, 2010). Evidence on the association of intertemporal choice tasks with selfreported impulsiveness is mixed, however (de Wit et al., 2007; Kirby \& Finch, 2010; Reynolds et al., 2006; Verdejo-Garcia, Lozano, Moya, Alcazar, \& Perez-Garcia, 2010).

In order to assess how strongly behaviour in the intertemporal choice task is related to impulsiveness in our sample, we correlated the estimated discount rates with the total score of the BIS-11 (Patton et al., 1995), as well its subscale 'Nonplanning Impulsiveness', which is conceptually most closely related to intertemporal choice. In addition, we selected individual items that ask for self-control, saving, spending, and future orientation, core factors that are believed to contribute to intertemporal choice behaviour (Frederick et al., 2002). In our present sample, there is a small, but significant positive correlation between the estimates for the discount rate and items relating to saving and spending behaviour (see Table 4.5). That is, people who report to rarely save and to spend more than they earn are less patient in the intertemporal choice task. However, responses to an item directly addressing the individual's future-orientation ("I am more interested in the present than in the future") are uncorrelated with the elicited discount rates. Discount rates are also not correlated with responses to the item "I am self-controlled", the subscale "Nonplanning Impulsivenes" or the total sum score of the BIS-11. To check the robustness of these results, we analysed data of an independent sample that was measured in 2011. In this data set we find a similar pattern. The discount rate again correlated most 
strongly with self-report items on saving and spending, but the correlations were generally higher (see Appendix 4.C).

Table 4.5: Correlations of discount rates with self-report items (Spearman's Rho)

\begin{tabular}{|c|c|c|c|c|c|c|}
\hline & \multicolumn{6}{|c|}{ Barratt Impulsiveness Scale $(N=142)$} \\
\hline & $\begin{array}{l}\text { Total } \\
\text { Score }\end{array}$ & $\begin{array}{c}\text { Subscale } \\
\text { Nonplanning }\end{array}$ & $\begin{array}{c}\text { Item } 8 \\
\text { Self-Control }\end{array}$ & $\begin{array}{c}\text { Item } 10 \\
\text { Saving }\end{array}$ & $\begin{array}{c}\text { Item } 25 \\
\text { Spending }\end{array}$ & $\begin{array}{l}\text { Item } 27 \\
\text { Present }\end{array}$ \\
\hline Average $\rho$ & -0.03 & 0.00 & -0.01 & $0.19^{*}$ & $0.18^{*}$ & 0.01 \\
\hline$\rho_{1}$ & -0.03 & -0.02 & 0.01 & $0.18^{*}$ & 0.13 & 0.00 \\
\hline$\rho_{2}$ & -0.05 & -0.02 & 0.05 & $0.18^{*}$ & $0.19^{*}$ & -0.03 \\
\hline$\rho_{3}$ & 0.03 & 0.07 & 0.02 & $0.17^{*}$ & $0.20^{*}$ & 0.03 \\
\hline
\end{tabular}

Note. Correlations at test date 1.

$* p<.05$

We further assess whether discount rates obtained from our choice set 1 , which involves an immediately available option, are higher than those obtained from the other sets - as would be expected if immediately available money invoked a self-control problem and delayed money did not. In set 2 the earliest option was available after 1 day, in set 3 it was available after 14 days. We find that the three estimates for $\rho$ do not differ significantly, neither at test date 1 (Friedman Test, $\chi^{2}=1.369, p=.490, N=142$ ), nor at test date 2 (Friedman Test, $\chi^{2}=1.714, p=.432, N=53$ ). That is, our subjects are not systematically less patient when the smaller, sooner reward is available immediately, the next day, or in 14 days, providing no evidence for time inconsistent choice behaviour.

In sum, we find that experimentally elicited discount rates do not correlate with self-reported impulsiveness, which is in line with Reynolds et al. (2006) and Verdejo-Garcia et al. (2010). Similarly, laboratory-measured discount rates over money were found to correlate only very weakly with impulsive field behaviours such as lack of exercising or smoking (Chabris et al., 2008; Reimers et al., 2009). Further, we do not observe time inconsistent behaviour in the intertemporal choice task. Our results thus add to accumulating evidence suggesting that intertemporal decisions over monetary rewards are not, or only very weakly related to general impulsiveness and lack of self-control. As Borghans et al. (2008) suggests, this could be due to 
the fact that a typical intertemporal choice task in an economic experiment does not mimic self-control problems outside the lab very well. ${ }^{8}$

Alternatively, what is referred to as 'time preference' and 'self-control' might differ across situations within one individual. For example, people might be very concerned about their future health, but not so much about their future financial situation (see Frederick et al., 2002). This idea is supported by our observation that discount rates over money correlate most strongly with self-report items on spending and saving behaviour, and not at all with aggregate measures of self-reported impulsiveness. Hence, discounting monetary payoffs in a lab experiment seems to relate specifically to those everyday decisions that involve money. This interpretation is also in line with the observation that discount rates for different reward types, like money and chocolate, are only moderately correlated (Reuben, Sapienza, \& Zingales, 2010b; Tsukayama, 2010). Together, these findings suggest that behaviour in an intertemporal choice task is stable over time and captures individual discount rates reliably. How patiently someone acts, however, seems to vary across situations within an individual.

\section{Risk preferences}

Descriptive statistics for the parameters of the curvature of the utility function and the probability weighting function are shown in Table 4.6. Given our specification of the utility function, $0<\alpha<1$ indicates risk aversion, $\alpha=1$ indicates risk neutrality and $\alpha>1$ indicates risk seeking behaviour. With a median of $\alpha=0.746$ we observe a moderate level of risk aversion. Given our specification for the probability weighting function, a smaller $\gamma$ indicates a stronger deviation from linear probability weighting. We observe a median $\gamma=0.413$, which corresponds to pronounced deviations from linear

\footnotetext{
${ }^{8}$ If the choice between an immediate and a delayed reward invokes a self-control problem, we would expect a correlation between the discount rate derived from set 1 (where the smaller reward is available immediately) and self-reported impulsiveness. One could argue that only the difference between the discount rates from set 1 and set 3 (where the smaller reward is available only after 14 days) should be associated with impulsiveness. Note however, that on average our subjects are time-consistent. That is, the average discount rates derived from set 1 are not different from the ones derived from set 3 . For those individuals who do display a higher discount rate in set 1 than in set 3 we do not observe higher self-reported impulsiveness (Mann-Whitney Test, $p=.245$ ).
} 
probability weighting, and is in line with the results of Epper et al. (2009) and Bruhin et al. (2010). There are no significant differences $(p \geq .071)$ in risk aversion and probability weighting between the subjects that were retested $(N=53)$ and those that did not return for the retest $(N=91) .{ }^{9}$ This indicates that with respect to $\alpha$ and $\gamma$ there is no self-selection effect in the retested subsample. The test statistics of Kolmogorov-Smirnov Tests and Mann-Whitney Tests for all pairwise comparisons are listed in Table 4.11 in Appendix 4.C.

Table 4.6: Descriptive statistics of risk preferences

\begin{tabular}{lccccc}
\hline & $N$ & & Median & Mean & $95 \%$ CI of Mean \\
\hline Date 1 & \multirow{2}{*}{144} & $\alpha$ & 0.746 & 0.784 & {$[0.726,0.843]$} \\
whole sample & & $\gamma$ & 0.413 & 0.442 & {$[0.398,0.485]$} \\
\hline Date 1 & \multirow{2}{*}{53} & $\alpha$ & 0.693 & 0.715 & {$[0.649,0.781]$} \\
retest subsample & & $\gamma$ & 0.391 & 0.410 & {$[0.340,0.480]$} \\
\hline \multirow{2}{*}{ Date 2 } & \multirow{2}{*}{53} & $\alpha$ & 0.717 & 0.659 & {$[0.570,0.748]$} \\
& & $\gamma$ & 0.339 & 0.374 & {$[0.306,0.441]$} \\
\hline
\end{tabular}

Reliability of these measures of risk attitudes was assessed using a splithalf procedure. Therefore, the set of lotteries was split into two independent sets using an odd-even split of the lottery numbers. The estimation procedure was then repeated for all odd and all evenly numbered lotteries separately and the resulting parameters were correlated. If the estimated parameters were distorted by erratic choice behaviour, then two independently measured parameter sets should not be highly correlated. However, the resulting split-half correlations are very high (Spearman's Rho $\geq .78$ ), indicating that estimated parameters are highly reproducible. Hence, our data suggest that this lottery choice task is reliable (see Table 4.7).

\footnotetext{
${ }^{9}$ Kolmogorov-Smirnov Tests and Mann-Whitney Tests. All other $p \geq .178$.
} 


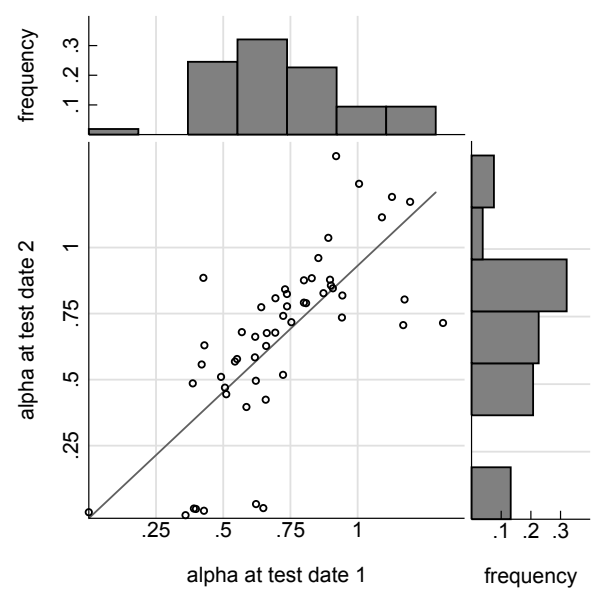

(a) Curvature of the utility function

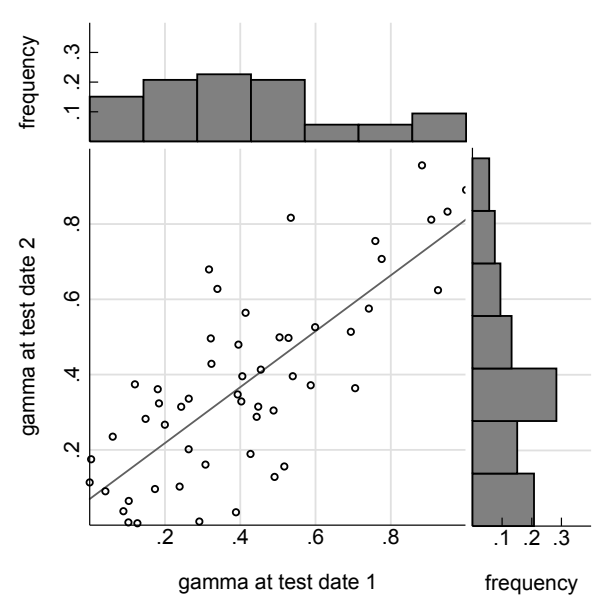

(b) Probability weighting

Figure 4.2: Test-retest data for risk preferences. For each parameter, the estimate derived at the second test date is plotted as a function of the estimate from the first test date, together with univariate histograms of each estimated parameter. 
Table 4.7: Reliability measures for risk preferences (Spearman's Rho)

\begin{tabular}{|c|c|c|c|}
\hline & \multicolumn{2}{|c|}{ Within-Session Correlations } & Test-Retest \\
\hline & \multicolumn{2}{|c|}{ Split-Half Reliability } & \multirow{2}{*}{$\begin{array}{c}\text { Correlation Date } 1 \\
\text { with Date } 2(N=53)\end{array}$} \\
\hline & Test Date $1(N=144)$ & Test Date $2(N=53)$ & \\
\hline$\alpha$ & $0.82^{* * *}$ & $0.82^{* * * *}$ & $0.77^{* * * *}$ \\
\hline$\gamma$ & $0.78^{* * * *}$ & $0.83^{* * * *}$ & $0.73^{* * *}$ \\
\hline
\end{tabular}

Note. Intercorrelations of parameters estimated from 2 independent subsets of lotteries within the same test session, both for test date 1 and test date 2 (left side). Test-retest correlations of parameters estimated at two separate test dates using the same choice set (right side).

$* * * p<.001$

To assess whether risk preferences are stable over time on the aggregate level, we compared the estimates for risk attitudes across the two test dates. There are no significant differences in risk aversion and probability weighting between the two test dates (Wilcoxon Signed-Rank Tests, $p \geq .174$ ), indicating that risk attitudes are indeed stable on the aggregate level. In order to evaluate individual test-retest stability, parameter estimates obtained at test date 1 were correlated with those obtained at test date 2. Figure 4.3 illustrates the test-retest data for $\alpha$ and $\gamma$ using scatterplots with univariate histograms. As is evident from the scatterplots, test-retest correlations are high (Spearman's Rho $\geq .61$, see Table 4.7 for complete statistics). Thus, subjects who display high risk aversion and high probability weighting at one test date do so also at the other test date. ${ }^{10}$ The test-retest correlations are comparable to those reported for the Balloon Analogue Risk Task (White, Lejuez, \& de Wit, 2008), a behavioural measure of risk attitudes commonly employed in the psychological literature. The test-retest correlations for the individual certainty equivalents of all lotteries range from Spearman's Rho $=.36$ to Spearman's Rho $=.68$. The fact that test-retest correlations are lower for individual lotteries than for the estimated param-

\footnotetext{
${ }^{10}$ Again, the test-retest correlations reported here could be inflated by subjects remembering their previous choices and wishing to be consistent. Therefore we assessed correlations between the parameters derived from the odd and even sets across test dates. These ranged from Spearman's Rho $=.54$ to Spearman's Rho $=.75$. Hence, this effect is unlikely to play a role.
} 
eters illustrates that aggregating choice data from several decisions is valuable as it increases the reproducibility of the results. This observation could also explain why we observe higher stability than Andersen et al. (2008b), who used a single multiple price list. ${ }^{11}$

In sum, we find high correlations for risk aversion and probability weighting parameters obtained from independent sets of lotteries. Further, testretest correlations over an interval of 5-10 weeks are high. This shows that the lottery choice task used in this study measures with satisfactory reliability and that behaviour in this task is remarkably stable over time even on the individual level.

Investigating how different measures of risk attitudes relate to each other can help to understand the nature of risk attitudes and assess the generalizability of obtained results. To this end, we correlated parameters from the lottery choice task with the answers to the SOEP's general risk questions (see Table 4.8). Correlations with self-reported attitudes towards risk in general, the sum of all risk questions, as well as towards financial risks are statistically significant (Spearman's Rho $\geq .27$ ), and moderate in effect size (Cohen, 1992). People who report to take more risks show also less risk aversion and less deviations from linear probability weighting in the lottery choice task. However, risk attitudes elicited with the lottery choice task correlate most with domain-specific self-reports regarding financial decision making and are entirely uncorrelated to self-reported attitudes towards risk in other domains such as leisure activities and health. We replicated this finding in an entirely independent sample (see Table 4.12). Our data corroborates experimental data by Dohmen et al. (2011) and Pennings and Smidts (2000), and recent field data by Barseghyan and Prince (2011) and Einav et al. (2012). Taken together, this strongly suggests that individual risk attitudes are domain specific.

\footnotetext{
${ }^{11}$ This example illustrates that it is important to establish reliability of a measurement technique before assessing stability over time. If reliability at one test date is unknown, low stability over time can be either due to high measurement error, or to true fluctuations over time.
} 


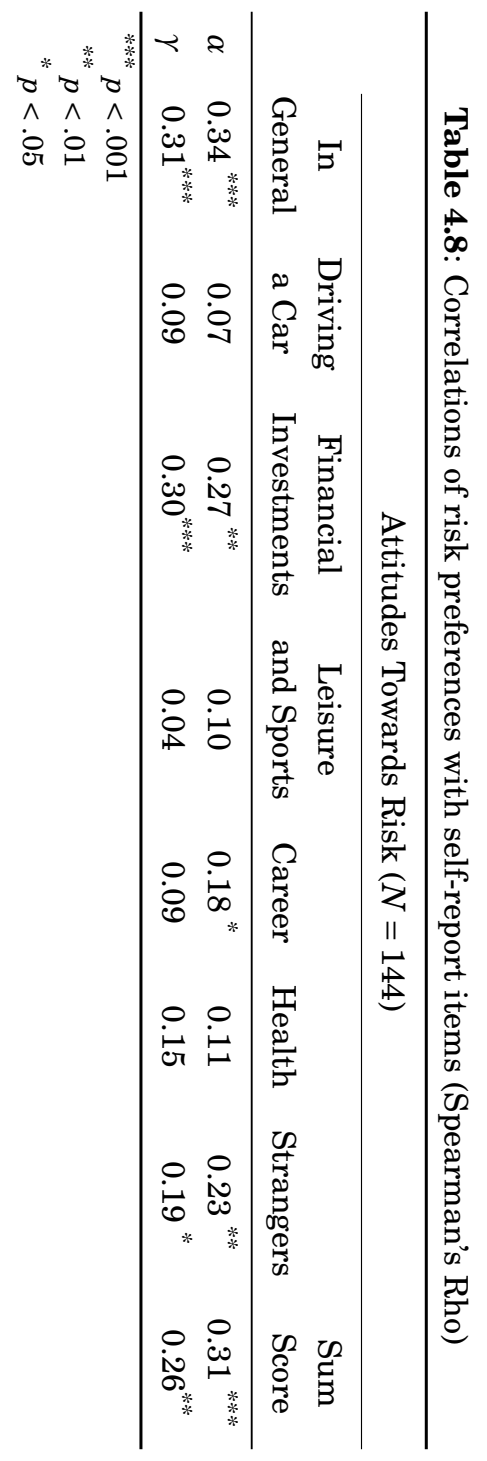




\section{Discussion}

In this study, we measure time and risk preferences independently. However, time preferences may be intertwined with risk preferences (Andersen, Harrison, Lau, \& Rutström, 2008a; Andreoni \& Sprenger, 2010; Frederick et al., 2002), which makes it difficult to determine time preference independently of risk preference. This assumption implies that discount rates should correlate with risk aversion. We observe a small and only marginally significant correlation between the discount rate and the risk aversion parameter (see Table 4.14 in Appendix 4.C). Subjects that are less risk averse tend to be more patient. The portion of explained variance is small, however. This suggests that risk inherent to future payoffs governs intertemporal decision making only to a small extent. Alternatively, as is suggested by our results, people react differently to various forms of risk, and this may also apply to the risk inherent in an intertemporal choice as opposed to a lottery choice task.

Further, we cannot control for credit constraints of our subjects. Hence, the observed correlation of excess spending and low savings with discounting could arise from current cash constraints of these subjects. However, Meier and Sprenger (2010a) found that present-biased preferences in an intertemporal choice task were associated with increased credit card debt even after controlling for credit constraints. This indicates that cash constraints are not the only factor driving the association between intertemporal choice behaviour in the laboratory and spending.

We provide correlations of behaviourally elicited preference parameters with conceptually related self-report scales. When evaluating the association between self-report instruments and behavioural measures of the same construct it is important to consider that these correlations are likely to be at best moderate due to differences in the methodology (Campbell \& Fiske, 1959; Robins, Fraley, \& Krueger, 2007). For example, answers to self-report scales might only imperfectly reflect subjects' true dispositions because selfreports can be distorted by motives like self-enhancement. Further, selfreport scales like the BIS-11 focus on traits, which prompts subjects to reflect on their habits across different situations. Behavioural measures, on the other hand, are more likely to be influenced by situational factors, such 
as task-specificities or the current financial situation of the subject (Andersen et al., 2008b). Eventually, it would be desirable to establish preference elicitation techniques that possess high predictive validity for field behaviour (Campbell \& Fiske, 1959).

\subsection{Summary and conclusion}

We provide data on the reliability and stability for behavioural measures that are frequently used to elicit time and risk preferences in economic experiments. Parameters estimated from independent subsets of the choice tasks are highly correlated, indicating that the behavioural measures are reliable and provide reproducible estimates. Individual discount rates, risk aversion and nonlinear probability weighting parameters show high testretest correlations over a period of $5-10$ weeks. We contribute to a growing body of research demonstrating satisfactory reliability and differential stability of economic preference measures. To the best of our knowledge we are the first to present data on reliability of risk preferences elicited with a lottery choice task.

Approaching time and risk preferences with different methods, such as behavioural and self-report measures, can help to increase our understanding of the nature of preferences. Therefore, we investigate the association of the estimated preference parameters with subjects' self-reported impulsiveness and attitudes towards risk. Correlations with self-report scales suggest that time and risk preferences are domain specific. In particular, behaviour in a monetary intertemporal choice task is not associated with general selfreported impulsiveness or future orientation. Instead, discount rates relate specifically to self-reports on excess spending and low savings. Likewise, we find that behaviour in a lottery choice task correlates most with self-reported attitudes towards risks in financial investments.

In sum, we find that individual time and risk preferences are stable over time, but not across different situations. This suggests that the impact of preferences on behaviour can be more accurately understood when accounting for the specific situation rather than assuming that preferences are stable and all-encompassing. Important goals for future research would be to systematically explore the dimensionality of time and risk preference and to arrive at a consensus on how each aspect is best described and measured. 


\section{References}

Ainslie, G. (1975). Specious reward: a behavioral theory of impulsiveness and impulse control. Psychological Bulletin, 82(4), 463-496.

Andersen, S., Harrison, G. W., Lau, M. I., \& Rutström, E. E. (2008a). Eliciting risk and time preferences. Econometrica, 76(3), 583-618.

Andersen, S., Harrison, G. W., Lau, M. I., \& Rutström, E. E. (2008b). Lost in state space: are preferences stable? International Economic Review, 49(3), 1091-1112.

Andreoni, J., \& Sprenger, C. (2010). Estimating time preferences from convex budgets (NBER Working Paper 16347). Retrieved 6.03.2013, from http:// www.nber.org/papers/w16347

Ashraf, N., Karlan, D., \& Yin, W. (2006). Tying Odysseus to the mast: evidence from a commitment savings product in the Philippines. The Quarterly Journal of Economics, 121(2), 635-672.

Barseghyan, L., \& Prince, J. (2011). Are risk preferences stable across contexts? Evidence from insurance data. American Economic Review, 101(2), 591-631.

Berns, G. S., Laibson, D., \& Loewenstein, G. (2007). Intertemporal choice - toward an integrative framework. Trends in Cognitive Sciences, 11(11), 482-488.

Borghans, L., Duckworth, A. L. A., Heckman, J. J., \& ter Wel, B. (2008). The economics and psychology of personality traits. Journal of Human Resources, 43(4), 972-1059.

Borghans, L., \& Golsteyn, B. H. (2006). Time discounting and the body mass index: evidence from the Netherlands. Economics and Human Biology, 4(1), 39-61.

Bruhin, A., Fehr-Duda, H., \& Epper, T. (2010). Risk and rationality: uncovering heterogeneity in probability distortion. Econometrica, 78(4), 1375-1412.

Campbell, D. T., \& Fiske, D. W. (1959). Convergent and discriminant validation by the multitrait-multimethod matrix. Psychological Bulletin, 56(2), 81-105.

Chabris, C. F., Laibson, D., Morris, C. L., Schuldt, J. P., \& Taubinsky, D. (2008). Individual laboratory-measured discount rates predict field behavior. Journal of Risk and Uncertainty, 37(2-3), 237-269.

Cohen, J. (1992). A power primer. Psychological Bulletin, 112(1), 155-159.

Crockett, M., Clark, L., Lieberman, M., Tabibnia, G., \& Robbins, T. (2010). Impulsive choice and altruistic punishment are correlated and increase in tandem with serotonin depletion. Emotion, 10(6), 855-862.

de Wit, H., Flory, J. D., Acheson, A., McCloskey, M., \& Manuck, S. B. (2007). IQ and nonplanning impulsivity are independently associated with delay discounting in middle-aged adults. Personality and Individual Differences, 42(1), 111121.

Dohmen, T., Falk, A., Huffman, D., \& Sunde, U. (2010). Are risk aversion and 
impatience related to cognitive ability? American Economic Review, 100(3), 1238-1260.

Dohmen, T., Falk, A., Huffman, D., Sunde, U., Schupp, J., \& Wagner, G. G. (2011). Individual risk attitudes: measurement, determinants and behavioral consequences. Journal of the European Economic Association, 9(3), 522-550.

Dohmen, T., Wagner, G. G., Falk, A., \& Huffman, D. (2005). Individual risk attitudes: new evidence from a large, representative, experimentallyvalidated survey (DIW Discussion Paper). Retrieved from http://www.diw.de/ documents/publikationen/73/diw_01.c.43553.de/dp511.pdf

Einav, L., Finkelstein, A., \& Pascu, I. (2012). How general are risk preferences? Choices under uncertainty in different domains. American Economic Review, 102(6), 2606-2638.

Epper, T., Bruhin, A., \& Fehr-Duda, H. (2009). Uncertainty breeds decreasing impatience: the role of risk preferences in time discounting (IEW Discussion Paper). Retrieved 6.03.2013, from http://www.iew.uzh.ch/wp/iewwp412.pdf

Figner, B., Knoch, D., Johnson, E. J., Krosch, A. R., Lisanby, S. H., Fehr, E., \& Weber, E. U. (2010). Lateral prefrontal cortex and self-control in intertemporal choice. Nature Neuroscience, 13(5), 538-539.

Fischbacher, U. (2007). z-Tree: Zurich toolbox of ready-made economic experiments. Experimental Economics, 10(2), 171-178.

Fox, C. R., \& Tannenbaum, D. (2011). The elusive search for stable risk preferences. Frontiers in Psychology, 2(298).

Frederick, S., Loewenstein, G., \& O’Donoghue, T. (2002). Time discounting and time preference: a critical review. Journal of Economic Literature, 40(2), 351-401.

Fudenberg, D., \& Levine, D. K. (2006). A dual-self model of impulse control. American Economic Review, 96(5), 1449-1476.

Gonzalez, R., \& Wu, G. (1999). On the shape of the probability weighting function. Cognitive Psychology, 38, 129-166.

Gregory, R. J. (2007). Psychological testing: History, principles, and applications (5th ed.). Boston: Pearson.

Hey, J. D., \& Lee, J. (2005). Do subjects separate (or are they sophisticated)? Experimental Economics, 8(3), 233-265.

Holt, C. A., \& Laury, S. K. (2002). Risk aversion and incentive effects. American Economic Review, 92(5), 1644-1655.

Ifcher, J., \& Zarghamee, H. (2011). Happiness and time preference: the effect of positive affect in a random-assignment experiment. American Economic Review, 101(7), 3109-3129.

Kable, J. W., \& Glimcher, P. W. (2007). The neural correlates of subjective value during intertemporal choice. Nature Neuroscience, 10(12), 1625-1633. 
Kirby, K. N. (2009). One year temporal stability of discount rates. Psychonomic Bulletin \& Review, 16(3), 457-462.

Kirby, K. N., \& Finch, J. C. (2010). The hierarchical structure of self-reported impulsivity. Personality and Individual Differences, 48(6), 704-713.

Kirby, K. N., Petry, N. M., \& Bickel, W. K. (1999). Heroin addicts have higher discount rates for delayed rewards than non-drug-using controls. Journal of Experimental Psychology: General, 128(1), 78-87.

Laibson, D. (1997). Golden eggs and hyperbolic discounting. Quarterly Journal of Economics, 112(2), 443-477.

Logue, A. W. (1988). Research on self-control: an integrating framework. Behavioral and Brain Sciences, 11(4), 665-709.

McClure, S. M., Laibson, D. I., Loewenstein, G., \& Cohen, J. D. (2004). Separate neural systems value immediate and delayed monetary rewards. Science, 306(5695), 503-507.

Meier, S., \& Sprenger, C. (2010a). Present-biased preferences and credit card borrowing. American Economic Journal: Applied Economics, 2(1), 193-210.

Meier, S., \& Sprenger, C. (2010b). Stability of time preferences (IZA Discussion Paper 4756). Retrieved 6.03.2013, from http://papers.ssrn.com/sol3/papers .cfm?abstract_id $=1556544$

Patton, J. H., Stanford, M. S., \& Barratt, E. S. (1995). Factor structure of the Barratt Impulsiveness Scale. The Quarterly Journal of Experimental Psychology Section A: Human Experimental Psychology, 51(6), 768-774.

Pennings, J., \& Smidts, A. (2000). Assessing the construct validity of risk attitude. Management Science, 46(10), 1337-1348.

Prelec, D. (1998). The probability weighting function. Econometrica, 66(3), 497527.

Reimers, S., Maylor, E. A., Stewart, N., \& Chater, N. (2009). Associations between a one-shot delay discounting measure and age, income, education and realworld impulsive behavior. Personality and Individual Differences, 47(8), 973 - 978.

Reuben, E., Sapienza, P., \& Zingales, L. (2010a). Procrastination and impatience (Working Paper). Retrieved 6.03.2013, from http://ereuben.net/research/ ProcrastinationImpatience.pdf

Reuben, E., Sapienza, P., \& Zingales, L. (2010b). Time discounting for primary and monetary rewards. Economics Letters, 106(2), 125-127.

Reynolds, B., Ortengren, A., Richards, J., \& de Wit, H. (2006). Dimensions of impulsive behavior: personality and behavioral measures. Personality and Individual Differences, 40(2), 305-315.

Robins, R. W., Fraley, R. C., \& Krueger, R. F. (Eds.). (2007). Handbook of research 
methods in personality psychology. New York: Guilford.

Stanford, M. S., Mathias, C. W., Dougherty, D. M., Lake, S. L., Anderson, N. E., \& Patton, J. H. (2009). Fifty years of the Barratt Impulsiveness Scale: an update and review. Personality and Individual Differences, 47(5), 385-395.

Stott, H. P. (2006). Cumulative prospect theory's functional menagerie. Journal of Risk and Uncertainty, 32(2), 101-130.

Thaler, R. (1981). Some empirical evidence on dynamic inconsistency. Economics Letters, 8(3), 201-207.

Trepel, C., Fox, C. R., \& Poldrack, R. A. (2005). Prospect theory on the brain? Toward a cognitive neuroscience of decision under risk. Cognitive Brain Research, 23(1), 34-50.

Tsukayama, E. (2010). Domain-specific temporal discounting and temptation. Judgment and Decision Making, 5(2), 72-82.

Verdejo-Garcia, A., Lozano, O., Moya, M., Alcazar, M. A., \& Perez-Garcia, M. (2010). Psychometric properties of a Spanish version of the UPPS-P impulsive behavior scale: reliability, validity and association with trait and cognitive impulsivity. Journal of Personality Assessment, 92(1), 70-77.

Wakker, P. P. (2008). Explaining the characteristics of the power (CRRA) utility family. Health Economics, 17(12), 1329-1344.

White, T. L., Lejuez, C. W., \& de Wit, H. (2008). Test-retest characteristics of the Balloon Analogue Risk Task (BART). Experimental and Clinical Psychopharmacology, 16(6), 565-570.

Zeisberger, S., Vrecko, D., \& Langer, T. (2012). Measuring the time stability of prospect theory preferences. Theory and Decision, 72(3), 359-386. 


\section{A Screenshot of lottery choice task}

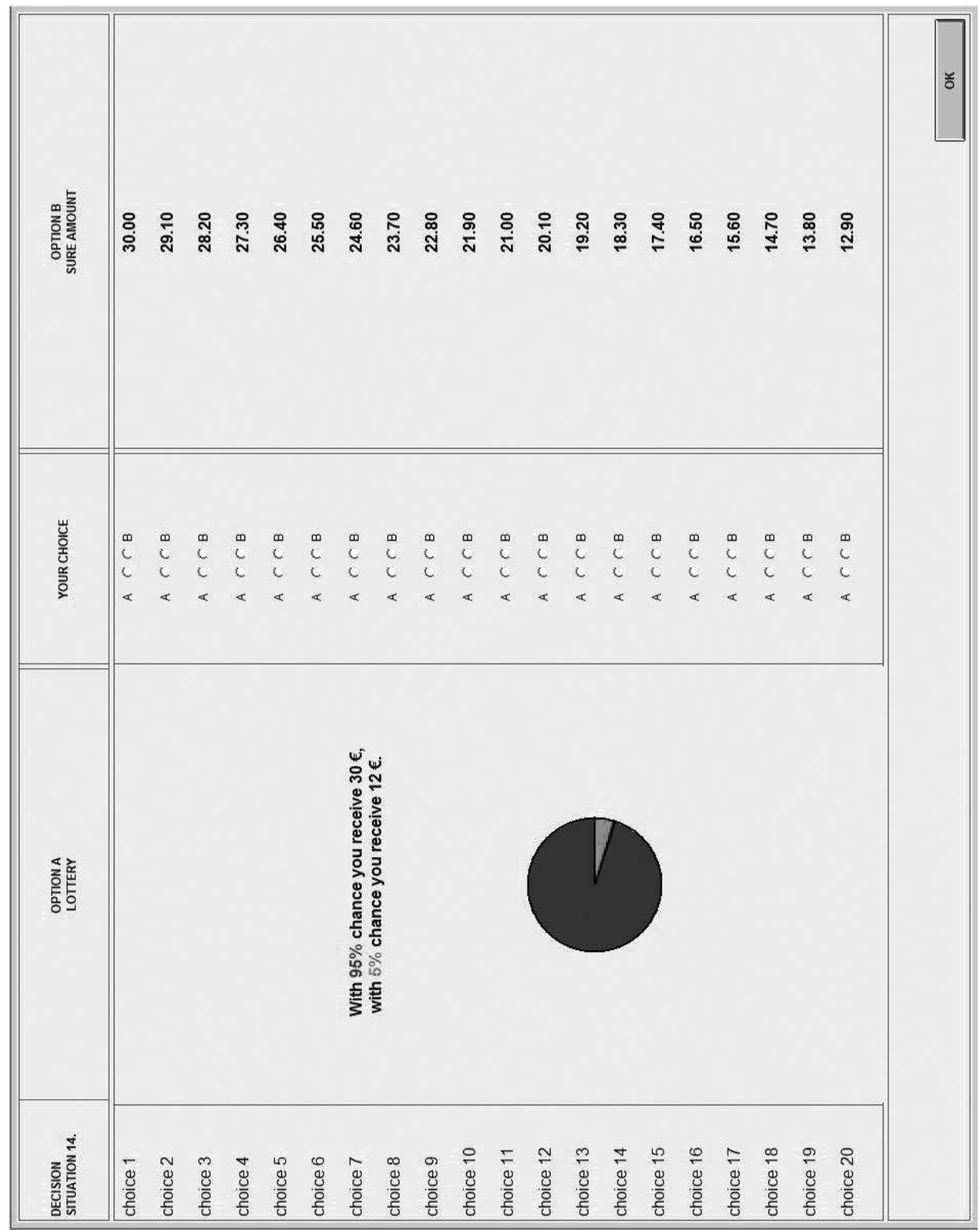

Figure 4.3: Screenshot of a lottery choice situation. Subjects filled in one such screen for each lottery. 


\section{B Self-report scales}

Table 4.9: Items of the Barratt Impulsiveness Scale (Patton et al., 1995)

\begin{tabular}{|c|c|c|}
\hline Order & $\operatorname{Item}^{a}$ & Subscale \\
\hline 1 & I plan tasks carefully. ${ }^{b}$ & Nonplanning \\
\hline 2 & I do things without thinking. & Motor \\
\hline 3 & I make up my mind quickly. & Motor \\
\hline 4 & I am happy go-lucky. & Motor \\
\hline 5 & I don't pay attention. & Attention \\
\hline 6 & I have "racing" thoughts. & Attention \\
\hline 7 & I plan trips well ahead of time. ${ }^{b}$ & Nonplanning \\
\hline 8 & I am self-controlled. ${ }^{b}$ & Nonplanning \\
\hline 9 & I concentrate easily. ${ }^{b}$ & Attention \\
\hline 10 & I save regularly. ${ }^{b}$ & Nonplanning \\
\hline 11 & I squirm at plays or lectures. & Attention \\
\hline 12 & I am a careful thinker. ${ }^{b}$ & Nonplanning \\
\hline 13 & I plan for job security. ${ }^{b}$ & Nonplanning \\
\hline 14 & I say things without thinking. & Nonplanning \\
\hline 15 & I like to think about complex problems. ${ }^{b}$ & Nonplanning \\
\hline 16 & I change jobs. & Motor \\
\hline 17 & I act “on impulse". & Motor \\
\hline 18 & I easily get bored when solving thought problems. & Nonplanning \\
\hline 19 & I act on the spur of the moment. & Motor \\
\hline 20 & I am a steady thinker. ${ }^{b}$ & Attention \\
\hline 21 & I change residences. & Motor \\
\hline 22 & I buy things on impulse. & Motor \\
\hline 23 & I can only think about one problem at a time. & Motor \\
\hline 24 & I change hobbies & Attention \\
\hline 25 & I spend or charge more than I earn. & Motor \\
\hline 26 & I often have extraneous thoughts when thinking. & Attention \\
\hline 27 & I am more interested in the present than in the future. & Nonplanning \\
\hline 28 & I am restless at the theatre or lectures. & Attention \\
\hline 29 & I like puzzles. ${ }^{b}$ & Nonplanning \\
\hline 30 & I am future oriented. ${ }^{b}$ & Motor \\
\hline
\end{tabular}

${ }^{a}$ Subjects rated each item on the following 4-point rating scale: 1 (rarely/never) 2 (occasionally) 3 (often) 4 (always/almost always).

${ }^{b}$ Item scoring was reversed. 
Table 4.10: Items for "Attitudes Towards Risk" (Dohmen et al., 2005)

Generally speaking,

are you a person who is ready to take risks or are you trying to avoid risks?

One can behave differently in different circumstances.

In the following circumstances, how would you assess your readiness to take risks?

Driving a car?

Making a financial investment?

In leisure and when doing sports?

Regarding your professional career?

Regarding your health?

Regarding confidence in strangers?

Note. Subjects rated each item on a scale from 0 (unwilling to take risks) to 10 (fully prepared to take risks).

\section{C Tests statistics}

Table 4.11: Comparison of the retested and notretested subsamples at Test Date 1

\begin{tabular}{|c|c|c|c|c|}
\hline & \multicolumn{2}{|c|}{ Median } & \multirow{2}{*}{$\frac{\mathrm{K}-\mathrm{S}}{p}$} & \multirow{2}{*}{$\frac{\mathrm{M}-\mathrm{W}}{p}$} \\
\hline & not retested $(N=91)$ & retested $(N=53)$ & & \\
\hline$\rho_{1}$ & 0.00821 & 0.00821 & 0.345 & 0.919 \\
\hline$\rho_{2}$ & 0.00821 & 0.00821 & 0.951 & 0.354 \\
\hline$\rho_{3}$ & 0.00737 & 0.00737 & 0.782 & 0.587 \\
\hline$\alpha$ & 0.790 & 0.693 & 0.178 & 0.071 \\
\hline$\gamma$ & 0.429 & 0.391 & 0.506 & 0.263 \\
\hline
\end{tabular}

Note. Comparison of the discount rates and risk attitudes for the retested and non-retested subsamples, using Kolmogorov-Smirnov Test (K-S) and Mann-Whitney Test (M-W). No test indicates significant differences between the retested and the not retested subsamples. 
Table 4.12: Correlations of risk preferences with self-report items in 2011 sample (Spearman's Rho)

\begin{tabular}{ccccccccc}
\hline \multicolumn{7}{c}{ Attitudes Towards Risk $(N=128)$} \\
\cline { 2 - 8 } & $\begin{array}{c}\text { In } \\
\text { General }\end{array}$ & $\begin{array}{c}\text { Driving } \\
\text { a Car }\end{array}$ & $\begin{array}{c}\text { Financial } \\
\text { Investments }\end{array}$ & $\begin{array}{c}\text { Leisure } \\
\text { and Sports }\end{array}$ & Career & Health & Strangers & $\begin{array}{c}\text { Sum } \\
\text { Score }\end{array}$ \\
\hline$\alpha$ & $0.28^{* *}$ & 0.14 & $0.30^{* * *}$ & 0.09 & $0.22^{*}$ & 0.07 & $0.27^{* *}$ & $0.31^{* * *}$ \\
$\gamma$ & $0.22^{*}$ & 0.11 & $0.29^{* *}$ & 0.08 & 0.16 & -0.03 & 0.16 & $0.22^{*}$ \\
\hline
\end{tabular}

Note. These data were obtained from an entirely independent sample and was measured in exactly the same way.

*** $p<.001, * * p<.01, * p<.05$

Table 4.13: Correlations of discount rates with self-report items in 2011 sample (Spearman's Rho)

\begin{tabular}{ccccccc}
\hline & \multicolumn{5}{c}{ Barratt Impulsiveness Scale $(N=128)$} \\
\cline { 2 - 6 } & $\begin{array}{c}\text { Total } \\
\text { Score }\end{array}$ & $\begin{array}{c}\text { Subscale } \\
\text { Nonplanning }\end{array}$ & $\begin{array}{c}\text { Item 8 } \\
\text { Self-Control }\end{array}$ & $\begin{array}{c}\text { Item 10 } \\
\text { Saving }\end{array}$ & $\begin{array}{c}\text { Item 25 } \\
\text { Spending }\end{array}$ & Item 27 \\
& 0.13 & $0.19^{*}$ & $0.26^{* *}$ & $0.39^{* * *}$ & $0.30^{* * *}$ & 0.02 \\
\hline Averagent & $\rho .18^{* *}$ & $0.24^{* *}$ & $0.37^{* * *}$ & $0.29^{* * *}$ & 0.07 \\
$\rho_{1}$ & 0.14 & 0.12 & $0.23^{* *}$ & $0.32^{* * *}$ & $0.22^{*}$ & 0.01 \\
$\rho_{2}$ & 0.04 & 0.12 & $0.20^{*}$ & $0.33^{* * *}$ & $0.27^{* *}$ & -0.03 \\
$\rho_{3}$ & 0.12 & 0.16 & & &
\end{tabular}

Note. These data were obtained from an entirely independent sample and was measured in exactly the same way.

$* * * p<.001, * * p<.01, * p<.05$

Table 4.14: Correlation of time preferences with risk preferences

\begin{tabular}{ccc}
\hline & $\alpha$ & $\gamma$ \\
\hline Average $\rho$ & $-0.14^{a}$ & -0.09 \\
$\rho_{1}$ & $-0.16^{a}$ & -0.11 \\
$\rho_{2}$ & $-0.15^{a}$ & -0.11 \\
$\rho_{3}$ & -0.05 & -0.01 \\
\hline${ }^{a} p<.1$ &
\end{tabular}




\title{
Chapter 5
}

\section{White Matter Integrity and Impulsiveness}

\begin{abstract}
Impulsiveness refers to the tendency to act spontaneously and with little concern for the future. Several cortical and subcortical regions have been associated with impulsive behaviour, but the nature of their interaction remains unclear. Knowing which areas possess more or less efficient connections in people who are habitually more impulsive would contribute towards understanding the specific contributions and the interaction of the regions involved. In this study we therefore assess which white matter regions are associated with self-reported impulsiveness using diffusion weighted magnetic resonance imaging. We assess integrity of white matter using fractional anisotropy (FA) and perform voxel-wise correlations with self-reported impulsiveness. We observe a positive correlation of selfreported impulsiveness with FA in frontal white matter regions that are implicated in action selection. This finding suggests that impulsive tendencies need not arise from a lack of cognitive control, but might result from excess motivation or drive to pursue impulsive actions.
\end{abstract}

Based on: Woelbert, E., Pullens, P., Okamoto-Barth, S., Strobel, M., Riedl, A., \& Goebel, R. White matter integrity and impulsiveness (in preparation). 


\subsection{Introduction}

The term "impulsive" describes premature behaviours that lack foresight, such as acting without much hesitation or deliberation, low self-control, as well as acting with little concern for future consequences (Dalley, Everitt, \& Robbins, 2011; Evenden, 1999). High impulsiveness is mostly considered dysfunctional, since it often interferes with the pursuit of long-term goals. It is part of the diagnostic criteria for several psychiatric disorders, such as attention-deficit hyperactivity disorders, mania, antisocial and aggressive behaviour (Evenden, 1999). Levels of impulsiveness are increased in addiction, and accumulating evidence suggests that impulsiveness is a predisposing factor for developing addictive behaviour (Dalley et al., 2011). Because of its prominent role for a wide range of maladaptive behaviours, a substantial body of research aims at understanding the concept of impulsiveness as well as its neural substrates.

Impulsive tendencies can become apparent in very different domains, such as weaknesses in attention, high spontaneity, or inability to control body movement. Thus, impulsiveness is likely to be a multifaceted construct, and several attempts have been made to define different components of impulsiveness (Eysenck \& Eysenck, 1978; Kirby \& Finch, 2010; Patton, Stanford, \& Barratt, 1995; Reynolds, Ortengren, Richards, \& de Wit, 2006; Whiteside \& Lynam, 2001). As a result, there exist several different self-report scales of impulsiveness. In addition, more behaviourally oriented measures of impulsivity test the ability to delay gratification or to inhibit motor responses and use these as indicators for impulsiveness (Ainslie, 1975; Kirby \& Finch, 2010; Logue, 1988; Newman, Gorenstein, \& Kelsey, 1983; Soubrié, 1986). While different self-report scales are usually intercorrelated, evidence on behavioural measures of impulsiveness is inconsistent. Different behavioural tasks seem to correlate only weakly with each other and with self-report scales, suggesting that these might represent distinct constructs (de Wit, Flory, Acheson, Mccloskey, \& Manuck, 2007; Kirby \& Finch, 2010; Reynolds et al., 2006; Swann, Bjork, Moeller, \& Dougherty, 2002; Verdejo-Garcia et al., 2010).

For the purpose of this study, we are interested in impulsiveness as a personality trait and therefore focus on impulsiveness as defined in the Barratt 
Impulsiveness Scale (BIS-11, Patton et al., 1995), a standard questionnaire to measure self-reported impulsiveness. There is ample inter-individual variability with respect to BIS-11 scores, which is stable over time (Stanford et al., 2009).

Most evidence on the neural substrates of impulsiveness is limited to behavioural measures of impulsiveness, such as response inhibition (Dalley et al., 2011). Lesion studies in humans and animals, as well as pharmacological and functional neuroimaging studies suggest that a network comprising the prefrontal cortex and the basal ganglia are involved in impulsive behaviour and the control thereof. The basal ganglia are a complex structure that receives input from and connects to different regions of the frontal cortex and is involved in a wide range of functions, including movement, reward processing, and cognitive control (Alexander \& Crutcher, 1990; Arsalidou, Duerden, \& Taylor, 2012). It is hypothesized that the role of the basal ganglia in all of these different functions is to select which actions are executed, and which are suppressed (Houk et al., 2007; Redgrave, Prescott, \& Gurney, 1999). The prefrontal cortex, in particular the dorsolateral part and the inferior frontal gyrus, is assumed to exert cognitive control and inhibit impulsive tendencies, a.o. through its projections to the basal ganglia (Cardinal, 2006; Dalley et al., 2011; Diekhof \& Gruber, 2010; Figner et al., 2010; Hariri et al., 2006; Heatherton \& Wagner, 2011; Kim \& Lee, 2011; McClure, Laibson, Loewenstein, \& Cohen, 2004). Still, the role of the individual brain areas and their interactions in impulsive behaviour, in particular in stable interindividual differences in impulsiveness, remains incompletely understood.

Variability in brain structure associated with stable individual characteristics can provide useful information about the brain-behaviour relationship that is complementary to - sometimes inconclusive or contradictory — functional data (Kanai \& Rees, 2011). Here, the grey matter volume and surface area of particular brain regions as well as white matter integrity are currently the most commonly used measures (Zatorre, Fields, \& JohansenBerg, 2012). Diffusion weighted magnetic resonance imaging provides data on how directed (i.e. anisotropic) water diffusion is in a given voxel. This can be used to assess the integrity of white matter. Fractional anisotropy (FA) is a functionally relevant indicator of local white matter integrity. It re- 
flects several microstructural factors of white matter organization, such as fibre density and myelinisation, and high FA is related to better structural connectivity and cognitive function (Boorman, Shea, Sebastian, Rushworth, \& Johansen-Berg, 2007; Scholz, Klein, Behrens, \& Johansen-Berg, 2009).

To date, only few studies have investigated structural correlates for impulsiveness in healthy populations. Structural brain imaging studies that focus on healthy subjects have measured impulsiveness with a delay discounting task, where subjects had to decide between smaller, sooner and larger, later amounts of money. In a voxel-based morphometry study of healthy adults, Bjork, Momenan, and Hommer (2009) found that preference for immediate gratification was associated with lower lateral frontal cortex gray matter volume, in line with the hypothesis that this brain region contributes towards patient choice (Figner et al., 2010). Peper et al. (2012) report that high white matter integrity in frontostriatal tracts was associated with more patient intertemporal choice. This suggests that effective communication between the frontal cortex and the striatum is associated with higher impulse control. Similarly, Olson et al. (2009) report a positive correlation between patient choice and FA in adolescents. Their whole-brain analysis showed associations in the left inferior longitudinal fasciculus, the right anterior thalamic radiation and inferior fronto-occipitial fasciculus, i.e. tracts connecting the frontal lobes with the thalamus, but also tracts connecting to the parietal and occipital lobes. Taken together, these studies provide some support for the notion that the interaction of frontal and subcortical brain regions contributes towards patient intertemporal choice.

Intertemporal choice is only weakly related to self-reported impulsiveness (Kirby \& Finch, 2010; Reynolds et al., 2006), however, and evidence on structural correlates of self-reported impulsiveness in healthy subjects is scarce. A study by $\mathrm{Xu}$ et al. (2011) investigated the relationship between white matter integrity and the Behavioural Inhibition System / Behavioural Activation System (BIS/BAS) questionnaire (Carver \& White, 1994), a concept related to impulsiveness. In a large sample of healthy adults selfreported behavioural activation (BAS), specifically the subscale fun seeking, was positively correlated with white matter integrity in the corona radiata and superior longitudinal fasciculus, i.e. fibres connecting frontal cortex, parietal cortex and subcortical regions. No association was found between 
self-reported behavioural inhibition (BIS) and white matter integrity. Berns, Moore, and Capra (2009) investigated the association of white matter integrity and self-reported engagement in risky behaviour in adolescents. Surprisingly, greater white matter integrity in extended regions of the frontal cortex was associated with greater involvement in risky behaviour. White matter integrity increases during adolescence (Paus, Zijdenbos, \& Worsley, 1999). Thus, at least during adolescence, a relatively more mature brain is more likely to engage in dangerous behaviour. These findings illustrate that impulsive behaviour need not necessarily result from weak integrity in white matter, but could also arise from strong anatomical connections, for example if these were associated with excessive motivation or urge.

Up to now, studies investigating the structural correlates of self-reported impulsiveness as defined by the BIS- 11 have focused on clinical populations and have investigated only specific regions of interest. Mostly, these studies have focussed on the corpus callosum, which contains fibres connecting the two hemispheres. Moeller et al. (2005) investigated whether FA in the corpus callosum is associated with BIS- 11 scores and performance in a response inhibition task in cocaine dependent subjects and a healthy control group. For cocaine dependent subjects, response inhibition, but not the BIS11 score, was negatively correlated with FA in the rostral body of the corpus callosum. No association between FA in the corpus callosum and the BIS11 score was found for healthy control subjects. Gruber, Silveri, Dahlgren, and Yurgelun-Todd (2011) performed a similar study in chronic marijuana smokers. BIS-11 scores were positively correlated with FA in a bilateral region of interest placed in the frontal white matter. Liu et al. (2010) report a negative correlation of BIS-11 scores with white matter integrity in callosal fibre tracts connecting the bilateral orbitofrontal cortices in alcohol dependent individuals. Qiu et al. (in press) investigated whether grey matter volume is associated with BIS-11 scores in heroin-dependent individuals and in healthy controls. Both for heroin-dependent individuals, and for a healthy control group, BIS-11 scores correlated negatively with grey matter volume in bilateral medial prefrontal cortex as well as dorsolateral prefrontal cortex, in line with the hypothesis that the prefrontal cortex inhibits impulsive tendencies.

In sum, there is some evidence from healthy participants that impulsive 
choice in delay discounting tasks is associated with white matter integrity. Correlations have been observed mostly, but not only, in fibre tracts connecting the frontal cortex to subcortical regions. Studies on structural correlates of self-reported impulsiveness also suggest an involvement of white matter integrity in impulsiveness, but evidence is inconclusive, and limited to clinically motivated regions of interest. Knowing which areas possess more (or less) efficient connections in people who are habitually more impulsive than others would contribute towards understanding the specific contribution and the interaction of the regions involved in impulsive behaviour.

In this study we therefore explore whether self-reported impulsiveness, measured with the BIS-11, correlates with white matter integrity in healthy young adults. Based on evidence from functional brain imaging, and the limited evidence from clinical studies, we expect a correlation of BIS-11 with white matter integrity in fibres connecting to the frontal cortex. Since the frontal cortex, in particular the dorsolateral prefrontal cortex and the inferior frontral gyrus, have been associated with cognitive control and response inhibition (Chambers, Garavan, \& Bellgrove, 2009; Dalley et al., 2011; Heatherton \& Wagner, 2011), it seems most plausible to assume that higher white matter integrity in the frontal lobe should be associated with lower impulsiveness. However, as demonstrated by Berns et al. (2009) and $\mathrm{Xu}$ et al. (2011), high trait-impulsivity could not only arise from a lack of inhibitory control, but in principle also from a generally high drive to act impulsively. Thus, our hypothesis is undirected.

\subsection{Methods}

\section{Subjects}

Eighteen right-handed healthy volunteers ( 9 women) were screened for current or past psychiatric illness (axis I) using the Structured Clinical Interview for DSM-IV (SCID; First, Spitzer, Miriam, \& Williams, 2002). History of attention-deficit-hyperactivity disorder, substance dependence or pathological gambling, as well as current psychiatric illness was exclusionary for any volunteer. The study protocol was approved by the local ethics committee. Written informed consent was obtained and subjects received financial 
compensation for their participation. Subjects were recruited via Email from the subject pool of the behavioural and experimental economics lab (BEElab) at Maastricht University, which consists of students of all fields of Maastricht University, the majority being students of Business and Economics. Behavioural data was acquired as part of a larger study in the behavioural and experimental economics lab (BEElab) of Maastricht University before the MRI sessions.

\section{Self-reported impulsiveness}

Self reported impulsiveness was measured with the Barratt Impulsiveness Scale (BIS-11, Patton et al., 1995). This scale allows computing a total impulsiveness score, which integrates several aspects of impulsive behaviour (Stanford et al., 2009). All items of the BIS-11 are listed in Table 4.9 in Appendix 4.B.

\section{Intelligence}

Ability to delay gratification in childhood is predictive of academic skills in adolescence (Mischel, Shoda, \& Peake, 1988) and impulsive choice has been found to be associated with lower intelligence (de Wit et al., 2007; Dohmen, Falk, Huffman, \& Sunde, 2010) and academic achievement (Benjamin, Brown, \& Shapiro, 2006; Frederick, 2005). In order to be able to control for intelligence, we applied the short form of the Culture Fair Test (CFT) of intelligence by Cattell and Cattell (2008).

\section{Image acquisition}

All subjects were scanned on a 3.0 Tesla Siemens Magnetom Allegra head scanner (Siemens, Erlangen, Germany) at the Maastricht Brain Imaging centre, equipped with a standard birdcage head coil. Foam padding was placed around the head to minimize movement and subjects were provided with adequate hearing protection. Spin-echo diffusion weighted echoplanar imaging was used to measure 75 contiguous slices of $2 \mathrm{~mm}$ thickness along 72 isotropically distributed directions, covering the whole brain (echo time (TE), $83 \mathrm{~ms}$; repetition time (TR), $9400 \mathrm{~ms}$; field of view (FOV), 256x256 
$\mathrm{mm}^{2}$; matrix size $128 \times 128$; b value, $1000 \mathrm{~s} / \mathrm{mm}^{2} ; 2 \times 2 \times 2 \mathrm{~mm}^{3}$ voxel size). This sequence minimizes distortion due to eddy currents (Reese, Heid, Weisskoff, \& Wedeen, 2003). Initially, and interleaved with the diffusion weighted images, seven b0 images were obtained as anatomical reference for alignment and motion correction. To improve data quality, two identical diffusion weighted scans were obtained for later averaging of FA maps. For anatomical reference, high resolution anatomical images (voxel size $1 \times 1 \times 1 \mathrm{~mm}^{3}$ ) were obtained using a T1-weighted three-dimensional (3D) ADNI MP-RAGE sequence (TR, $2250 \mathrm{~ms}$; TE, $2.6 \mathrm{~ms}$; FOV, 256x256 mm² flip angle, $9^{\circ}$; 192 sagittal slices). All scans were obtained in one scanning session which lasted approximately 40 minutes.

\section{MRI data processing}

There is considerable discussion about the appropriate processing of data obtained from diffusion MRI. The major problem for group analysis is the spatial coregistration of images, since different alignment procedures can lead to remarkably different results of the group statistics (Jones and Cercignani, 2010). In order to avoid reporting artefacts of one particular data analysis pipeline, we processed the data in two distinct ways, and looked for converging evidence. Specifically, we used two different approaches for spatial coregistration of the images, namely piecewise linear transformation of the images to Talairach space (Talairach \& Tournoux, 1988), and tract-based spatial statistics (TBSS), part of FSL (Smith et al., 2004). TBSS involves nonlinear alignment of the individual images, and then constrains the analysis to white matter voxels that presumably represent individual tract centres. This procedure is thought to improve local alignment, reduce partial volume effects and increase sensitivity (Smith et al., 2006). However, since it is based on nonlinear alignment of the individual images, it may considerably displace voxels. Compared to a linear alignment it is therefore more difficult to interpret the location of the identified regions.

\section{Piecewise-linear alignment}

Analysis based on piecewise-linear alignment was performed using Brain Voyager QX (version 2.3, Brain Innovation, Maastricht, the Netherlands, 
Goebel, Esposito, \& Formisano, 2006). Diffusion weighted images were corrected for motion including reorienting the gradient directions and subsequently co-registered to the individual 3D anatomical dataset. Since eddy currents were minimal, distortion correction was omitted. Diffusion tensors were estimated to calculate the FA value for each voxel. Two diffusion weighted data sets were acquired per subject and the resulting two FA maps were then averaged for each subject. For group analysis, these were then spatially normalized into Talairach space. Voxelwise correlations of FA values in each voxel with the BIS-11 score were performed on the whole brain. Correction for multiple comparisons was performed using cluster-size threshold based on Monte Carlo simulation, as implemented in BrainVoyager QX. Images were thresholded at $p<0.05$, corrected.

\section{TBSS}

For the TBSS analysis, preprocessing of diffusion data was repeated using the diffusion toolbox (FDT) in FSL (Smith et al., 2004), and following the standard preprocessing steps suggested for TBSS (Smith et al., 2006). FA maps were mapped onto the Montreal Neurological Institute (MNI) template space using FNIRT nonlinear alignment (Andersson, Jenkinson, \& Smith, 2007). For TBSS, all subjects' coregistered FA images were averaged to create a mean FA image which was then thinned to a skeleton that represents the centres of the tracts common to all subjects. Then all subjects' FA values were projected onto this skeleton for statistical analysis.

We computed voxelwise correlations of FA values with the BIS-11 total score for the whole skeleton. These were statistically assessed with the "randomise" program in FSL with 5000 permutations, using threshold-free cluster enhancement with default settings (Smith \& Nichols, 2009). Images were FWE-corrected and thresholded at $p<0.05$.

JHU white-matter tractography atlas (Hua et al., 2008) and ICBM-DTI81 white-matter label atlas (Wakana, Jiang, Nagae-Poetscher, van Zijl, \& Mori, 2004) were used to determine anatomical structures. 


\subsection{Results}

Descriptive statistics for demographics and behavioural variables are given in Table 5.1. Mean and standard deviation for the BIS-11 total score are comparable to a large sample of healthy adults recently reported by Stanford et al. (2009). Mean intelligence scores of our sample are about 1 standard deviation above average, presumably due to the fact that our sample consisted of university students.

Table 5.1: Descriptive statistics

\begin{tabular}{lcccc}
\hline & Mean & SD & Min & Max \\
\hline age & 22.33 & 2.38 & 19 & 29 \\
IQ & 117.72 & 17.18 & 88 & 161 \\
BIS-11 score & 59.33 & 8.52 & 49 & 79 \\
\hline
\end{tabular}

\section{Results of piecewise-linear alignment}

Whole brain voxelwise correlations between FA value and BIS-11 score yielded significant positive correlations of self-reported impulsiveness with FA in a white matter cluster within the anterior corona radiata in both hemispheres ( $p=0.035$, cluster level corrected). That is, we observed higher local FA values in individuals with higher self-reported impulsiveness. No clusters were negatively correlated with self-reported impulsiveness. To verify that the identified region lies fully in white matter for each subject, individual FA maps and coregistered T1-weighted high resolution anatomical scans were inspected visually. Tractography from the identified clusters in the individual subject data consistently revealed that fibres in the identified region extended into the capsula interna, which contains fibres connecting different parts of the frontal cortex with subcortical structures, mainly the thalamus (Mori et al., 2008; Schmahmann, Smith, Eichler, \& Filley, 2008). Since age and IQ have been reported to relate both to impulsiveness and to white matter integrity, we next performed a partial correlation of FA values with the BIS-11 score, controlling for age and IQ. This analysis yielded qualitatively similar results, but only the left cluster was marginally significant 


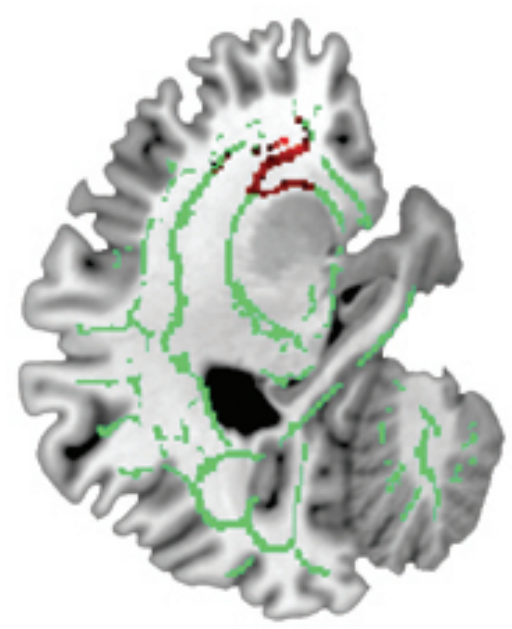

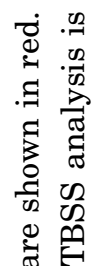

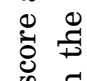

क..

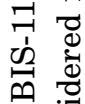

串

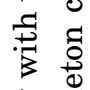

굴

胥
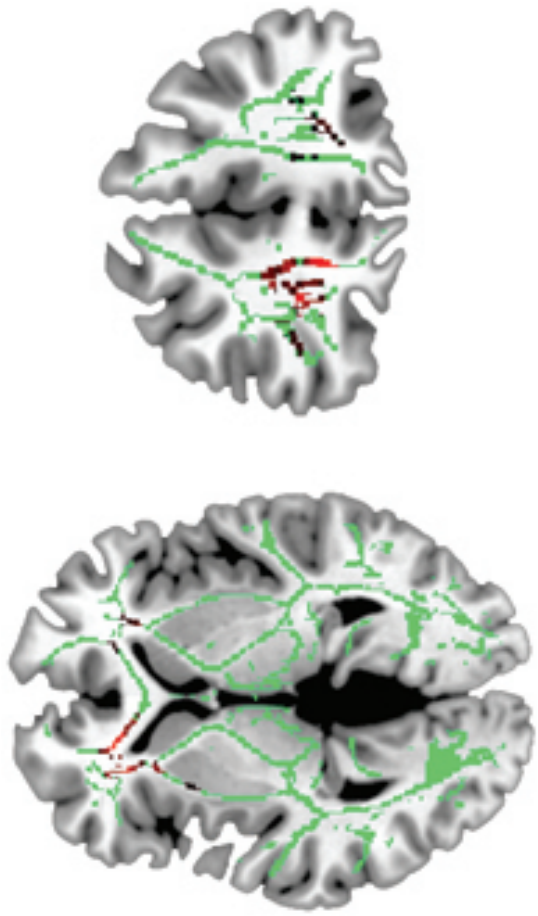

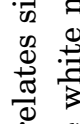

웡 $\frac{0}{3}$

质

ह

今 वृ

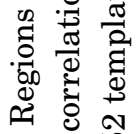

$\dot{\dot{2}}$ के

त.

ส

जी चี

돌 울

पै

品

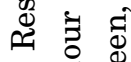

두

10.

苟

空 
after cluster size threshold correction ( $p=0.074$, cluster level corrected), the right cluster did not reach significance.

\section{Results of TBSS analysis}

We computed voxelwise correlations of FA with the BIS-11 score for the whole white matter skeleton, while controlling for age and IQ. The voxelwise analysis on the skeletonized FA data again indicated a correlation of FA with the BIS-11 score in the anterior corona radiata, extending into the anterior limb of the capsula interna, the capsula externa, the superior longitudinal fasciculus, and the genu of the corpus callosum (see Figure 5.1). For illustration purposes, a scatterplot of the average FA in the identified region and the BIS-11 score is given in Figure 5.2.

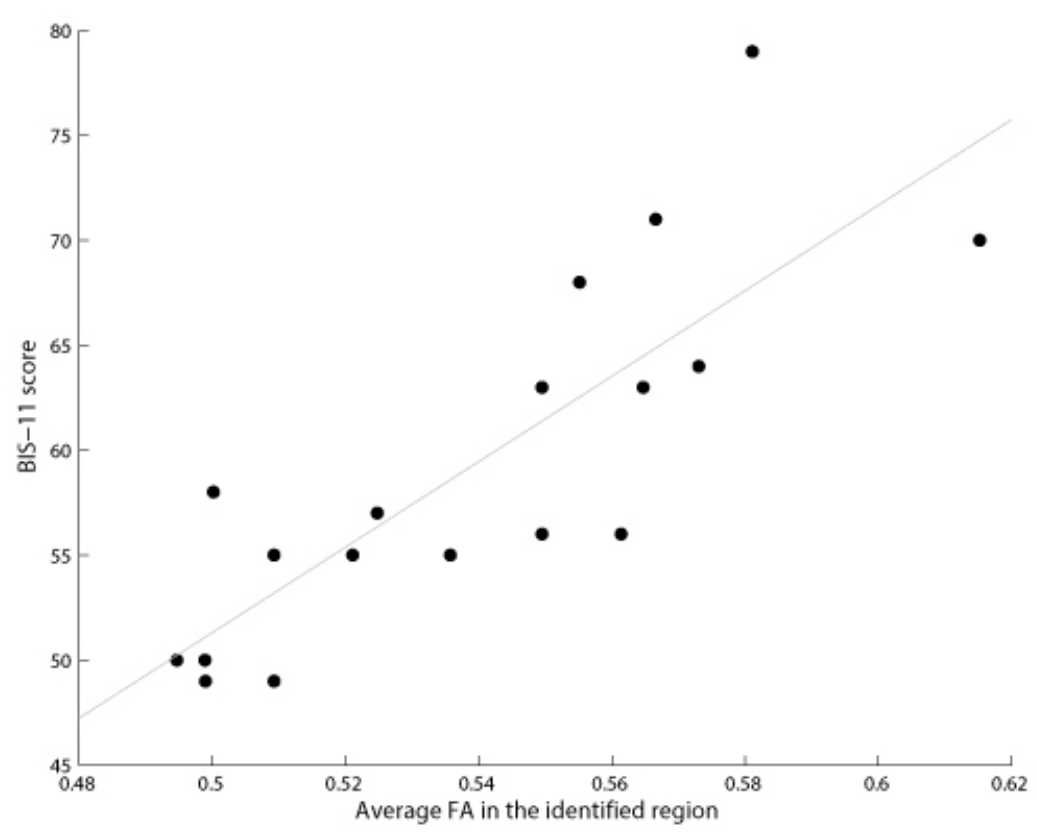

Figure 5.2: BIS-11 scores plotted against the average FA value in the identified regions $(r=0.83)$. 


\subsection{Discussion}

This study aimed at assessing the relationship between white-matter integrity and self-reported impulsiveness in a healthy population. Using two different techniques to spatially align the data, we find converging evidence that white matter integrity correlates positively with impulsiveness in frontal white matter. The correlation was most pronounced in the anterior region of the corona radiata, which contains both ascending and descending fibres connecting the frontal cortex to subcortical structures, mainly the thalamus. The correlation also extended into the external capsule, which a.o. contains fibres connecting the ventral and medial portions of the frontal cortex to the striatum (Mori et al., 2008; Schmahmann et al., 2008; Wakana et al., 2004). The frontal cortex and subcortical structures, specifically the basal ganglia and the thalamus, form a loop system that is critically involved in action selection and impulse control (Alexander \& Crutcher, 1990; Chambers et al., 2009; Dalley et al., 2011; Kim \& Lee, 2011). Higher FA has been associated with better structural connectivity (Boorman et al., 2007) and better cognitive function (Fjell, Westlye, Amlien, \& Walhovd, 2011; Flöel, De Vries, Scholz, Breitenstein, \& Johansen-Berg, 2009; Johansen-Berg, DellaMaggiore, Behrens, Smith, \& Paus, 2007). Hence, our finding suggests that higher impulsiveness goes along with better structural connectivity as measured with FA in fibres involved in action selection.

We observe a positive correlation between FA in frontal white matter and self-reported impulsiveness. This is not in line with the finding that impatient choices in delay discounting tasks seem associated with lower frontostriatal white matter integrity (Olson et al., 2009; Peper et al., 2012). Since the relationship between delay discounting and self-reported impulsiveness is weak, this does not need to be a strong contradiction, however. More importantly, our finding is at odds with the assumption that ineffective cognitive control by the frontal cortex is the driving force underlying impulsive behaviour (Dalley et al., 2011; Diekhof \& Gruber, 2010). However, a recent study on adolescents yielded a result similar to ours: Higher frontal white matter integrity was associated with a higher propensity to engage in dangerous behaviour (Berns et al., 2009). Similarly, Xu et al. (2011) found no association of white matter integrity and self-reported behavioural inhi- 
bition, but a positive association of white matter integrity with fun seeking. Together, these findings underline that impulsive behaviour may not only result from a lack of cognitive control, but instead - or more so - from excessive drive or motivation to act impulsively. This interpretation is in line with findings from a recent neuroimaging study. Casey et al. (2011) investigated adults who had been classified as more or less impulsive at preschool age. They report that even 40 years after this classification more impulsive subjects had more difficulty inhibiting a response to appealing cues. This result confirms that impulsivity has a very stable trait-component. Interestingly, the more impulsive participants were only impaired in response inhibition when the task included compelling stimuli, such as emotional faces. In addition, the more impulsive subjects had higher activity levels in the ventral striatum, a key region involved in reward processing and motivation, in response to happy faces. These findings suggest that the impaired performance of the more impulsive subjects resulted from stronger behavioural activation following appetitive stimuli, rather than from a lack of inhibition. The higher white matter integrity that we observe in more impulsive subjects might thus reflect an excess in motivation or drive, which results in impulsive behaviour.

\section{Methodological considerations}

Relating individual differences to structural differences in the brain obtained by diffusion weighted magnetic resonance imaging is a relatively new neuroscientific approach. FA has been shown to relate to structural connectivity (Boorman et al., 2007) and to be functionally relevant (Flöel et al., 2009; Johansen-Berg et al., 2007). However, FA is likely to be influenced by a variety of microstructural factors, which comprise the number of axons, packing density of fibres, and myelination, but remain incompletely understood (Zatorre et al., 2012). Differences in FA must therefore be interpreted with caution. This is underlined by a longitudinal study that found a decrease in local FA in response to learning, where an increase in FA would be expected (Taubert et al., 2010). The fact that FA is plastic, and changes with experience and learning, additionally complicates the interpretation of correlational results as shown in this study. That is, while our results sug- 
gest an involvement of frontal white matter in trait-impulsivity, it is not clear whether higher white matter integrity in more impulsive individuals is the result or the cause of habitually more impulsive behaviour, or both. Heritability studies have found that a large part of variability in frontal white matter is genetically determined, suggesting that white matter integrity might indeed be a predisposing factor for high trait-impulsiveness (Zatorre et al., 2012).

Further, diffusion weighted imaging currently sees a rapid development of image acquisition and analysis techniques, whereas consensus on the most valid procedures along the data processing pipeline is missing (Jones \& Cercignani, 2010). One critical point for studies like the present one is the co-registration of the individual brains for group analysis, and there is still considerable disagreement with respect to the optimal procedure. In this study, we have addressed this problem by using two different analysis pipelines, one based on piece-wise linear transformations that align individual images in standard stereotactic (Talairach) space. This procedure is minimally invasive, but is also limited with respect to aligning functionally equivalent regions and might suffer from partial volume artefacts. Therefore, we analysed the data again using tract-based spatial statistics, an approach that suffers less from these problems (Smith et al., 2006). The fact that both processing procedures yield comparable results suggests that our finding is not an artefact of the specific alignment technique. Our study followed an exploratory voxel-based analysis. Based on such exploratory studies, more specific hypotheses can be developed and tested using tractographybased analyses. A tractography-based approach does not require co-registration of the individual images, but instead isolates the voxels to consider based on tractography results (Kanaan et al., 2006; Peper et al., 2012). It circumvents some of the problems of the voxel-based approach, but requires a specific a-priori hypothesis, and therefore lends itself to the confirmation of voxel-based findings.

\section{Conclusion}

In sum, we investigated whether self-reported impulsiveness is associated with white matter integrity in healthy young adults. We observed a positive 
correlation between frontal white matter and impulsiveness. Our finding suggests that a tendency to behave impulsively is associated with increased motivation or drive rather than a lack of cognitive control. As our study followed an exploratory approach, it is desirable to confirm this finding using a tractography-based approach. 


\section{References}

Ainslie, G. (1975). Specious reward: a behavioural theory of impulsiveness and impulse control. Psychological Bulletin, 82(4), 463-496.

Alexander, G. E., \& Crutcher, M. D. (1990). Functional architecture of basal ganglia circuits: neural substrates of parallel processing. Trends in Neurosciences, 13(7), 266-271.

Andersson, J. L. R., Jenkinson, M., \& Smith, S. M. (2007). Non-linear registration aka spatial normalisation (Oxford Centre for Functional Magnetic Resonance Imaging of the Brain. Technical Report TR07JA02). Oxford Centre for Functional Magnetic Resonance Imaging of the Brain. Retrieved 2.03.2013, from http://www.fmrib.ox.ac.uk/analysis/techrep/tr07ja2/tr07ja2.pdf

Arsalidou, M., Duerden, E. G., \& Taylor, M. J. (2012). The centre of the brain: topographical model of motor, cognitive, affective, and somatosensory functions of the basal ganglia. Human Brain Mapping.

Benjamin, D. J., Brown, S. A., \& Shapiro, J. M. (2006). Who is behavioral? Cognitive ability and anomalous preferences (Working Paper). Retrieved 3.03.2013, from http://www.dklevine.com/archive/refs4122247000000001334.pdf

Berns, G. S., Moore, S., \& Capra, C. M. (2009). Adolescent engagement in dangerous behaviors is associated with increased white matter maturity of frontal cortex. PloS one, 4(8), e6773.

Bjork, J. M., Momenan, R., \& Hommer, D. W. (2009). Delay discounting correlates with proportional lateral frontal cortex volumes. Biological Psychiatry, 65(8), 710-713.

Boorman, E. D., Shea, J. O., Sebastian, C., Rushworth, M. F. S., \& Johansen-Berg, $H$. (2007). Individual differences in white-matter microstructure reflect variation in functional connectivity during choice. Current Biology, 17(16), 14261431.

Cardinal, R. N. (2006). Neural systems implicated in delayed and probabilistic reinforcement. Neural Networks, 19(8), 1277-1301.

Carver, C. S., \& White, T. L. (1994). Behavioral inhibition, behavioral activation, and affective responses to impending reward and punishment: the BIS/BAS scales. Journal of Personality and Social Psychology, 67(2), 319-333.

Casey, B. J., Somerville, L. H., Gotlib, I. H., Ayduk, O., Franklin, N. T., Askren, M. K., ... Shoda, Y. (2011). Behavioral and neural correlates of delay of gratification 40 years later. Proceedings of the National Academy of Sciences, 108(36), 14998-15003.

Cattell, R. B., \& Cattell, A. K. (2008). Measuring Intelligence with the Culture Fair Tests. Oxford: Hogrefe.

Chambers, C. D., Garavan, H., \& Bellgrove, M. A. (2009). Insights into the neural 
basis of response inhibition from cognitive and clinical neuroscience. Neuroscience \& Biobehavioral Reviews, 33(5), 631-646.

Dalley, J. W., Everitt, B. J., \& Robbins, T. W. (2011). Impulsivity, compulsivity, and top-down cognitive control. Neuron, 69(4), 680-694.

de Wit, H., Flory, J. D., Acheson, A., Mccloskey, M., \& Manuck, S. B. (2007). IQ and nonplanning impulsivity are independently associated with delay discounting in middle-aged adults. Personality and Individual Differences, 42(1), 111121.

Diekhof, E. K., \& Gruber, O. (2010). When desire collides with reason: functional interactions between anteroventral prefrontal cortex and nucleus accumbens underlie the human ability to resist impulsive desires. Journal of Neuroscience, 30(4), 1488-1493.

Dohmen, T., Falk, A., Huffman, D., \& Sunde, U. (2010). Are risk aversion and impatience related to cognitive ability? American Economic Review, 100(3), 1238-1260.

Evenden, J. L. (1999). Varieties of impulsivity. Psychopharmacology, 146(4), 348361.

Eysenck, S. B. G., \& Eysenck, H. J. (1978). Impulsiveness and venturesomeness: their position in a dimensional system of personality description. The Quarterly Journal of Experimental Psychology Section A: Human Experimental Psychology, 43(3 Pt 2), 1247-1255.

Figner, B., Knoch, D., Johnson, E. J., Krosch, A. R., Lisanby, S. H., Fehr, E., \& Weber, E. U. (2010). Lateral prefrontal cortex and self-control in intertemporal choice. Nature Neuroscience, 13(5), 538-539.

First, M. B., Spitzer, R. L., Miriam, G., \& Williams, J. B. (2002). Structured clinical interview for DSM-IV-TR axis I disorders, research version, non-patient edition. (SCID-I/NP). New York: Biometrics Research, New York State Psychiatric Institute.

Fjell, A. M., Westlye, L. T., Amlien, I. K., \& Walhovd, K. B. (2011). Reduced white matter integrity is related to cognitive instability. Journal of Neuroscience, 31(49), 18060-18072.

Flöel, A., De Vries, M. H., Scholz, J., Breitenstein, C., \& Johansen-Berg, H. (2009). White matter integrity in the vicinity of Broca's area predicts grammar learning success. NeuroImage, 47(4), 1974-1981.

Frederick, S. (2005). Cognitive reflection and decision making. Journal of Economic Perspectives, 19(4), 25-42.

Goebel, R., Esposito, F., \& Formisano, E. (2006). Analysis of functional image analysis contest (FIAC) data with Brainvoyager QX: from single-subject to cortically aligned group general linear model analysis and self-organizing group 
independent component analysis. Human Brain Mapping, 27(5), 392-401.

Gruber, S. A., Silveri, M. M., Dahlgren, M. K., \& Yurgelun-Todd, D. (2011). Why so impulsive? White matter alterations are associated with impulsivity in chronic marijuana smokers. Experimental and Clinical Psychopharmacology, 19(3), 231-242.

Hariri, A. R., Brown, S. M., Williamson, D. E., Flory, J. D., de Wit, H., \& Manuck, S. B. (2006). Preference for immediate over delayed rewards is associated with magnitude of ventral striatal activity. Journal of Neuroscience, 26(51), 13213-13217.

Heatherton, T. F., \& Wagner, D. D. (2011). Cognitive neuroscience of self-regulation failure. Trends in Cognitive Sciences, 15(3), 132-139.

Houk, J. C., Bastianen, C., Fansler, D., Fishbach, A., Fraser, D., Reber, P. J., ... Simo, L. S. (2007). Action selection and refinement in subcortical loops through basal ganglia and cerebellum. Philosophical Transactions of the Royal Society of London. Series B, Biological Sciences, 362(1485), 1573-1583.

Hua, K., Zhang, J., Wakana, S., Jiang, H., Li, X., Reich, D. S., ... Mori, S. (2008). Tract probability maps in stereotaxic spaces: analyses of white matter anatomy and tract-specific quantification. NeuroImage, 39(1), 336-347.

Johansen-Berg, H., Della-Maggiore, V., Behrens, T. E. J., Smith, S. M., \& Paus, T. (2007). Integrity of white matter in the corpus callosum correlates with bimanual co-ordination skills: cortical control of higher motor cognition. NeuroImage, 36(Supplement 2), T16-T21.

Jones, D. K., \& Cercignani, M. (2010). Twenty-five pitfalls in the analysis of diffusion MRI data. NMR in Biomedicine, 23(7), 803-820.

Kanaan, R. A., Shergill, S. S., Barker, G. J., Catani, M., Ng, V. W., Howard, R., ... Jones, D. K. (2006). Tract-specific anisotropy measurements in diffusion tensor imaging. Psychiatry Research, 146(1), 73-82.

Kanai, R., \& Rees, G. (2011). The structural basis of inter-individual differences in human behaviour and cognition. Nature Reviews Neuroscience, 12(4), 231242.

Kim, S., \& Lee, D. (2011). Prefrontal cortex and impulsive decision making. Biological Psychiatry, 69(12), 1140-1146.

Kirby, K. N., \& Finch, J. C. (2010). The hierarchical structure of self-reported impulsivity. Personality and Individual Differences, 48(6), 704-713.

Liu, I.-C., Chiu, C.-H., Chen, C.-J., Kuo, L.-W., Lo, Y.-C., \& Tseng, W.-Y. I. (2010). The microstructural integrity of the corpus callosum and associated impulsivity in alcohol dependence: a tractography-based segmentation study using diffusion spectrum imaging. Psychiatry Research: Neuroimaging, 184(2), 128-134. 
Logue, A. W. (1988). Research on self-control: an integrating framework. Behavioral and Brain Sciences, 11(4), 665-709.

McClure, S. M., Laibson, D. I., Loewenstein, G., \& Cohen, J. D. (2004). Separate neural systems value immediate and delayed monetary rewards. Science, 306(5695), 503-507.

Mischel, W., Shoda, Y., \& Peake, P. K. (1988). The nature of adolescent competencies predicted by preschool delay of gratification. Journal of Personality and Social Psychology, 54(4), 687-696.

Moeller, F. G., Hasan, K. M., Steinberg, J. L., Kramer, L. A., Dougherty, D. M., Santos, R. M., ... Narayana, P. A. (2005). Reduced anterior corpus callosum white matter integrity is related to increased impulsivity and reduced discriminability in cocaine-dependent subjects: diffusion tensor imaging. $\mathrm{Neu}$ ropsychopharmacology, 30(3), 610-617.

Mori, S., Oishi, K., Jiang, H., Jiang, L., Li, X., Akhter, K., ... Mazziotta, J. (2008). Stereotaxic white matter atlas based on diffusion tensor imaging in an ICBM template. NeuroImage, 40(2), 570-582.

Newman, J. P., Gorenstein, E. E., \& Kelsey, J. E. (1983). Failure to delay gratification following septal lesions in rats: implications for an animal model of disinhibitory psychopathology. Personality and Individual Differences, 4(2), 147-156.

Olson, E., Collins, P., Hooper, C., Muetzel, R., Lim, K., \& Luciana, M. (2009). White matter integrity predicts delay discounting behavior in 9-to 23-yearolds: a diffusion tensor imaging study. Journal of Cognitive Neuroscience, 21(7), 1406-1421.

Patton, J. H., Stanford, M. S., \& Barratt, E. S. (1995). Factor structure of the Barratt Impulsiveness Scale. The Quarterly Journal of Experimental Psychology Section A: Human Experimental Psychology, 51(6), 768-774.

Paus, T., Zijdenbos, A., \& Worsley, K. (1999). Structural maturation of neural pathways in children and adolescents: in vivo study. Science, 283(5409), 1908-1911.

Peper, J. S., Mandl, R. C. W., Braams, B. R., de Water, E., Heijboer, A. C., Koolschijn, P. C., \& Crone, E. A., Eveline. (2012). Delay discounting and frontostriatal fiber tracts: a combined DTI and MTR study on impulsive choices in healthy young adults. Cerebral Cortex. Advance access publication. Retrieved from http://www.ncbi.nlm.nih.gov/pubmed/22693341

Qiu, Y. W., Jiang, G. H., Su, H. H., Lv, X. F., Tian, J. Z., Li, L. M., \& Zhuo, F. Z. (in press). The impulsivity behavior is correlated with prefrontal cortex gray matter volume reduction in heroin-dependent individuals. Neuroscience Letters. 
Redgrave, P., Prescott, T., \& Gurney, K. (1999). The basal ganglia: a vertebrate solution to the selection problem? Neuroscience, 89(4), 1009-1032.

Reese, T. G., Heid, O., Weisskoff, R. M., \& Wedeen, V. J. (2003). Reduction of eddy-current-induced distortion in diffusion MRI using a twice-refocused spin echo. Magnetic Resonance in Medicine, 49(1), 177-182.

Reynolds, B., Ortengren, A., Richards, J., \& de Wit, H. (2006). Dimensions of impulsive behavior: personality and behavioral measures. Personality and Individual Differences, 40(2), 305-315.

Schmahmann, J. D., Smith, E. E., Eichler, F. S., \& Filley, C. M. (2008). Cerebral white matter: neuroanatomy, clinical neurology, and neurobehavioral correlates. Annals of the New York Academy of Sciences, 1142, 266-309.

Scholz, J., Klein, M. C., Behrens, T. E. J., \& Johansen-Berg, H. (2009). Training induces changes in white-matter architecture. Nature Neuroscience, 12(11), 1370-1371.

Smith, S. M., Jenkinson, M., Johansen-Berg, H., Rueckert, D., Nichols, T. E., Mackay, C. E., ... Behrens, T. E. (2006). Tract-based spatial statistics: voxelwise analysis of multi-subject diffusion data. NeuroImage, 31(4), 14871505.

Smith, S. M., Jenkinson, M., Woolrich, M. W., Beckmann, C., Behrens, T. E., Johansen-Berg, H., ... Matthews, P. (2004). Advances in functional and structural MR image analysis and implementation as FSL. NeuroImage, 23 Suppl 1, S208-S219.

Smith, S. M., \& Nichols, T. E. (2009). Threshold-free cluster enhancement: addressing problems of smoothing, threshold dependence and localisation in cluster inference. NeuroImage, 44(1), 1-20.

Soubrié, P. (1986). Reconciling the role of central serotonin neurons in human and animal behavior. Behavioral and Brain Sciences, 9(02), 319-335.

Stanford, M. S., Mathias, C. W., Dougherty, D. M., Lake, S. L., Anderson, N. E., \& Patton, J. H. (2009). Fifty years of the Barratt Impulsiveness Scale: an update and review. Personality and Individual Differences, 47(5), 385-395.

Swann, A. C., Bjork, J. M., Moeller, F. G., \& Dougherty, D. M. (2002). Two models of impulsivity: relationship to personality traits and psychopathology. Biological Psychiatry, 51(12), 988-994.

Talairach, J., \& Tournoux, P. (1988). Co-planar Stereotaxic Atlas of the Human Brain. New York: Thieme Medical.

Taubert, M., Draganski, B., Anwander, A., Müller, K., Horstmann, A., Villringer, A., \& Ragert, P. (2010). Dynamic properties of human brain structure: learningrelated changes in cortical areas and associated fiber connections. Journal of Neuroscience, 30(35), 11670-11677. 
Verdejo-Garcia, A., Lozano, O., Moya, M., Alcazar, M. A., Perez-Garcia, M., VerdejoGarcia, A., .. Perez-Garcia, M. (2010). Psychometric properties of a Spanish version of the UPPS-P impulsive behavior scale: reliability, validity and association with trait and cognitive impulsivity. Journal of Personality Assessment, 92(1), 70-77.

Wakana, S., Jiang, H., Nagae-Poetscher, L. M., van Zijl, P. C. M., \& Mori, S. (2004). Fiber tract-based atlas of human white matter anatomy. Radiology, 230(1), 77-87.

Whiteside, S. P., \& Lynam, D. (2001). The five factor model and impulsivity: using a structural model of personality to understand impulsivity. Personality and Individual Differences, 30(4), 669-689.

Xu, J., Kober, H., Carroll, K. M., Rounsaville, B. J., Pearlson, G. D., \& Potenza, M. N. (2011). White matter integrity and behavioral activation in healthy subjects. Human Brain Mapping, 33(4), 994-1002.

Zatorre, R., Fields, R., \& Johansen-Berg, H. (2012). Plasticity in gray and white: neuroimaging changes in brain structure during learning. Nature Neuroscience, $15(4), 528-536$. 


\title{
Chapter 6
}

\section{Value Signals in the Prefrontal Cortex Predict Individual Preferences \\ Within and Across Reward Categories}

\begin{abstract}
Almost daily we choose between options that belong to different reward categories like having something to eat, relaxing or doing sports. Our ability to decide between such options suggests a neural representation of subjective value on one common scale, irrespective of the type of reward. Consequently, value-related activity patterns in the brain should be sufficiently similar to allow predictions about individual preferences across different reward categories. To test this, we analyzed functional magnetic resonance data of the ventromedial prefrontal cortex (vmPFC) from subjects imagining the pleasure of eating different snack foods and engaging in different activities. We were able to predict individual preferences based on brain patterns in the vmPFC, even if the predictive model was obtained from a different reward category. This shows that value signals in the vmPFC are comparable across items with very different characteristics, supporting the idea that subjective value is represented on a common scale.
\end{abstract}




\subsection{Introduction}

Every day we make choices to ensure the satisfaction of our needs and the pursuit of our goals. According to utilitarian philosophers, humans are motivated to avoid pain and seek pleasure when making these choices. As Jeremy Bentham famously stated in the Principles of Morals and Legislation (Bentham, 2007) 'Nature has placed mankind under the governance of two sovereign masters, pain and pleasure. It is for them alone to point out what we ought to do, as well as to determine what we shall do' (p. 1). Modern economic decision theory still builds on this idea and assumes the concept of a unique currency of value ('utility' or subjective value), which integrates all benefit and harm that an action might produce. A key property of such an abstract currency is that it can make all options comparable, even if they are associated with very different needs, such as going on vacation or buying a car.

A growing body of research on the neural mechanisms underlying valuation and choice suggests that the brain might indeed perform such an integration of various pains and pleasures into one value and that the ventromedial prefrontal cortex (vmPFC) plays a crucial role in this (Fehr \& Rangel, 2011). In the first human functional magnetic resonance imaging (fMRI) studies on value and choice subjects either actively chose or passively viewed different items of one specific reward type, such as lotteries (Kahnt, Heinzle, Park, \& Haynes, 2011; Knutson, Taylor, Kaufman, Peterson, \& Glover, 2005), food (Plassmann, O'Doherty, \& Rangel, 2007), and consumer goods (e.g. CDs or books, I. Levy, Lazzaro, Rutledge, \& Glimcher, 2011). Interestingly all of these studies found that activity in the striatum, ventromedial prefrontal cortex (vmPFC) and anterior cingulate cortex consistently correlated with subjective value. In accordance with these results, single-cell recordings showed that neurons in the monkey orbitofrontal cortex encoded subjective value of different juice offers during choice (Padoa-Schioppa \& Assad, 2006). Confirming that the vmPFC is indeed functionally relevant for value-based decision making, a recent lesion study in humans found that

Based on: Gross, J.*, Woelbert, E.*, Zimmermann, J.*, Okamoto-Barth, S., Riedl, A., \& Goebel, R. Value signals in the prefrontal cortex predict individual preferences within and across reward categories (in preparation). *Authors share equal author contributions. 
people with a selective lesion in the vmPFC were less consistent in preference judgments than both healthy controls and people with a frontal lesion sparing the vmPFC (Henri-Bhargava \& Simioni, 2012).

Few studies have presented different types of rewards, such as food, art, other consumer goods, or money to the same subjects and were thus able to test the idea of a common subjective value representation (Chib, Rangel, Shimojo, \& O’Doherty, 2009; FitzGerald, Seymour, \& Dolan, 2009; Kim, Shimojo, \& O'Doherty, 2011; Lebreton, Jorge, Michel, Thirion, \& Pessiglione, 2009; D. J. Levy \& Glimcher, 2011). Importantly, all of these studies observed an overlap of value-related signals for different reward types in the vmPFC. Further, D. J. Levy and Glimcher (2011) showed that reward value for money and food options was not only encoded in overlapping subregions of the vmPFC, but that equally preferred money and food options also elicited comparable BOLD responses in this area. Taken together, these studies suggest that neurons in the vmPFC process value information across reward types in a way that is consistent with the idea of a common currency of value (D. J. Levy \& Glimcher, 2012).

Based on these findings we hypothesize that activity patterns in the vmPFC should allow to infer subjective value of an item, independent of the type of reward. In this study, we test this idea using multivariate analysis of functional magnetic resonance imaging (fMRI) data while subjects evaluated items belonging to two different reward categories. Specifically, we chose snack food and engaging activities as reward categories because they differ fundamentally with respect to the sensory and motivational systems involved. Snack food items (like doughnut, vanilla ice, cheese cake, chocolate, peanuts, etc.) constitute primary rewards that serve energy intake and are directly linked to gustatory perception, while the engaging activities serve the pursuit of secondary needs as diverse as relaxing, fitness and culture (e.g. daydreaming, playing tennis, taking a nap, painting, vacuum cleaning, etc.). Nevertheless, assuming that subjective value for all these items is represented on one common scale, a model that can infer subjective values of snack food items from BOLD response patterns, should also be able to infer preferences over activities, and vice versa. 


\subsection{Methods}

\section{Subjects}

Four healthy subjects ( 3 female, 1 male, aged between 26 and 29 years) without prior history of psychiatric or neurological disorders participated in this study. All subjects gave their written informed consent before participation and the study protocol was approved by the Ethics Committee Psychology of the Faculty of Psychology and Neuroscience, Maastricht University. Subjects were asked to refrain from eating for 3 hours before the start of the experiment.

\section{Experimental design and stimuli}

Subjects in the fMRI scanner were presented one item at a time. In total 120 items, 60 different snack foods (like a doughnut, cheesecake or chocolate ice cream) and 60 different activities (like playing tennis, having a nap or window cleaning) were presented in random order. For snack food items subjects were instructed to focus on how much pleasure they would derive from eating it, while for activity items they should imagine the pleasure they would derive from engaging in the activity. Items were randomly presented in written form for 2.5 seconds.

In order to keep subjects engaged in the task, they were given 3 seconds on each trial to rate the imagined pleasure on a visual analogue scale. After functional brain scanning, outside the scanner, subjects were presented with pairs of the shown items and asked to indicate which of the two items they prefer. Some of these choice pairs contained two items of the same category, others contained a snack food and an activity item. With this procedure we obtained a subjective value ranking over all items for each individual.

\section{MRI data acquisition}

Measurements were performed on a 3T Allegra scanner (Siemens, Erlangen, Germany). Functional responses were measured in four independent runs using a whole brain standard gradient echo EPI sequence $(\mathrm{TE}=30 \mathrm{~ms}$; slices $=32$; TR $=2,000 \mathrm{~ms} ; \mathrm{FOV}=224 \times 224 \mathrm{~mm}^{2}$; voxel size $=3 \times 3 \times 3 \mathrm{~mm}^{3}$ ). Stimuli were separated by a varying inter-trial interval of 8 to 10 seconds. 
A T1 weighted magnetization prepared rapid acquisition gradient echo (3DMPRAGE; TR: $2050 \mathrm{~ms}$; TE: $2.6 \mathrm{~ms}$; FOV: 256x256 mm² ; flip angle: $9^{\circ}$; 192 sagittal slices, voxel size: $1 \times 1 \times 1 \mathrm{~mm}^{3}$ ) anatomical dataset was acquired for visualization of the functional results.

\section{MRI data analysis}

Functional and anatomical images were analysed using BrainVoyager QX (Brain Innovation, Maastricht, The Netherlands) as well as custom code in R (R Development Core Team, 2008). Preprocessing of the functional data included interscan slice-time correction, rigid body motion correction as well as temporal filtering using a Fourier basis set of five cycles per run. The functional data was then coregistered with the individual anatomical scan and transferred into Talairach space (Talairach \& Tournoux, 1988). All fMRI data analysis was performed on a single subject level and was restricted to an anatomically defined region of interest in the vmPFC (see Figure 6.3), following the results of previous studies that employed different reward types (see D. J. Levy \& Glimcher, 2012, for review).

To identify neural activity patterns encoding subjective value, we used a machine learning algorithm. For each subject, two linear support vector regression (SVR) models were trained to identify subjective value ranks. One model was trained using BOLD response patterns during evaluation of activities only. A second model was trained on the remaining dataset, consisting of snack food trials.

\section{Multivoxel pattern analysis}

Features were created by taking the mean of the raw fMRI signal of the second and third functional volume after stimulus onset. A linear support vector regression model (epsilon-SVR) was trained in predicting preference ranks separately for each category. Recursive feature elimination (De Martino et al., 2008) was used to eliminate $75 \%$ of the voxels, dropping those that were least informative within one category. On the remaining voxels, 10 -fold cross validation was performed to assess within-category prediction accuracy. The SVR model trained on preferences over snack food items was then used to predict the preference ranking of different activities and vice 
versa. Correlations between the observed preference ranks and predicted ranks were calculated to assess prediction accuracies within and between categories for each subject. Permutation testing (2,000 permutations) was used to assess statistical significance of the correlations.

\section{Control condition}

At the end of each trial subjects rated the current item on a visual analogue scale. To ensure that neural processes related to the visual analogue scale, but unrelated to subjective value computation (like motor preparation or visual attention) cannot serve as an alternative explanation for our results, we added the following control condition. In some trials, instead of snack food or activity items, subjects saw the word 'left' or 'right' on the screen and were simply instructed to move the slider to the left or to the right. It was not possible to predict whether a subject was moving the slider to the left or to the right from the selected voxel sets. Prediction accuracies did not significantly exceed chance level in any of the four subjects. This indicates that motor preparation or visual attention cannot serve as an alternative explanation for our results.

\subsection{Results}

\section{Within-category predictions}

First, we evaluated each model's prediction performance within the training category using 10 -fold cross validation. That is, we tested whether each model was able to reliably predict the subjective value ranks of items that belonged to the same category but were not included in the model training. For all four subjects, correlations between subjective value ranks as obtained from the dual choice task and estimated subjective value ranks based on neural activity were significantly above chance level. For snack food items, correlations ranged between $r=.34$ (subject 4, $p<.05$ ) and $r=.81$ (subject $2, p<.01)-$ mean $r=.62$. For activity items, correlations ranged between $r=.26$ (subject $4, p<.05$ ) and $r=.76$ (subject $3, p<.01$ ) - mean $r=.61$. Thus, we were able to infer a subjective value ranking over a set of snack food items from brain patterns in the vmPFC when the predictive model 
was trained on a different set of snack food items. The same was true for engaging activities.

\section{Across-category predictions}

To address our central hypothesis we would, however, like to know, whether measured activity patterns only reflect value information that is specific for the category of reward, or whether they carry the abstract value signals implied by a common neural value scale. In order to infer whether similarly liked snack foods and activities evoke similar brain patterns, we evaluated each model's prediction performance for items from the other category. In other words, after an SVR model was trained on one category of items (e.g. snack food), it was used to estimate the subjective value for the other category of items (e.g. activities). The estimated subjective values of activities, obtained by an SVR model trained on snack food items, correlated with the observed subjective value between $r=.26$ (subject $4, p<.05$ ) and $r=.47$ (subject $1, p<.01$ ) - mean $r=.33$. Likewise, using the SVR model trained on activities, correlations between predicted and actual subjective value for snack food items ranged between $r=.22$ (subject $3, p<.05$ ) and $r=.45$ (subject $1, p<.01$ ) - mean $r=.34$. Figure 6.1 illustrates these correlations by plotting the actual subjective value ranks against the estimated subjective value ranks of all items for an exemplary subject.

\section{Category-independent predictions}

The fact that each model performed better on items of the same category that it was trained on suggests that next to abstract value information, there is also value-related brain activity that is specific to each reward category. If this is the case, a model trained on items from both categories together should be less influenced by category-specific brain activity and consequently perform better than a model trained only on items from the other category. Indeed, when training on items from both categories, the correlations between estimated and actual subjective value ranks were consistently higher than the across-category predictions for each subject (correlations ranged from $r=.33$ (subject $4, p<.05$ ) and $r=.50$ (subject $1, p<.01$ ) - mean $r=.41$ ). 


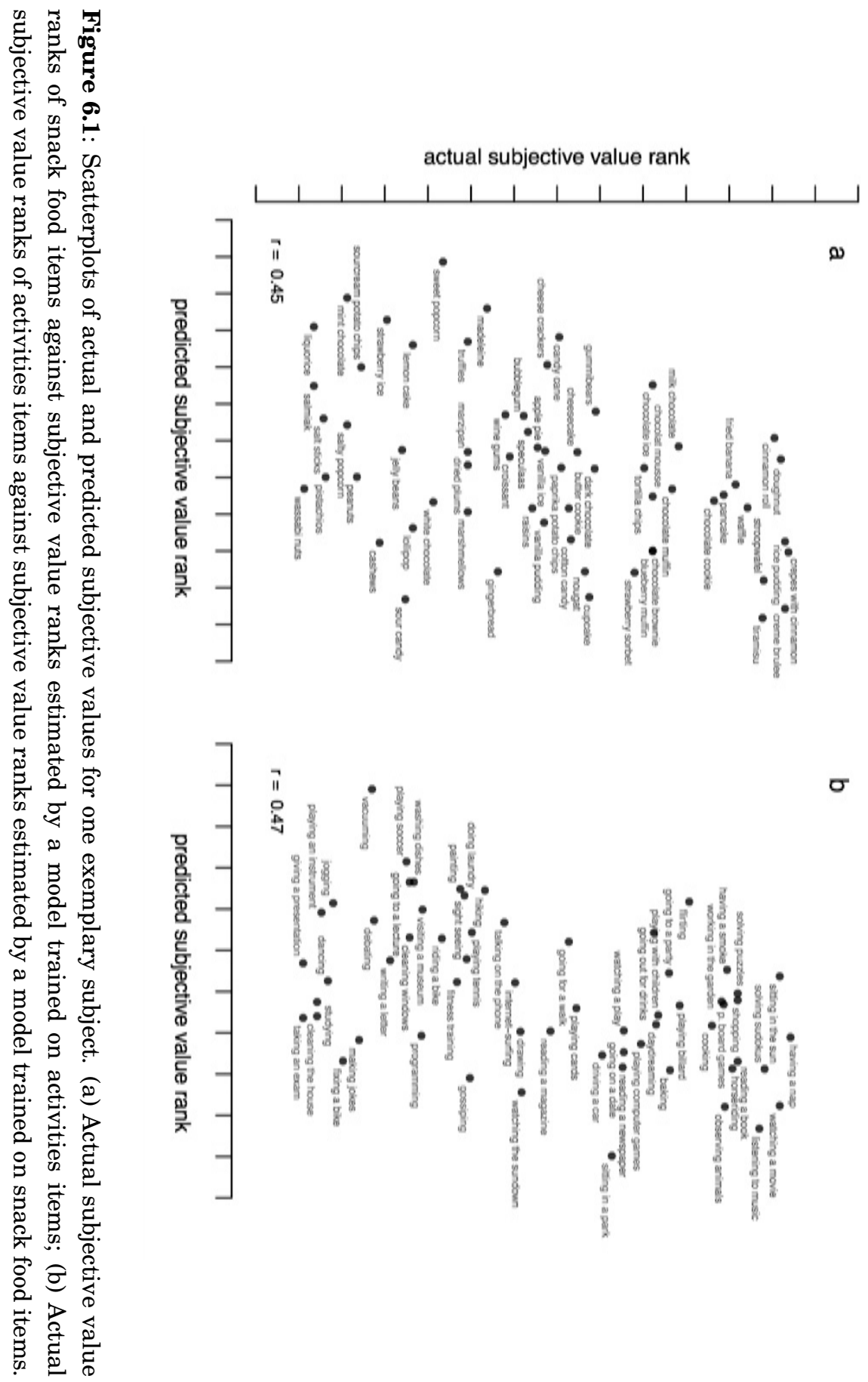




\section{Predicting binary choices}

In addition to comparing the estimated subjective value ranks with the observed subjective value ranks, we evaluated whether it is possible to predict subjects' actual choices in the binary decision task, simply by assuming that in a binary choice the item with the higher estimated subjective value rank should be chosen over the item with the lower rank. The purpose of this is twofold: First, estimated subjective value ranks do not only carry information about which item is preferred but also some information about how strongly it is preferred. Therefore, choices between similarly ranked items should be harder to predict than choices between items with very different predicted subjective value rank. As shown in Figure 6.2, this was indeed the case. The proportion of correctly predicted binary choices monotonically increased with the distance between the estimated subjective value ranks for two items, up to accuracies of $85 \%$ to $100 \%$ when subjects chose between items that were classified as highly disliked and highly liked by the SVR model. Secondly, we found that accuracies for binary choices between the two categories were not significantly different from the accuracies within each category (Pearson Chi-squared test, $\chi^{2}(2)=3.21, p=.21$ ). Thus, each SVR model did not only order items of one category correctly, as indicated by the significant correlations. In addition, neither of the models systematically over- or underestimated the subjective value ranks of the other category.

\section{Informative voxels}

Thus, it was possible to infer subjective value for items of different reward categories from BOLD response patterns in the vmPFC. This implies that there are voxels in the vmPFC that carry information about subjective value independent of the category of reward. To localize these, we plotted the voxels that were informative for predicting subjective value of both snack food items and activity items. For each subject, this analysis consistently revealed a cluster in a small subregion of the vmPFC (see Figure 6.3). 


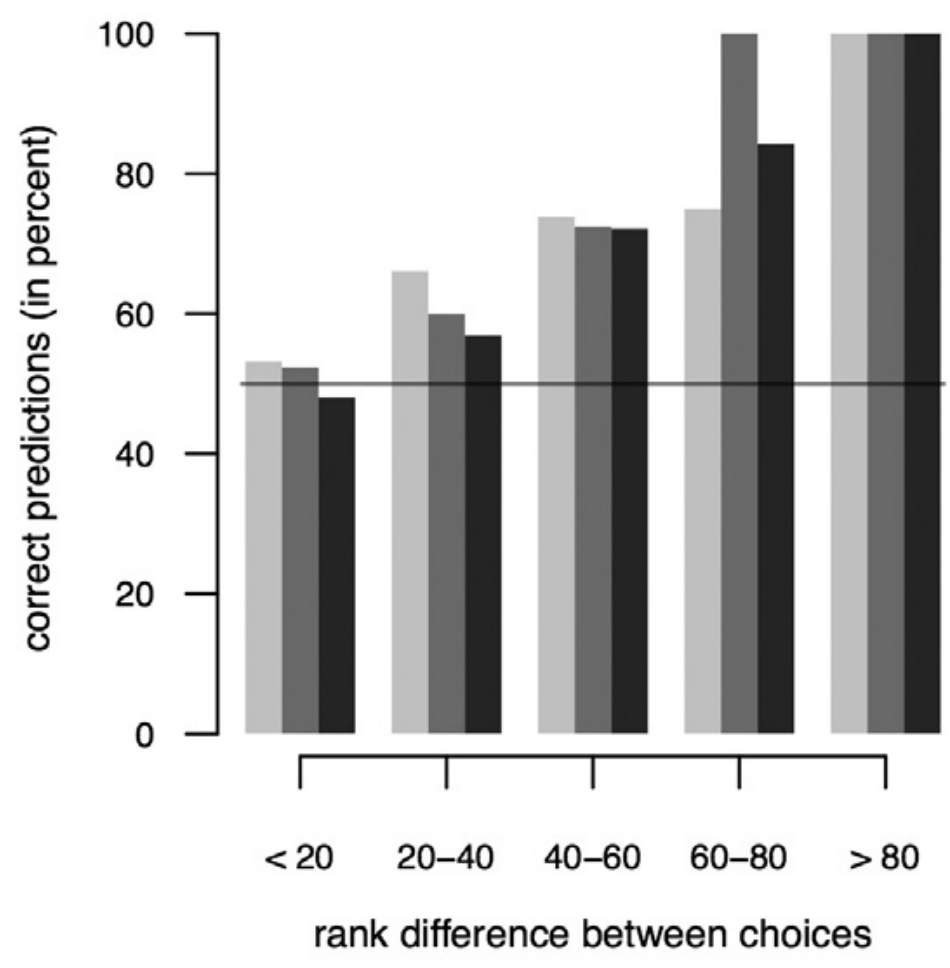

Figure 6.2: Proportion of correctly predicted binary choices, using the subjective value ranks estimated from brain activity patterns in the vmPFC. Bars show the percentage of correctly predicted binary choices depending on the distance between the estimated ranks of two items. Light gray bars refer to comparisons between two snack food items, dark gray bars to comparisons between two activity items and black bars correspond to comparisons between a snack food and an activity item. The horizontal line shows the accuracy expected by chance (50\%). 

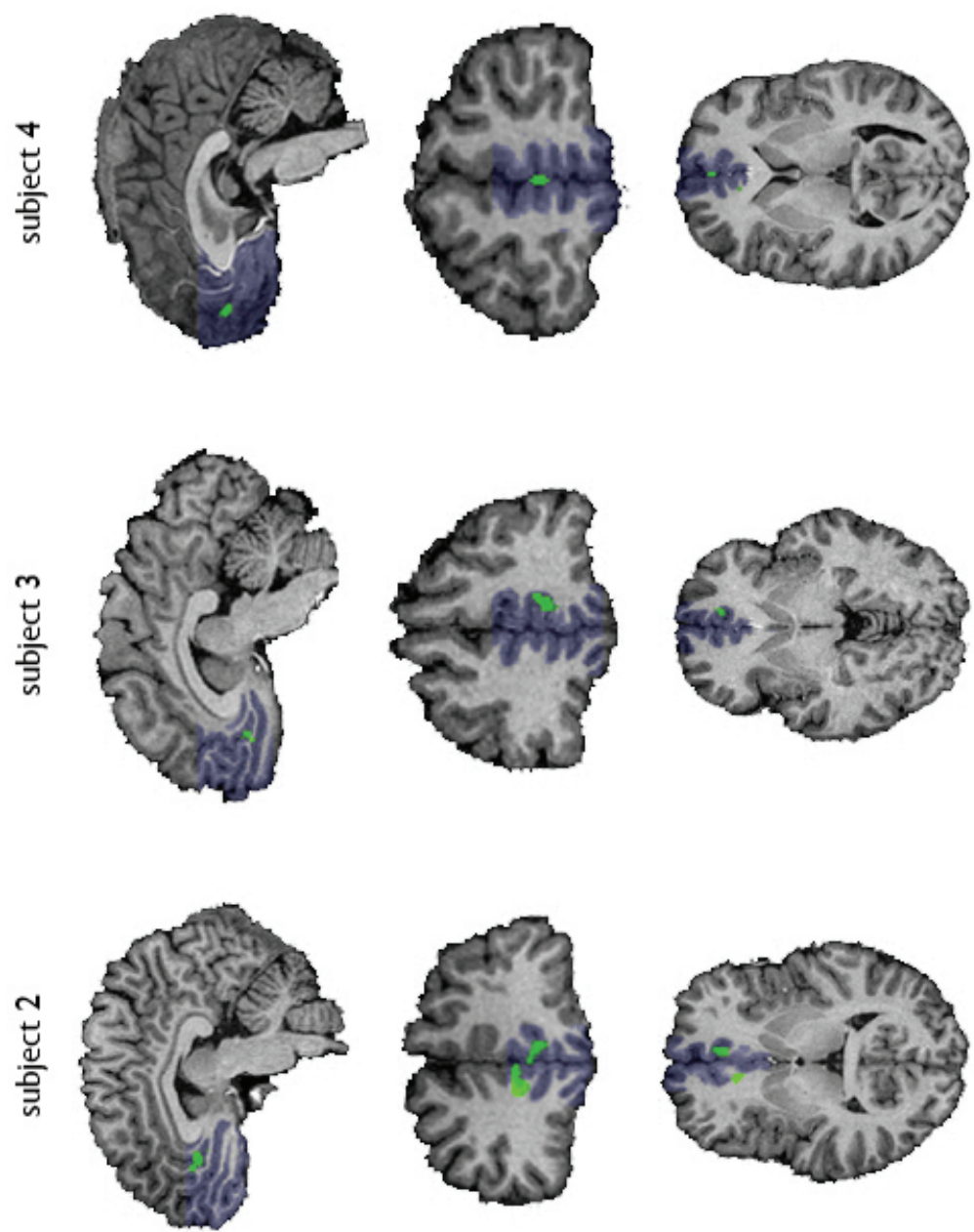

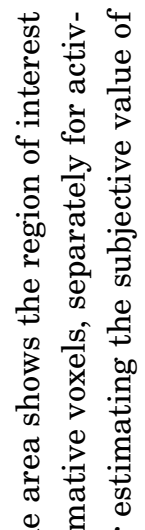

듕

¿.

E 券

के छ व

氙造

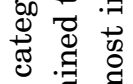

를 ह

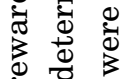

귱 焉

\&

๑ేّ

స

$>$ 기

. 苛

. ֻ

क्ञ

कू हี

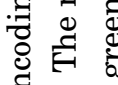
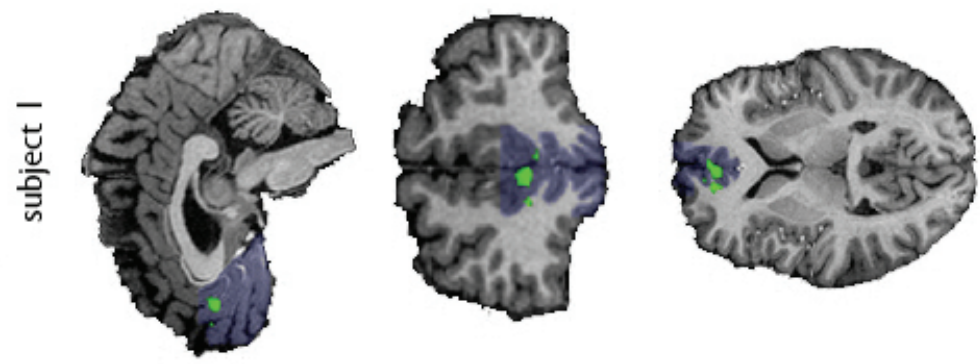

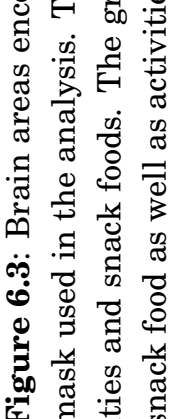




\subsection{Discussion}

In this study we tested whether value signals in the vmPFC are independent of specific reward characteristics and can therefore be used to infer the subjective value of inherently distinct reward types. A machine learning algorithm that was trained only in decoding subjective value of snack food items was indeed capable of predicting the subjective value of different engaging activities and vice versa. Hence, knowing the neuronal pattern that is associated with imagining the pleasure of, e.g. eating a doughnut or chocolate ice cream made it possible to reliably infer preferences over, e.g. playing tennis or painting, and the other way around. This is remarkable, since these items differ fundamentally with respect to the associated sensory and motivational systems. If subjective value representation was entirely linked to specific properties of a stimulus, this should not be possible. Our results thus indicate that subjective value is indeed represented in an abstract fashion in the vmPFC, using one common scale as implicated by the utility concept used in economics.

In contrast to other studies investigating common representations of subjective value for different consumer goods and money (Chib et al., 2009; D. J. Levy \& Glimcher, 2011) our activities category comprises items that are usually not tradable, not easily substitutable by money (like "going for a walk" or "having a nap") and whose value is inherently subjective. Therefore, our finding cannot be explained by cognitive processes that merely estimate the monetary value of an item, based on learned market prices instead of subjective value.

In accordance with the idea of an abstract value representation, we found a subregion in the vmPFC that encoded subjective value for both categories of items. The location of this subregion was comparable between all four subjects and is similar to regions previously associated with subjective value representation for multiple reward types (Chib et al., 2009; D. J. Levy \& Glimcher, 2011). Taken together, these results provide strong evidence for the existence of abstract value signals in the vmPFC, and that these could in principle be used to predict choice. 


\section{References}

Bentham, J. (2007). An introduction to the principles of morals and legislation. Mineola, New York, USA: Dover.

Chib, V. S., Rangel, A., Shimojo, S., \& O’Doherty, J. P. (2009). Evidence for a common representation of decision values for dissimilar goods in human ventromedial prefrontal cortex. Journal of Neuroscience, 29(39), 12315-12320.

De Martino, F., Valente, G., Staeren, N., Ashburner, J., Goebel, R., \& Formisano, E. (2008). Combining multivariate voxel selection and support vector machines for mapping and classification of fMRI spatial patterns. NeuroImage, 43(1), $44-58$.

Fehr, E., \& Rangel, A. (2011). Neuroeconomic foundations of economic choice recent advances. The Journal of Economic Perspectives, 25(4), 3-30.

FitzGerald, T. H. B., Seymour, B., \& Dolan, R. J. (2009). The role of human orbitofrontal cortex in value comparison for incommensurable objects. Journal of Neuroscience, 29(26), 8388-8395.

Henri-Bhargava, A., \& Simioni, A. (2012). Ventromedial frontal lobe damage disrupts the accuracy, but not the speed, of value-based preference judgments. Neuropsychologia, 50(7), 1533-1542.

Kahnt, T., Heinzle, J., Park, S. Q., \& Haynes, J.-D. (2011). Decoding different roles for vmPFC and dlPFC in multi-attribute decision making. NeuroImage, 56(2), 709-15.

Kim, H., Shimojo, S., \& O’Doherty, J. P. (2011). Overlapping responses for the expectation of juice and money rewards in human ventromedial prefrontal cortex. Cerebral Cortex, 21(4), 769-776.

Knutson, B., Taylor, J., Kaufman, M., Peterson, R., \& Glover, G. (2005). Distributed neural representation of expected value. Journal of Neuroscience, 25(19), 4806-4812.

Lebreton, M., Jorge, S., Michel, V., Thirion, B., \& Pessiglione, M. (2009). An automatic valuation system in the human brain: evidence from functional neuroimaging. Neuron, 64(3), 431-439.

Levy, D. J., \& Glimcher, P. W. (2011). Comparing apples and oranges: using reward-specific and reward-general subjective value representation in the brain. Journal of Neuroscience, 31(41), 14693-14707.

Levy, D. J., \& Glimcher, P. W. (2012). The root of all value: a neural common currency for choice. Current Opinion in Neurobiology, 22(6), 1027-1038.

Levy, I., Lazzaro, S. C., Rutledge, R. B., \& Glimcher, P. W. (2011). Choice from non-choice: predicting consumer preferences from blood oxygenation leveldependent signals obtained during passive viewing. Journal of Neuroscience, 31(1), 118-125. 
Padoa-Schioppa, C., \& Assad, J. A. (2006). Neurons in the orbitofrontal cortex encode economic value. Nature, 441(7090), 223-226.

Plassmann, H., O’Doherty, J., \& Rangel, A. (2007). Orbitofrontal cortex encodes willingness to pay in everyday economic transactions. Journal of Neuroscience, 27(37), 9984-9988.

$\mathrm{R}$ Development Core Team. (2008). R: A language and environment for statistical computing. Vienna: R Foundation for Statistical Computing. Retrieved from http://www.r-project.org

Talairach, J., \& Tournoux, P. (1988). Co-planar stereotaxic atlas of the human brain. New York: Thieme Medical. 


\section{Chapter 7}

\section{Summary and Conclusions}

Value-based decisions are a central aspect of life. Drawing from theories and research methods in psychology, neuroscience, and economics, the studies presented in this thesis aimed towards understanding how value-based decisions are made, and how they can best be investigated.

One puzzle in the study of value-based decisions is why people give in to temptations such as overeating, or drug abuse, despite the fact that they explicitly state that they do not wish to do so. The explanations that have emerged for this phenomenon in psychology, neuroscience, and economics highlight the role of the decision situation and the stimuli it contains. Not only decisions regarding food intake or drug abuse are influenced by the stimulus situation, but also typical economic decisions such as intertemporal choice. Chapter 2 of this thesis summarizes the literature on situational control of economic decisions. There is evidence that exposure to reward, or to stimuli that are associated with reward, affects economic decisions in several different domains. When faced with reward predicting stimuli in intertemporal choice, people decide less patiently. In choice under uncertainty they are more risk averse, and in consumer decisions they show higher willingness to pay (WTP) and biased choice. We note that well-known biases in decision making, namely dynamic inconsistency, certainty effects, and the endowment effect, occur in decision situations that naturally entail some form of immediacy to reward. Therefore, we argue that these biases could be driven by a similar mechanism. This approach could help to organize a 
large amount of previously unconnected experimental results across different decision domains.

In studies of individual decision making it is often necessary to measure the value a person assigns to a good. To encourage participants to give true and accurate answers, many studies make use of an incentivised value elicitation task, the Becker-DeGroot-Marschak (BDM) mechanism. Chapter 3 of this thesis shows that in this task, people do not behave according to the predictions of standard economic theory. Expected utility theory predicts that a person should always report the same WTP for a given consumer good, irrespective of the distribution of possible prices used in the BDM mechanism. Instead, we observe that individual bids for the same good vary. Specifically, subjects report higher WTP if this yields a significantly higher chance of obtaining the item, i.e. they show distributional dependence with a mass-seeking bias. Importantly, this bias persists over on average 140 value elicitation trials per subject, strongly suggesting that distributional dependence is a persistent phenomenon that is not abolished by experience. This study casts doubt on the commonly held assumption that the BDM mechanism induces truthful revelation of a fixed value a person assigns to a goods. As the observed pattern is not in line with existing theories of anchoring or reference-dependent preferences, this study highlights a novel violation of expected utility theory that may provide useful insights on the processes underlying valuation.

Individual time and risk preferences are an important component of economic models and they are measured in many studies on human decision making. Since they are defined by economic theory, the question whether they exist as psychological constructs, and - if so - how they are best described and measured, has received little attention in the economic literature. In Chapter 4 we show that commonly used elicitation tasks for time and risk preferences generate reproducible results and thus possess satisfactory reliability. Further, as the measured parameters are differentially stable over several weeks, individual time and risk preferences can be understood as individual characteristics that are at least moderately stable over time. However, our data suggest that time and risk preferences measured with monetary choice tasks are specific to the domain of financial decisions. Thus, if researchers or policy makers measure time and risk pref- 
erences using monetary choice tasks, the results cannot be generalized to other domains, such as health- or career-related decisions. In order to refine the definitions of time and risk preferences, future research should measure indicators of time and risk preferences in different decision domains, both in the laboratory and in the field.

Recent neuroscientific evidence suggests that stable interindividual differences can be explained by interindividual differences in brain structure. Identifying relationships between brain structure and stable interindividual differences can provide useful information on the relationship between brain function and behaviour that is complementary to results from functional neuroimaging. In Chapter 5 we investigate whether interindividual differences in impulsiveness are associated with differences in brain structure. We use diffusion weighted magnetic resonance imaging to assess the integrity of white matter. Specifically, we compute fractional anisotropy (FA), which reflects the microstructural organization of connections between brain regions and is an indicator of structural connectivity. Employing two different methods to spatially co-register the individual datasets, we find converging evidence that people who score higher on self-reported impulsiveness have higher white matter integrity in regions that contain connections from the frontal cortex to subcortical regions. This result suggests that stable interindividual differences in impulsiveness might not arise from a lack of inhibitory control by the frontal cortex, but from an excess of motivation or drive. Measuring white matter integrity and comparing it across subjects is a new and still rapidly developing neuroscientific technique. Therefore these findings must be interpreted with caution.

The neuroeconomic model of choice postulates that value-based decisions are performed by computing subjective value of each option under consideration and choosing the option with the highest subjective value. Subjective value of an option incorporates all aspects that are relevant to the desirability of the option and can then be compared to that of other options. To enable choice between fundamentally distinct options, subjective value must be independent of the type of reward and represented on one common scale of desirability. It is hypothesised that such an abstract subjective value signal is represented in the ventromedial prefrontal cortex. In Chapter 6 of this thesis, we test this hypothesis using multivoxel pattern analysis of func- 
tional magnetic resonance data. We find that it is possible to predict individual preferences from brain activity in the ventromedial prefrontal cortex. Moreover, a model that is only trained to predict preferences over one specific category of reward, e.g. snack food items, can also predict preference over a fundamentally distinct category of reward, e.g. engaging activities. Therefore, subjective value representation for these two categories must be similar. This is the case although engaging activities, such as playing tennis or reading a book, have nothing in common with snack foods, are not easily substitutable by money and are not normally traded. This result strongly suggests that subjective value representation in the ventromedial prefrontal cortex is abstract and maps subjective value on one common scale of desirability for fundamentally distinct options. 




\section{Acknowledgements}

During the past four years I have received a great deal of help and support that made the writing of this thesis possible. I am most grateful to my supervisors, colleagues, family and friends. Thank you all. 


\section{Short Curriculum Vitae}

Eva Wölbert was born on January 211985 in Koblenz, Germany. Eva studied Psychology in Braunschweig and Trier in Germany from 2003 to 2009. During her Psychology studies she spent a semester abroad at the Faculty of Psychology and Neuroscience at Maastricht University. After obtaining a Diplom in Psychology from Trier University, she started her doctoral studies in Maastricht in May 2009. She is affiliated both with the Department of Cognitive Neuroscience and the Department of Economics, and her research focuses on the psychological and neural mechanisms underlying value-based decisions. During spring 2012 Eva was a visiting scholar at the Center for Neuroeconomics of New York University. 